Florida International University FIU Digital Commons

7-6-2011

\title{
Reduced Organic Sulfur: Analyisis and Interaction with Mercury in the Aquatic Environment
}

Sen Chen

Florida International University, schen004@fiu.edu

DOI: $10.25148 /$ etd.FI1 1072604

Follow this and additional works at: https://digitalcommons.fiu.edu/etd

\section{Recommended Citation}

Chen, Sen, "Reduced Organic Sulfur: Analyisis and Interaction with Mercury in the Aquatic Environment" (2011). FIU Electronic Theses and Dissertations. 442.

https://digitalcommons.fiu.edu/etd/442 


\section{FLORIDA INTERNATIONAL UNIVERSITY}

Miami, Florida

REDUCED ORGANIC SULFUR: ANALYSIS AND INTERACTION WITH MERCURY IN THE AQUATIC ENVIRONMENT

A dissertation submitted in partial fulfillment of the requirements for the degree of DOCTOR OF PHILOSOPHY

in

CHEMISTRY

by

SEN CHEN

2011 
To: Dean Kenneth Furton

College of Arts and Sciences

This dissertation, written by Sen Chen, and entitled Reduced Organic Sulfur: Analysis and Interaction with Mercury in the Aquatic Environment, having been approved in respect to style and intellectual content, is referred to you for judgment.

We have read this dissertation and recommend that it be approved.

Rudolf Jaffe

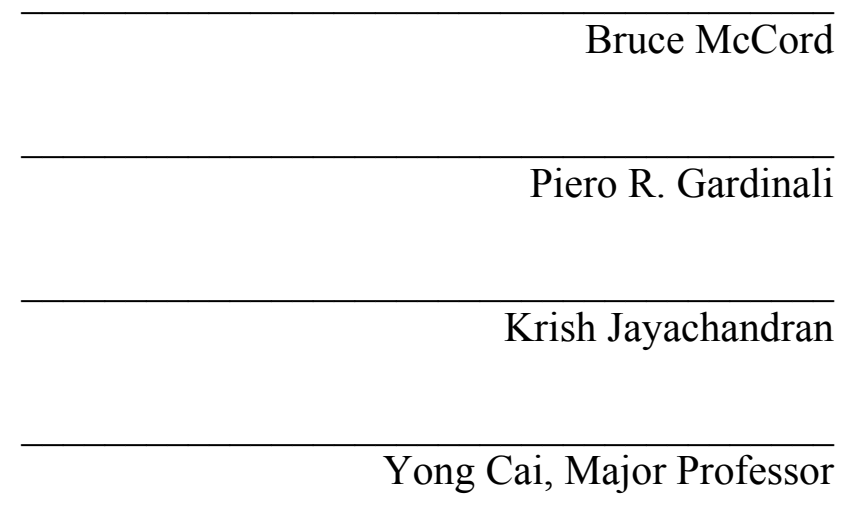

Date of Defense: July 6, 2011

The dissertation of Sen Chen is approved.

\begin{tabular}{r}
$\begin{array}{r}\text { Dean Kenneth Furton } \\
\text { College of Arts and Sciences }\end{array}$ \\
\hline Interim Dean Kevin O'Shea \\
University Graduate School
\end{tabular}

Florida International University, 2011 
(C) Copyright 2011 by Sen Chen

All rights reserved. 


\section{DEDICATION}

I dedicate this dissertation to my wife Song Mao, my son and my parents. Without their support, understanding, encouragement and most of the love, the completion of this work would not have been possible. 


\section{ACKNOWLEDEGMENT}

I am so grateful to my major professor. Dr. Yong Cai, for giving me incredible guidance, encouragement over my graduate study at FIU. I would never achieve my academics goals without his patience and faith in me. I would extend my thanks to my committee members, Dr. Rudolf Jaffe, Dr. Bruce McCord, Dr. Piero R. Gardinali and Dr. Krish Jayachandran for their critical comments, suggestion, and guidance of my research. I would like to thank Dr. Guangliang Liu, Dr. G. Melodie Naja, Dr. Ligang Hu, Dr. Zheng Wang and Dr. Lucy Yehiayan for all helpful suggestion and discussion. I also like thank all members in Dr. Yong Cai's group: Dr. Yongguang Yin, Dr.

Yanbin Li, Dionne Dickson, Szabina Stice, Zhiwei Duan and Shuo Li. I would like to thank University Graduate School and Department of Chemistry \& Biochemistry at Florida International University for the financial supports.

I would like to thank the Everglades Foundation for the Everglades Foundation fellowship awarded to me. 


\section{ABSTRACT OF THE DISSERTATION \\ REDUCED ORGANIC SULFUR: ANALYSIS AND INTERACTION WITH \\ MERCURY IN THE AQUATIC ENVIRONMENT}

by

\section{Sen Chen}

Florida International University, 2011

Miami, Florida

\section{Professor Yong Cai, Major Professor}

Reduced organic sulfur (ROS) compounds are environmentally ubiquitous and play an important role in sulfur cycling as well as in biogeochemical cycles of toxic metals, in particular mercury. Development of effective methods for analysis of ROS in environmental samples and investigations on the interactions of ROS with mercury are critical for understanding the role of ROS in mercury cycling, yet both of which are poorly studied.

Covalent affinity chromatography-based methods were attempted for analysis of ROS in environmental water samples. A method was developed for analysis of environmental thiols, by preconcentration using affinity covalent chromatographic column or solid phase extraction, followed by releasing of thiols from the thiopropyl sepharose gel using TCEP and analysis using HPLC-UV or HPLC-FL. Under the optimized conditions, the detection limits of the method using HPLC-FL detection were 0.45 and $0.36 \mathrm{nM}$ for Cys and GSH, respectively. Our results suggest that covalent affinity methods are efficient for thiol enrichment and interference elimination, 
demonstrating their promising applications in developing a sensitive, reliable, and useful technique for thiol analysis in environmental water samples.

The dissolution of mercury sulfide ( $\mathrm{HgS})$ in the presence of ROS and dissolved organic matter (DOM) was investigated, by quantifying the effects of ROS on $\mathrm{HgS}$ dissolution and determining the speciation of the mercury released from ROS-induced $\mathrm{HgS}$ dissolution. It was observed that the presence of small ROS (e.g., Cys and GSH) and large molecule DOM, in particular at high concentrations, could significantly enhance the dissolution of $\mathrm{HgS}$. The dissolved $\mathrm{Hg}$ during $\mathrm{HgS}$ dissolution determined using the conventional $0.22 \mu \mathrm{m}$ cutoff method could include colloidal Hg (e.g., HgS colloids) and truly dissolved $\mathrm{Hg}$ (e.g., Hg-ROS complexes). A centrifugal filtration method (with 3 $\mathrm{kDa}$ MWCO) was employed to characterize the speciation and reactivity of the $\mathrm{Hg}$ released during ROS-enhanced HgS dissolution. The presence of small ROS could produce a considerable fraction (about $40 \%$ of total mercury in the solution) of truly dissolved mercury $(<3 \mathrm{kDa})$, probably due to the formation of $\mathrm{Hg}$-Cys or $\mathrm{Hg}$-GSH complexes. The truly dissolved $\mathrm{Hg}$ formed during GSH- or Cys-enhanced $\mathrm{HgS}$ dissolution was directly reducible ( $100 \%$ for GSH and $40 \%$ for Cys) by stannous chloride, demonstrating its potential role in $\mathrm{Hg}$ transformation and bioaccumulation. 


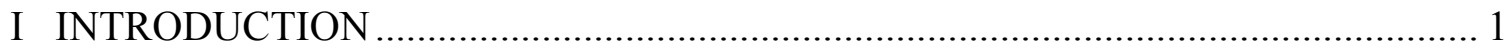

1.1 Reduced Organic Sulfur in the Environment...................................................... 1

1.2 Analysis of Reduced Organic Sulfur in Environmental Samples ............................ 1

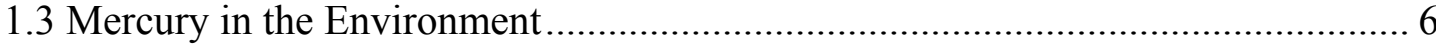

1.4 Interaction of Inorganic Mercury with Reduced Organic Sulfur........................... 7

1.5 Interactions of Methylmercury with Reduced Organic Sulfur ............................ 12

1.6 Interactions of Mercury Sulfide with Reduced Organic Sulfur and DOM ........... 13

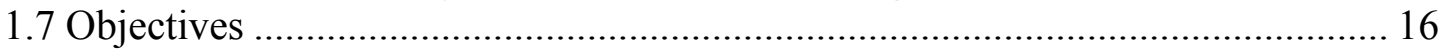

II ANALYSIS OF REDUCED ORGANIC SULFUR USING COVALENT AFFINITY CHROMATOGRAPHY COUPLED WITH HPLC-UV/Vis..................... 18

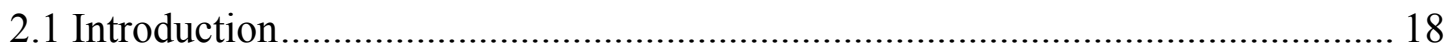

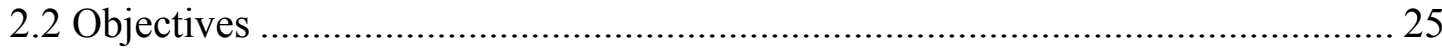

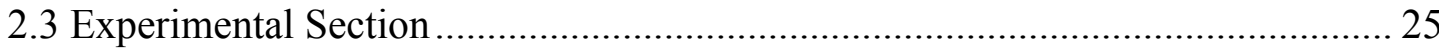

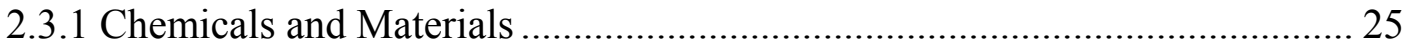

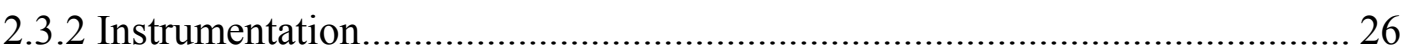

2.3.3 Synthesis of Activated Thiopropyl Sepharose 6B.......................................... 27

2.3.4 Procedures for Thiol Preconcentration and Analysis .................................... 28

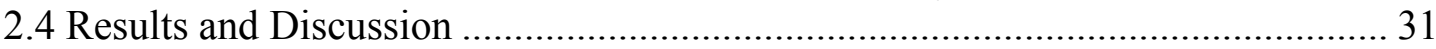

2.4.1 Synthesis and Storage of the Activated Thiopropyl Gel ................................ 31

2.4.2 Preconcentration of Thiols using Affinity Chromatographic Column............ 32

2.4.3 Release of Thiols from the Affinity Chromatographic Column ..................... 34

2.4.4 HPLC Separation-online Derivatization and UV/Vis Detection..................... 35

2.4.5 Figures of Merit of the Developed Method.................................................. 37

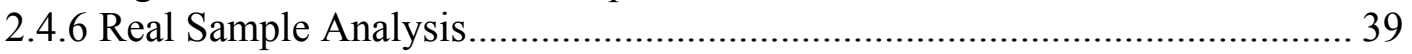

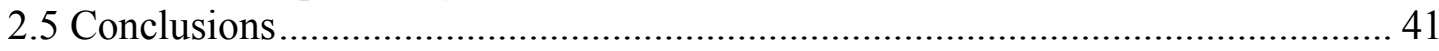

III ANALYSIS OF REDUCED ORGANIC SULFUR IN WATER SAMPLES USING AFFINITY CHROMATOGRAPHIC PRECONCENTRATION COUPLED WITH

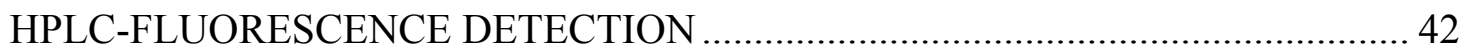

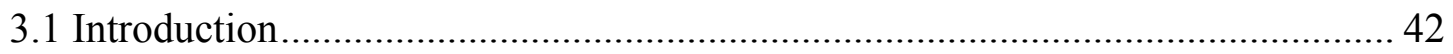

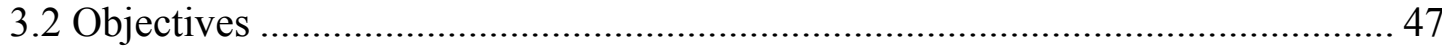

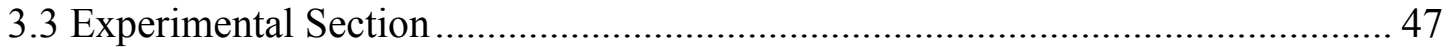

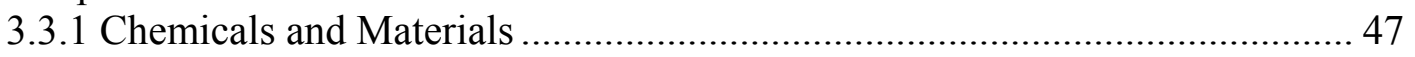

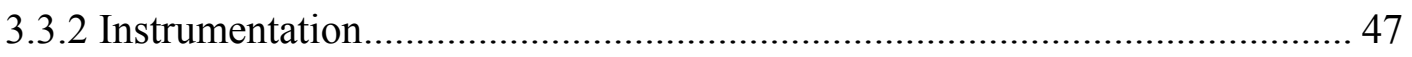

3.3.3 Covalent Affinity Chromatographic Enrichment ........................................... 48

3.3.3.1 Synthesis of Activated Thiopropyl Sepharose 6 B ................................... 48

3.3.3.2 Peconcentration of Thiols Using Covalent Affinity Columns.................. 49

3.3.3.3 Preconcentration of Thiols Using Covalent Affinity Solid Phase Extraction without Being Loaded on a Column ....................................... 51

3.3.3.4 Derivatization of the Enriched Thiols with SBD-F ................................ 52

3.3.4 HPLC-FL Analysis................................................................................. 52 


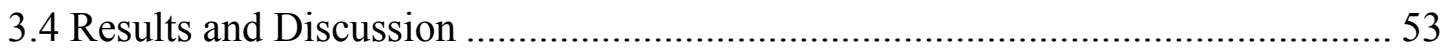

3.4.1 Selection of Reducing Reagents to Release Thiols on Thiopropyl

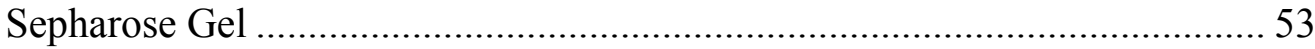

3.4.2 SBD-F Derivatization and HPLC-FL Analysis.............................................. 54

3.4.3 Optimization of the TCEP Concentration Using to Release Thiols from

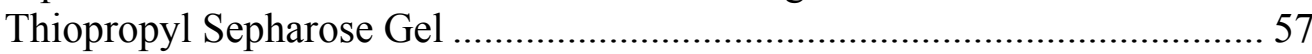

3.4.4 Thiol Stability under Room Temperature and Ice Condition........................... 58

3.4.5 Preconcentration Using Covalent Affinity Column ....................................... 60

3.4.6 Preconcentration of Thiols Using Covalent Affinity Solid Phase Extraction 63

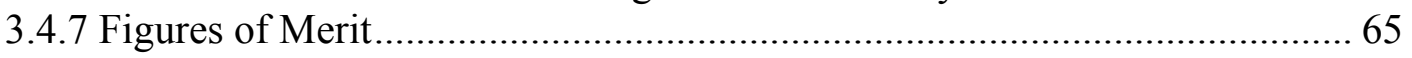

3.4.8 Application for Real Sample Analysis Using Covalent Affinity Solid Phase

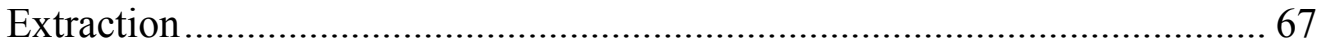

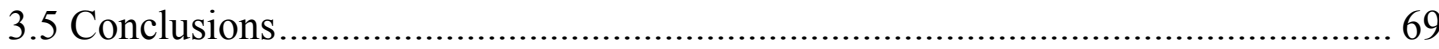

IV EFFECTS OF REDUCED ORGANIC SULFUR ON DISSOLUTION OF

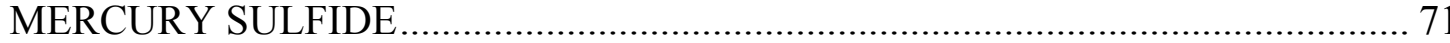

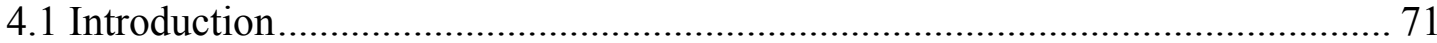

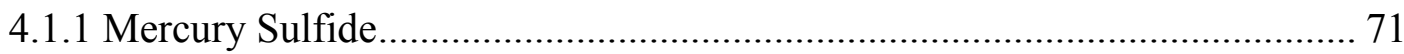

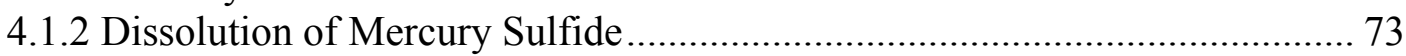

4.1.3 Role of Reduced Organic Sulfur in HgS Dissolution ................................... 74

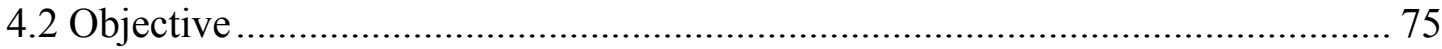

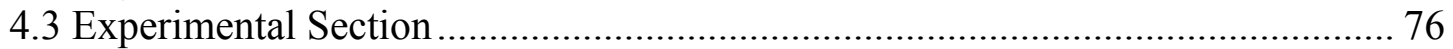

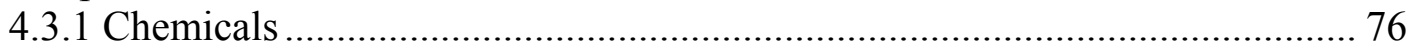

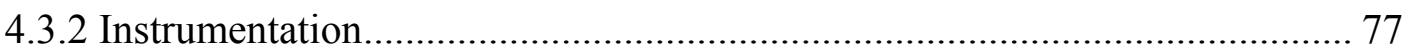

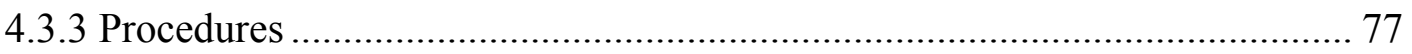

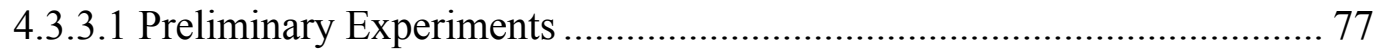

4.3.3.2 Effect of ROS and DOM on HgS Dissolution (with Glass Beads) ......... 78

4.3.3.3 Effect of ROS and DOM on HgS Dissolution (without Glass Beads)........ 79

4.3.3.4 Speciation of Hg Species during HgS Dissolution .................................... 80

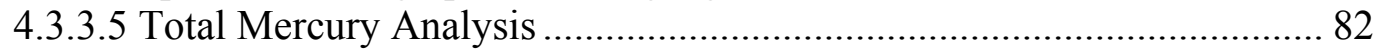

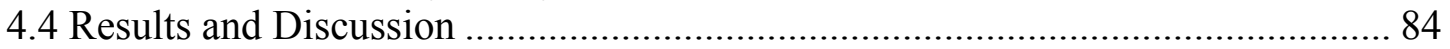

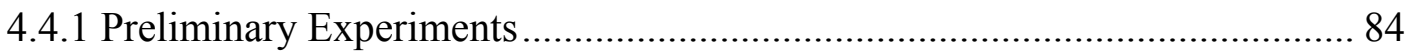

4.4.2 Effects of ROS and DOM on HgS Dissolution (with Glass Beads) .............. 90

4.4.3 Effect of ROS and DOM on HgS Dissolution (with Glass Beads) ................ 95

4.4.4 Distribution of Hg Species during HgS Dissolution ...................................... 97

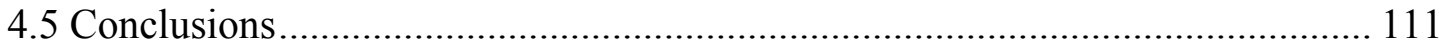

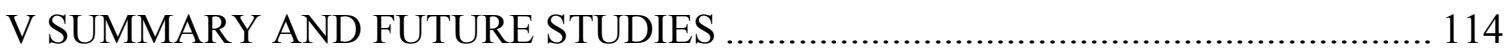

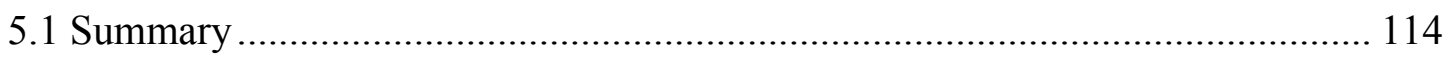

5.1.1 Covalent Affinity Chromatography Preconcentration for Thiol Analysis ... 114

5.1.2 Interaction of ROS with Mercury Sulfide .................................................. 114

5.2 Suggestions for Future Studies ................................................................... 116

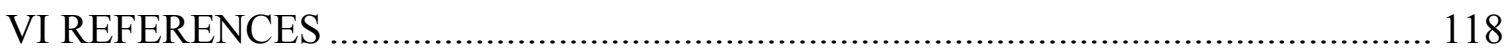




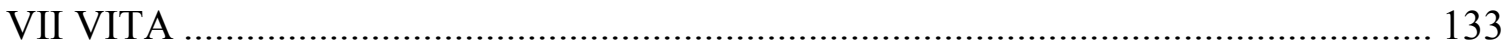


1.1 Stability constants of complexes of mercury with various inorganic and organic ligands are adapted from Ravichandran 2004.

1.2 Stability constants of $\mathrm{Hg}$-DOC complexes reported in literature. Data is adapted from Ravichandran (2004)....

2.1 Summary of the representative methods for thiol analysis in environmental and biological samples

2.2 Summary of the representative methods for the concentration of trace organic compounds in water.

2.3 Limits of detection for Cys and GSH calculated based on 3 times the standard deviation of $25 \mu \mathrm{M}$ Cys and GSH standard solution injected directly onto HPLC $(n=6)$. For the calculation of method LODs, sample was concentrated from 500 to $25 \mathrm{~mL}$

2.4 Recoveries and relative standard deviation for the analysis of Cys and GSH $25 \mu \mathrm{M}$ spiked in DDI, using activated thiopropyl sepharose gel preconcentration (4 times) and analysis using HPLC-UV/Vis $(\mathrm{N}=5)$

2.5 Analysis of water samples collected from the Everglade and a small pond at FIU. The samples were spiked with Cys and GSH at $10 \mu \mathrm{M}$ and preconcentrated using activated thiopropyl sepharose gel for 20 folds and analyzed by HPLC-UV/Vis $(\mathrm{N}=5)$.

3.1 Comparisons of using 2\% TCEP ( $250 \mu \mathrm{L})$ and different shaking methods (vortex, ultrasonic, and orbital shaking) to elute GSH and Cys enriched with affinity solid phase extraction $(\mathrm{N}=3))$.

3.2 Recoveries of Cys spiked in DIW at $200 \mathrm{nM}$ using $1 \%$ TCEP $(500 \mu \mathrm{L})$ or $10 \%$ TCEP $(50 \mu \mathrm{L})$ as releasing reagent $(\mathrm{N}=3)$. The sample was preconcentrated with $0.1 \mathrm{~g}$ activated thiopropyl gel from 10 to $2 \mathrm{~mL}$

3.3 Recoveries of thiols in DIW at $200 \mathrm{nM}$ spiked with $10 \mathrm{nM}$ Cys and GSH using activated thiopropyl gel preconcentrated and analyzed by HPLC-FL $(\mathrm{N}=3)$ Two consecutive releases were carried out using $50 \mu \mathrm{L} \mathrm{10 \%}$ TCEP

3.4 Limit of detection (LODs) calculated based on 3 times standard deviation of the analysis of $10 \mathrm{nM}$ Cys and GSH spiked in DDI water $(\mathrm{n}=6)$. 
The volume of the original standard solution was $25 \mathrm{~mL}$ and the final volume was $2.5 \mathrm{~mL}$

3.5 Recoveries of Cys and GSH spiked at 0, 5, and $200 \mathrm{nM}$ in a pond water sample collected at FIU. The samples were processed with activated thiopropyl gel solid phase preconcentration and followed by TCEP elution and HPLC-FL analysis

4.1 Concentration of released mercury from cinnabar $(400 \mathrm{mg} / \mathrm{L})$ in DDI by different sampling methods was compared. One group was sampled by $0.22 \mu \mathrm{m}$ filter; the other was centrifuged under $9400 \times \mathrm{g}$ for $20 \mathrm{~min}$ and put still for 8 hours...... 86

4.2 Cysteine and glutathione reacted with $200 \mathrm{ppb} \mathrm{Hg}$ standard were analyzed by SBD-F derivatization with fluorescence detection 85

4.3 Different mercury species presented during $\mathrm{HgS}$ dissolution control experiment. The initial concentration of $\mathrm{HgS}$ is $400 \mathrm{mg} / \mathrm{L}$. Separation of truly dissolved $(<3 \mathrm{kDa})$ and colloid $(>3 \mathrm{kDa})$ $\mathrm{Hg}$ species was conducted by microsep centrifugal devices with $3 \mathrm{k} \mathrm{MWCO}$ at $7000 \times \mathrm{g}$ for $20 \mathrm{~min}$

4.4 Different mercury species presented during $\mathrm{HgS}$ dissolution in the presence of AHA The initial $\mathrm{HgS}$ concentration was $400 \mathrm{mg} / \mathrm{L}$ and concentration of AHA was $22.5 \mathrm{mgC} / \mathrm{L}$. Separation of truly dissolved $(<3 \mathrm{kDa})$ and colloidal $(>3 \mathrm{kDa}) \mathrm{Hg}$ species was conducted by microsep centrifugal devices with $3 \mathrm{k}$ MWCO at $7000 \times \mathrm{g}$ for $20 \mathrm{~min}$. Colloidal on the filter refers to $\mathrm{Hg}$ absorbed by the filter during separation and was determined by digesting filter followed by total $\mathrm{Hg}$ analysis

4.5 Different mercury species presented during $\mathrm{HgS}$ dissolution in the presence of Cys. The initial $\mathrm{HgS}$ concentration was $400 \mathrm{mg} / \mathrm{L}$ and Cys concentration was $10 \mu \mathrm{M}$. Separation of truly dissolved $(<3 \mathrm{kDa})$ and colloidal $(>3 \mathrm{kDa}) \mathrm{Hg}$ species was conducted by microsep centrifugal devices with $3 \mathrm{k}$ MWCO at $7000 \times \mathrm{g}$ for $20 \mathrm{~min}$. Colloidal on the filter refers to $\mathrm{Hg}$ absorbed by the filter during separation and was determined by digesting filter followed by total $\mathrm{Hg}$ analysis

4.6 Different mercury species presented during $\mathrm{HgS}$ dissolution in the presence of glutathione. The initial $\mathrm{HgS}$ concentration was $400 \mathrm{mg} / \mathrm{L}$ and GSH concentration was $10 \mu \mathrm{M}$. Separation of truly dissolved $(<3 \mathrm{kDa})$ and colloidal $(>3 \mathrm{kDa}) \mathrm{Hg}$ species was conducted by microsep centrifugal devices with $3 \mathrm{k} \mathrm{MWCO}$ at $7000 \times \mathrm{g}$ for $20 \mathrm{~min}$ 102 
4.7 Different mercury species presented during the reaction of AHA and Hg STD by microsep centrifugal devices with $3 \mathrm{k}$ MWCO under $7000 \times \mathrm{g}$ centrifuge force for $20 \mathrm{~min}$. The initial $\mathrm{Hg}$ concentration was $100 \mathrm{ppb}$ and the initial AHA concentration was $22.5 \mathrm{mgC} / \mathrm{L} \ldots 102$

4.8 Different mercury species presented during HgS dissolution with and without glass beads in the present of GSH (shaking 72 hours at $200 \mathrm{rpm}$ ). The initial $\mathrm{HgS}$ concentration was $400 \mathrm{mg} / \mathrm{L}$ and the initial glutathione was $10 \mu \mathrm{M}$. Separation of truly dissolved $(<3 \mathrm{kDa})$ and colloid $(>3 \mathrm{kDa})$. $\mathrm{Hg}$ species was conducted by microsep centrifugal devices with $3 \mathrm{k}$ MWCO at $7000 \times \mathrm{g}$ for $20 \mathrm{~min}$ 105

4.9 Different mercury species presented during the reaction of GSH and $\mathrm{Hg}$ STD. The initial $\mathrm{Hg}$ concentration was $100 \mathrm{ppb}$ and GSH concentration was $10 \mu \mathrm{M}$. Separation of truly dissolved $(<3 \mathrm{kDa})$ and colloidal $(>3 \mathrm{kDa}) \mathrm{Hg}$ species was conducted by microsep centrifugal devices with $3 \mathrm{kDa}$ at $7000 \times \mathrm{g}$ for $20 \mathrm{~min}$ 106

4.10 Separation of mercury species in the solution from GSH-enhanced $\mathrm{HgS}$ dissolution in the absence of glass beads at $9400 \times \mathrm{g}$ centrifugal force. The initial $\mathrm{HgS}$ concentration was $400 \mathrm{mg} / \mathrm{L}$ and GSH concentration was $10 \mu \mathrm{M}$. Separation of truly dissolved $(<3 \mathrm{kDa})$ and colloid $(>3 \mathrm{kDa}) \mathrm{Hg}$ species was conducted by microsep centrifugal devices with $3 \mathrm{k}$ MWCO at $9400 \times \mathrm{g}$ for $20 \mathrm{~min}$. Colloidal on the filter refers to $\mathrm{Hg}$ adsorbed by the filter during separation and was determined by digesting filter followed by total $\mathrm{Hg}$ analysis

4.11 Separation of mercury species in the solution from GSH-enhanced $\mathrm{HgS}$ dissolution in the presence of glass beads at $9400 \times \mathrm{g}$ centrifugal force. The initial $\mathrm{HgS}$ concentration was $400 \mathrm{mg} / \mathrm{L}$ and GSH concentration was $10 \mu \mathrm{M}$. Separation of truly dissolved $(<3 \mathrm{kDa})$ and colloid $(>3 \mathrm{kDa})$ $\mathrm{Hg}$ species was conducted by microsep centrifugal devices with $3 \mathrm{k} \mathrm{MWCO}$ at $9400 \times \mathrm{g}$ for $20 \mathrm{~min}$. Colloidal on the filter refers to $\mathrm{Hg}$ adsorbed by the filter during separation and was determined by digesting filter followed by total $\mathrm{Hg}$ analysis.

4.12 The thiol-Hg complex (Cys and GSH STD reacted with $200 \mathrm{ppb}$ Hg STD) was analyzed by CVAFS without digestion

4.13 The truly dissolved mercury from cinnabar dissolution in the presence of $10 \mu \mathrm{M}$ GSH was analyzed by CVAFS with and without digestion. Separation of truly dissolved $(<3 \mathrm{kDa})$ and colloid $(>3 \mathrm{kDa})$ $\mathrm{Hg}$ species was conducted by microsep centrifugal devices with $3 \mathrm{k} \mathrm{MWCO}$ at $7000 \times \mathrm{g}$ for $20 \mathrm{~min}$ 110 
4.14 The truly dissolved mercury from cinnabar dissolution in the presence of $10 \mu \mathrm{M}$ Cys was analyzed by CVAFS with and without digestion ..................... 110 


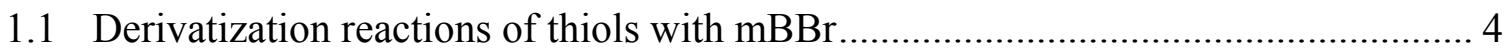

1.2 Derivatization reactions of thiols with DTNB.................................................. 4

1.3 Derivatization reactions of thiols with SBD-F and production of

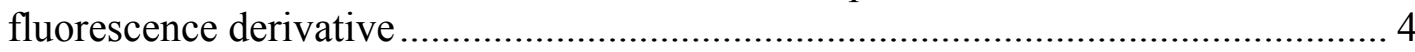

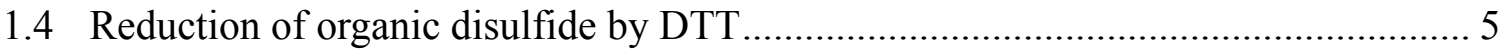

1.5 Reduction of organic disulfide by tributylphosphine TBP ................................... 5

1.6 Reduction of organic disulfide by 2-triscarbonethynolphosphine TCEP .................. 5

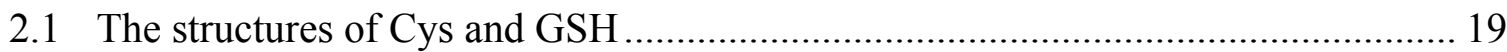

2.2 The reaction scheme of DTNB with thiol species ................................................ 22

2.3 The reaction scheme of DTNP with thiol species …………………………......... 22

2.4 Reactions showing the synthesis of activated thiopropyl sepharose $6 \mathrm{~B} \ldots \ldots \ldots \ldots \ldots \ldots . .28$

2.5 The schematic diagram showing the procedure of thiol preconcentration and elution using affinity covalent chromatography system.......................................... 30

2.6 Covalent affinity reactions between activated thiopropyl sepharose $6 \mathrm{~B}$ and reduced organic sulfur

2.7 Reactions showing the free thiol (RSH) released by DTT from affinity chromatographic column

2.8 The chromatogram of a mixture solution of Cys and GSH separated by HPLC with a linear gradient of $0-20 \%$ acetonitrile for $20 \mathrm{~min}$.

2.9 The chromatogram of a mixture solution of Cys and GSH separated by HPLC with a linear gradient of $0-5 \%$ acetonitrile for $20 \mathrm{~min}$........................................ 36

2.10 The standard of Cys and GSH calibration curve ……….................................... 38

3.1 The reaction scheme of reduced organic sulfur and thiopropyl sepharose $6 \mathrm{~B}$......... 44

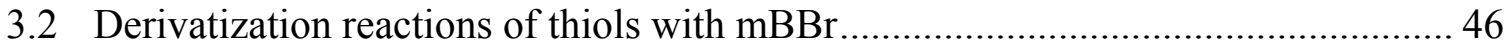


3.3 Derivatization reactions of thiols with OPA......................................................... 46

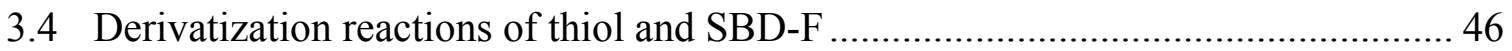

3.5 Schematic diagram is showing the thiol preconcentration system by covalent affinity chromatography. Pump 1 was used to load samples into the column, while pump 2 was used to draw effluent. 50

3.6 Reaction showing the release of the thiol of interest (R-SH) by TCEP from the affinity column with enriched thiols on thiopropyl sepharose gel..

3.7 Reduction of organic disulfide by dithiothreitol..................................................... 54

3.8 Organic disulfide is reduced by tributylphosphine. Dimethylformamide is used as the solvent. 54

3.9 Optimization of the reaction time for SBD-F derivatization of Cys and GSH $(10 \mu \mathrm{M})$.

3.10 Effects of the concentration of SBD-F on the fluorescence signals of Cys and GSH derivatives. Concentration of Cys and GSH used was $1.0 \mu \mathrm{M}$. 57

3.11 Chromatogram of a blank solution containing $80 \mu \mathrm{L} \mathrm{10 \%} \mathrm{TCEP} \mathrm{(a),}$ showing two of the interference peaks having similar retention times with $100 \mathrm{nM}$ Cys and GSH derivatives (b).

3.12 Stability tests of Cys and GSH ( $300 \mathrm{nM}$ spiked in DDI water) under room temperature.

3.13 Stability tests of Cys and GSH (300 nM spiked in DDI water) under ice condition.

3.14 Typical chromatograms of the procedure blank (a), and Cys and GSH spiked in DIW at $200 \mathrm{nM}$ (b), followed by covalent affinity column preconcentration, elution with TCEP, SBD-F derivatization, and HPLC-FL detection.

3.15 The schemes for the reactions (a) between TCEP and activated thiopropyl sepharose gel, and (b) the proposed reaction between SBD-F and 2-pridyl disulfide produced in scheme (a)

3.16 Cysteine Calibration curves of Cys and GSH using HPLC-FL after derivatization with SBD-F 
3.17 A typical chromatogram of the SBD-F derivatives of Cys and GSH analyzed by HPLC-FL. Thiol concentration was $100 \mathrm{nM}$

4.1 Mercury speciation under different $\mathrm{Eh} / \mathrm{pH}$ conditions (adapted from a USEPA report) (USEPA 2001)

4.2 The separation of different dissolved fraction by using microsep centrifugal devices. Colloidal fraction is retained in sample reservoir and truly dissolved fraction $(<3 \mathrm{kDa})$ is retained in filtrate receiver.

4.3 Typical calibration curve for mercury analysis using CVAFS 84

4.4 Cysteine STD and mix solution of cysteine STD and $338 \mathrm{ppb} \mathrm{Hg}$ (HgS dissolution) analyzed by SBD-F derivatization with fluorescence detection

4.5 Glutathione STD and mix solution of glutathione STD and $115 \mathrm{ppb}$ $\mathrm{Hg}$ ( $\mathrm{HgS}$ dissolution) analyzed by SBD-F derivatization with fluorescence detection

4.6 The kinetic data of $10 \mu \mathrm{M}$ Cys during the $\mathrm{HgS}(400 \mathrm{mg} / \mathrm{L})$ dissolution experiment

4.7 Kinetic data of GSH during the $\mathrm{HgS}(400 \mathrm{mg} / \mathrm{L})$ dissolution experiment. At initial, $10 \mu \mathrm{M}$ GSH was spiked into test tube. Another $10 \mu \mathrm{M}$ glutathione was added to test tube at 72 hours

4.8 $\mathrm{HgS}$ dissolution (solid $\mathrm{HgS}$ concentration was $400 \mathrm{mg} / \mathrm{L}$ ) in the presence of GSH at low concentrations: (a) $1 \mu \mathrm{M}$ and (b) $0.2 \mu \mathrm{M} \ldots \ldots \ldots \ldots \ldots \ldots \ldots \ldots . . . \ldots 92$

4.9 Kinetic data of dissolution of cinnabar $(400 \mathrm{mg} / \mathrm{L})$ in presence of $10 \mu \mathrm{M}$ Cys (add $8 \mu \mathrm{M}$ Cys at 72 hours).

4.10 Kinetic data of dissolution of cinnabar $(400 \mathrm{mg} / \mathrm{L})$ in presence of $10 \mu \mathrm{M}$ Cys (add $8 \mu \mathrm{M}$ GSH at 72 hours)

4.11 Kinetic data of dissolution of cinnabar $(400 \mathrm{mg} / \mathrm{L})$ in presence of $\mathrm{AHA}(22.5 \mathrm{mgC} / \mathrm{L})$.

4.12 Effect of $200 \mathrm{nM}$ of Cys on cinnabar dissolution. The initial concentration of cinnabar was $400 \mathrm{mg} / \mathrm{L}$. Cys was initially added at the concentration of $200 \mathrm{nM}$ at the beginning of the experiment 
4.13 Effect of Cys ( $200 \mathrm{nM}$ Cys was added at different time intervals $0,2,4,6,10,24,26,28,30,46,48$ and 52 hours) on the dissolution of $\mathrm{HgS}$

4.14 Total mercury concentration from cinnabar $(400 \mathrm{mg} / \mathrm{L})$ dissolution was obtained in the presence of varying concentrations of Cys and GSH (a) and AHA (b). The total dissolved mercury concentration of cinnabar in DIW is $742 \mathrm{ppt}$

4.15 Kinetic data of cinnabar dissolution $(400 \mathrm{mg} / \mathrm{L})$ without glass beads was obtained in the presence of AHA, WFA and WHA $(22.5 \mathrm{mgC} / \mathrm{L})$ in DIW 


\section{LIST OF ABBREVIATIONS}

\begin{tabular}{|c|c|}
\hline ABBREVIATION & FULL NAME \\
\hline CVAFS & cold vapor atomic fluorescence spectrometry \\
\hline Cys & cysteine \\
\hline DOM & dissolved organic matter \\
\hline DTNB & 5, 5'-Dithiobis - (2-nitrobenzoic acid) \\
\hline DTT & dithiothretol \\
\hline FL & fluorescence detector \\
\hline GSH & glutathione \\
\hline HPLC & high performance liquid chromatography \\
\hline $\mathrm{HgS}$ (red) & cinnabar \\
\hline LOD & limits of detection \\
\hline LWMTs & low molecular weight thiol-containing amino acids \\
\hline ROS & reduced organic sulfur \\
\hline RSD & relative standard deviation \\
\hline SBD-F & ammonium 7-fluorobenzo-2-oxa-1, 3-diazole-4-sulphonate \\
\hline $\mathrm{SD}$ & standard deviation \\
\hline STD & standard \\
\hline SUVA & specific ultraviolet absorption \\
\hline TCEP & tris 2-carboxyethyl phosphine \\
\hline $\mathrm{THg}$ & total concentration of mercury \\
\hline $\mathrm{UV} / \mathrm{V}$ is & ultraviolet visible spectroscopy \\
\hline
\end{tabular}




\section{Chapter I}

\section{INTRODUCTION}

\subsection{Reduced Organic Sulfur in the Environment}

Sulfur exists in nature at different oxidation states such as: sulfide $\left(\mathrm{S}^{2-}\right)$, sulfite $\left(\mathrm{SO}_{3}{ }^{2-}\right)$, sulfate $\left(\mathrm{SO}_{4}{ }^{2-}\right)$, thiosulfate $\left(\mathrm{S}_{2} \mathrm{O}_{3}{ }^{2-}\right)$ among others. It occurs in both combined and free states and is distributed widely over the Earth's surface and represents approximately $1.9 \%$ of the total weight of the Earth (USEPA 1991).

Among all forms of sulfur compounds, reduced organic sulfur (ROS) (compounds containing thiol group, $-\mathrm{SH}$ ), is the most active form. Examples of thiols in biomolecules include but are not limited to amino acid cysteine (Cys), non-protein forming amino acid homocysteine, and glutathione (GSH). Reduced organic sulfur compounds (R-SH) are especially important in biogeochemical reactions of the marine and freshwater ecosystem because of the high reactivity of the sulfhydryl group toward metals (Patai and Editor 1974; Boulegue et al. 1982). Glutathione, a tripeptide, one of the most abundant low molecular weight thiols in animals, plants and bacteria, is believed to play an important role in protecting cells against oxidative stress and elevated levels of heavy metals (Giovanelli 1987).

\subsection{Analysis of Reduced Organic Sulfur in Environmental Samples}

Thiols undergo rapid oxidation in air, which puts limitations on the storage and handling of the samples. Analysis is required on site or performed within very short periods of time upon sampling. This is one of the major problems in real environment studies, where storage is often necessary prior to analysis. No special techniques have been developed to prevent this rapid oxidation process. Thiol analysis in aquatic system 
also suffers from the limitation in instrumental sensitivity and method detection limits, since thiols exist in very low concentrations ( $\mathrm{nM}$ or sub $\mathrm{nM}$ ) in aquatic environment (Tang et al. 2003; Zhang et al. 2004). In addition, strong matrix interferences are encountered without sample cleanup. These limitations have greatly hampered the measurement of reduced organic sulfur in aquatic environment, particularly in freshwater ecosystems including surface and pore waters. Limitations in thiol analysis have hindered our further understanding of the role of ROS played in metal biogeochemistry. A reliable analysis method to detect thiol would be very helpful for us to understand the fate and transportation of sulfur and mercury and their interaction in aquatic system.

Despite the difficulties in thiol analysis, efforts have been made to develop and apply various methods for thiol detection in biological and natural aquatic systems. The preconcentration step is usually needed because of the extremely low concentration of reduced sulfur in aquatic system (nM level). Commonly used preconcentration techniques include solid phase extraction (SPE), freeze drying, rotary evaporation, solid phase microextraction (SPME) and affinity chromatography (used for biological samples). Thiol analysis involves separation using chromatography and electrophoresis followed by detection using electrochemical methods, fluorescence and postcolumn derivatization UV-Vis detection (Vairavamurthy and Mopper 1990; Owens and LaCourse 1997; Kabzinski 1998; Wang et al. 1998; Tang et al. 2000; Tang et al. 2003; Zhang et al. 2004; Gong et al. 2005; Petrlova et al. 2006; Wang et al. 2006). Some electrochemical methods have $\mu \mathrm{M}$ detection limits, but they suffer from oxide formations at the tip of the electrode used (usually gold) and adsorption of sulfur to the electrode surface (Owens and LaCourse 1997; Wang et al. 1998; Gong et al. 2005; Petrlova et al. 2006). Fluorescence 
derivatization of thiols prior to HPLC separation has also found applications for thiol analysis. The fluorescence reagents ammonium 7-fluorobenzo-2-oxa-1, 3-diazole-4sulphonate (SBD-F), o-phthalaldehyde (OPA) and thiol-monobromobimane (mBBr) are commonly used (Tang et al. 2000; Tang et al. 2003; Zhang et al. 2004). The ophthalaldehyde reaction is highly $\mathrm{pH}$ dependent and at $\mathrm{pH}$ values below 9 , no reaction occurs. Derivatization with $\mathrm{mBBr}$ is characterized by the formation of interfering adducts and time consuming clean-up steps required to remove the hydrolysis products (Figure 1.1). A commonly used reagent for determination of thiol containing compounds using post-column derivatization technique is 5,5 '-Dithiobis - (2-nitrobenzoic acid) (DTNB). The reagent oxidizes the thiol species and it is reduced and cleaved at the disulfide bond (Figure 1.2) producing a yellow color, which shows an absorption at $412 \mathrm{~nm}$ (Vairavamurthy and Mopper 1990; Zhang et al. 2004). Ammonium 7-fluorobenzo-2-oxa1,3-diazole-4-sulphonate derivatization is a common fluorescence precolumn technique for thiol analysis (Figure 1.3). It is a water-soluble reagent that reacts with sulfurhydryl groups to produce highly fluorescent compounds.

It is common to use reduced reagent in order to determine all the thiols including the oxidized thiols (disulfides). The common reducing reagents used to cleave the -s-s- bond are DTT, tributylphosphine (TBP) and tris 2-carboxyethyl phosphine (TCEP) (Figures 1.4-1.6). 5, 5'-Dithiobis - (2-nitrobenzoic acid) itself is thiol and thus may generate problems for total thiol determination. It has been found that TBP can decrease fluorescence signals. Therefore, extra extraction step is required to remove it before 


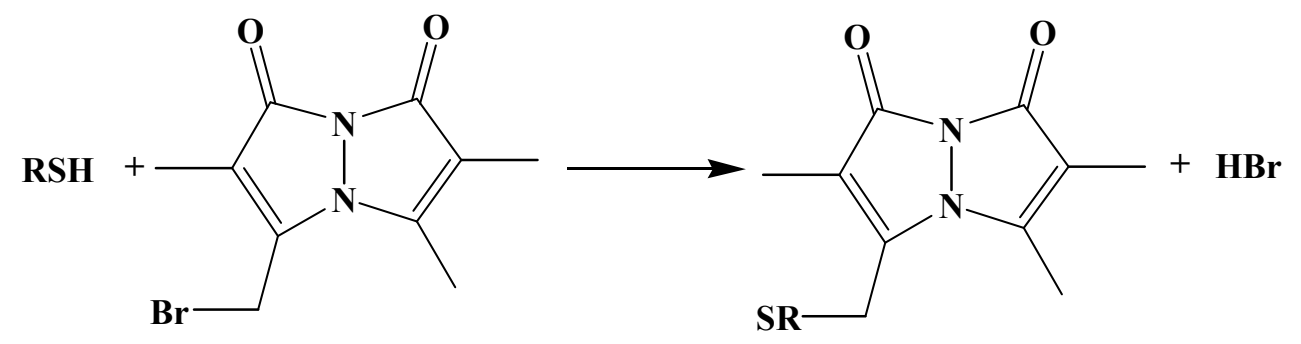

Figure 1.1. Derivatization reaction of thiols with $\mathrm{mBBr}$ (Chou et al. 2001).

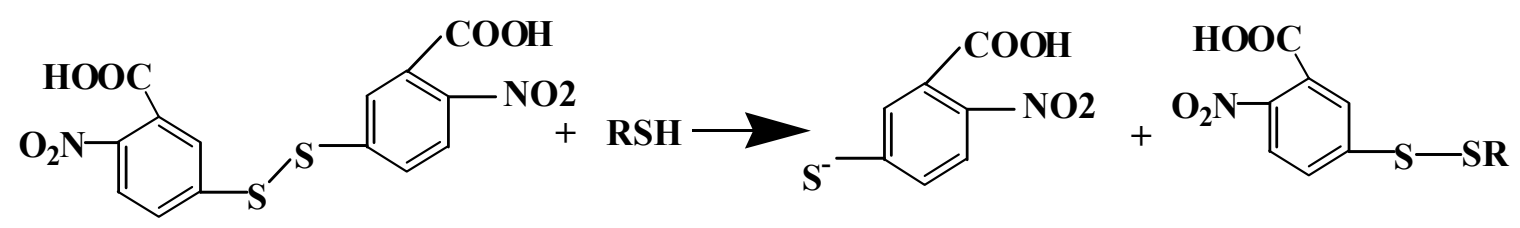

Figure 1.2 Derivatization reactions of thiols with DTNB.

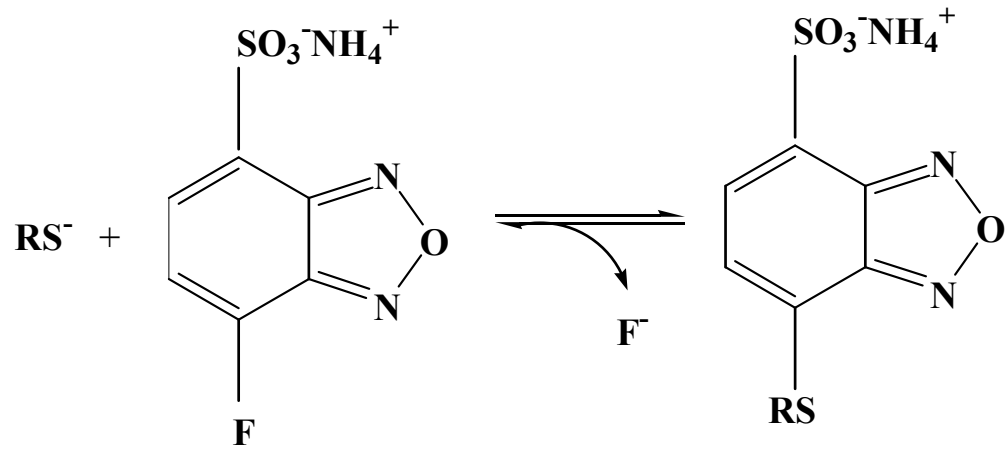

Figure 1.3 Derivatization reactions of thiols with SBD-F and production of fluorescence derivative.

derivatization. Tributylphosphine (TBP) has been shown to solve this problem, when SBD-F was used as derivatization reagent for thiol determination. TBP is not soluble in water and has an unpleasant odor. Another reagent, tris 2-carboxylethyl phosphine (TCEP) has been used recently instead of TBP. It does not have an unpleasant odor and is soluble in water. 


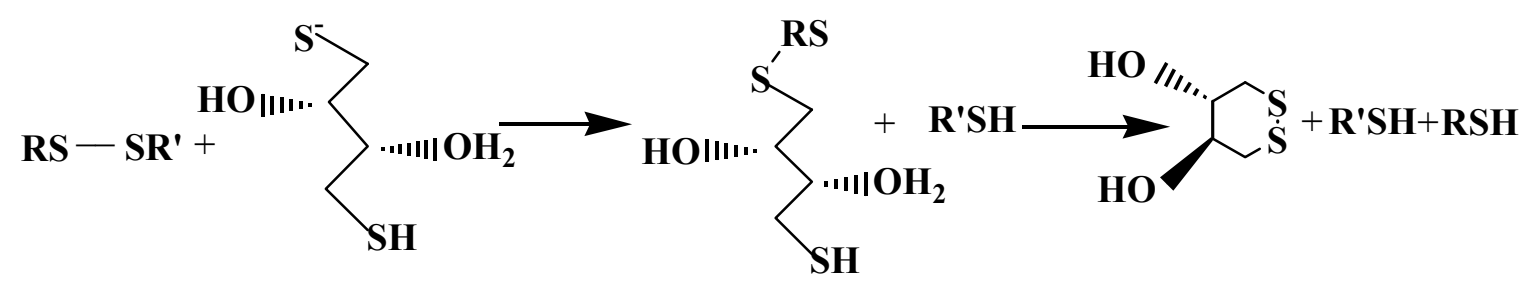

Figure 1.4 Reduction of organic disulfide by DTT.

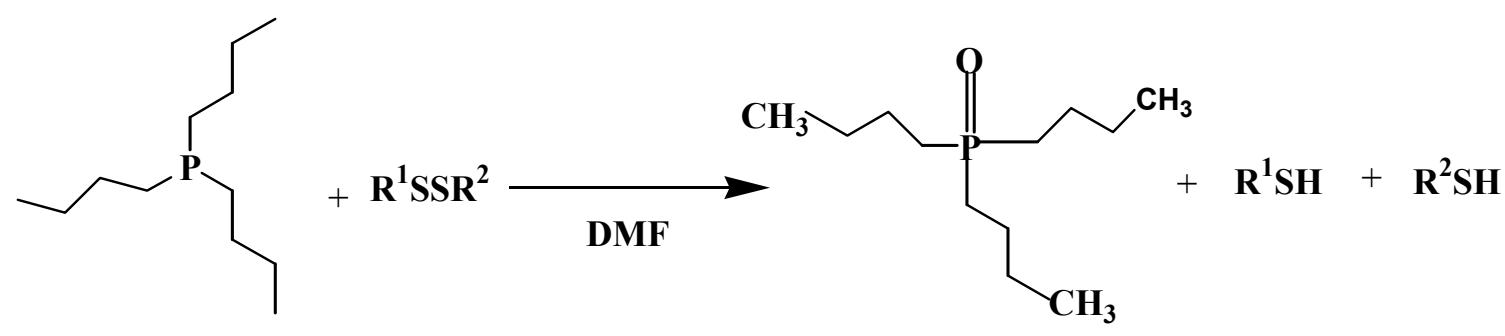

Figure 1.5 Reduction of organic disulfide by tributylphosphine TBP.

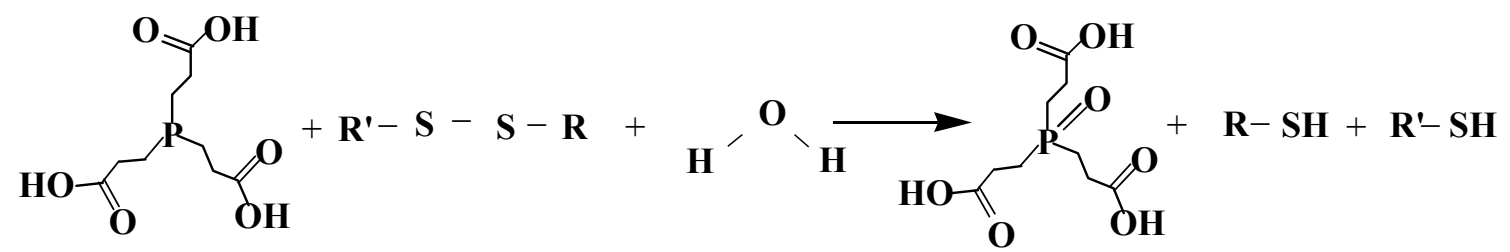

Figure 1.6 Reduction of organic disulfide by TCEP.

The lack of data on the mercury-ROS interaction is partially attributed to the limitation of analytical techniques that can be used for the determination of ROS at very low concentration levels in environmental water system. The development of a convenient and reliable method for the direct determination of the concentrations of naturally occurring thiol groups in natural freshwater is necessary to provide more specific information and to clarify its environmental role in relation to mercury binding. 


\subsection{Mercury in the Environment}

Mercury is a naturally occurring element distributed throughout the environment and occurs in different forms such as elemental mercury $\left(\mathrm{Hg}^{0}\right)$, ionic mercury $\left(\mathrm{Hg}^{+}, \mathrm{Hg}^{2+}\right)$, and methylated mercury $\left(\mathrm{CH}_{3} \mathrm{Hg}^{+}, \mathrm{CH}_{3} \mathrm{HgCH}_{3}\right)$. Element mercury is transported globally before depositing on soil or aquatic system. It is believed that all mercury ( $>95 \%)$ in most fish species occurs as methylmercury (Porcella 1994). Elemental mercury is slightly toxic, while short chain alkylmercury compounds are highly toxic, because of the highly lipophilic alkyl group. Methylmercury is neutrotoxic and causes blockage of binding sites of enzymes, interferes with protein synthesis. It is accumulative and persistent in the environment and ecosystem.

Mercury speciation in aquatic system is affected by a variety of organic and inorganic ligands that can bind mercury in water. The relative importance of different ligands for mercury complexation will depend on the concentration of mercury and the binding strength of the formed mercury-ligand complexes (such as stability constants). The stability constants of various complexes between mercury and inorganic and organic ligands are summarized in Table 1.1.

Chloride, hydroxide and sulfide are considered important inorganic ligands in controlling mercury speciation in aquatic system (Schuster 1991; Ravichandran et al. 1999). Mercury-hydroxide complexes $\left(\mathrm{Hg}(\mathrm{OH})_{2}, \mathrm{HgOH}^{+}\right)$are thought to be the important species and mercury-chloride complexes $\left(\mathrm{HgCl}_{2}, \mathrm{HgCl}^{2-}\right)$ are important at low $\mathrm{pH}$ or high chloride concentration. Mercury-sulfide complexes were hypothesized to be formed when sulfide is present in aquatic environment (Ravichandran 2004). The binding between inorganic sulfide and mercury play an important role in the speciation of 
mercury in anoxic environments. The following reactions are likely to be important (Hurley et al. 1994). The stability constants for these species are also listed below (Benoit et al. 1999):

$$
\begin{array}{ll}
\mathrm{Hg}^{2+}+\mathrm{HS}^{-} \leftrightarrow \mathrm{HgS}^{0}{ }_{\mathrm{aq}}+\mathrm{H}^{+} & K=10^{26.5} \\
\mathrm{Hg}^{2+}+2 \mathrm{HS}^{-} \leftrightarrow \mathrm{Hg}\left(\mathrm{S}_{2} \mathrm{H}\right)^{-}+\mathrm{H}^{+} & K=10^{32.0} \\
\mathrm{Hg}^{2+}+2 \mathrm{HS}^{-} \leftrightarrow \mathrm{Hg}(\mathrm{SH})_{2}{ }^{0} & K=10^{37.5}
\end{array}
$$

\subsection{Interaction of Inorganic Mercury with Reduced Organic Sulfur}

Mercury (II) has high affinity for ROS and tends to form covalent bonds with reduced sulfur (Hesterberg et al. 2001). Theoretical calculations have shown that the thiol group is the primary complexation group of GSH with many trace metals (Krezel and Bal 1999). It is well known that the reactivity of thiol to mercury is strong, compared to other transition metal ions (Cestari and Airoldi 1997). Complexing reaction between Hg and ROS can be written (Benoit et al. 2001 (b)):

$$
\mathrm{Hg}^{2+}+\mathrm{RSH}^{\mathrm{n}-}=\mathrm{HgRS}^{(\mathrm{n}-1)-}+\mathrm{H}^{+}
$$

A good example of mercury interaction with ROS present in the environment is the complexation between mercury and dissolved organic matter (Odom et al.1982), since DOM present in natural environment generally contains many ROS sites (Ravichandran 2004). Dissolved organic matter is defined as the portion of organic matter passing

Table 1.1 Stability constants of complexes of mercury with various inorganic and organic ligands are adapted from Ravichandran 2004 (Martell et al. 1998; Ravichandran 2004).

\begin{tabular}{llll}
\hline Ligand & Formula & $\mathrm{HgL}^{\mathrm{b}}$ & $\mathrm{HgL}_{2}^{\mathrm{b}}$
\end{tabular}




\begin{tabular}{|c|c|c|c|c|c|}
\hline & & \\
\hline & & $\log k^{e}$ & $T, I^{d}$ & $\log k^{e}$ & $T, I$ \\
\hline Chloride & $\mathrm{Cl}^{-}$ & 7.3 & 25,0 & 14.0 & 25,0 \\
\hline Carbonate & $\mathrm{CO}_{3}{ }^{2-}$ & 11.0 & $25,0.5$ & - & - \\
\hline Hydroxide & $\mathrm{OH}^{-}$ & 10.6 & 25,0 & 21.8 & 25,0 \\
\hline Sulfate & $\mathrm{SO}_{4}{ }^{2-}$ & 1.3 & $25,0.5$ & - & - \\
\hline Bromide & $\mathrm{Br}^{-}$ & 9.1 & $25,0.5$ & 17.3 & $25,0.5$ \\
\hline Fluoride & $\mathrm{F}^{-}$ & 1.0 & $25,0.5$ & - & - \\
\hline Ammonia & $\mathrm{NH}_{3}$ & 8.8 & $22,2.0$ & 17.4 & $22,2.0$ \\
\hline Sulfide & $\mathrm{HS}^{-}$ & - & - & 37.7 & $20,1.0$ \\
\hline Phosphate & $\mathrm{PO}_{4}{ }^{3-}$ & 9.5 & $25,3.0$ & - & - \\
\hline Acetic acid & $\mathrm{CH}_{3}(\mathrm{COOH})$ & 3.7 & $24,0.1$ & 8.4 & $25,3.0$ \\
\hline Citric acid & $\mathrm{HOC}\left(\mathrm{CH}_{2}\right)_{2}(\mathrm{COOH})_{3}$ & 10.9 & $25,0.1$ & - & - \\
\hline Nitrilotriacetic acid & $\mathrm{N}\left(\mathrm{CH}_{2} \mathrm{COOH}\right)_{3}$ & 14.3 & $25,0.1$ & - & - \\
\hline $\begin{array}{l}\text { Ethykebedubutrukitetraacetic acid } \\
\text { (EDTA) }\end{array}$ & $\left(\mathrm{HOOCCH}_{2}\right)_{4}\left(\mathrm{NCH}_{2}\right)_{2}$ & 21.5 & $25,0.1$ & - & - \\
\hline Cysteine & $\mathrm{HSCH}_{2} \mathrm{CH}\left(\mathrm{NH}_{2}\right) \mathrm{COOH}$ & 14.4 & $25,0.1$ & - & - \\
\hline Glycine & $\mathrm{NH}_{2} \mathrm{CH}_{2} \mathrm{COOH}$ & 10.3 & $20,0.5$ & 19.2 & $20,0.5$ \\
\hline Thiourea & $\mathrm{H}_{2} \mathrm{NCSNH}_{2}$ & 11.4 & $20,0.5$ & 22.1 & $25,0.5$ \\
\hline Thiosalicylic acid & $\mathrm{HSC}_{6} \mathrm{H}_{4} \mathrm{COOH}$ & 25.7 & - & & \\
\hline Thioglycolic acid & $\mathrm{HSCH}_{2} \mathrm{COOH}$ & 34.5 & $25,0.1$ & 43.8 & $25,1.0$ \\
\hline
\end{tabular}


${ }^{\mathrm{a}}$ The chemical formula for organic ligands are shown in unionized state, whereas stability constants are given for fully ionized forms.

${ }^{\mathrm{b}}$ Stability constants for $\mathrm{HgL}$ complexes are for reaction $\mathrm{Hg}^{2+}+\mathrm{L}^{\mathrm{X}-} \leftrightarrow \mathrm{HgL}^{\mathrm{X}+2}$, and for $\mathrm{HgL} 2$ type complexes, the reaction is $\mathrm{Hg}^{2+}+2 \mathrm{~L}^{\mathrm{x}-} \leftrightarrow \mathrm{HgL}_{2}{ }^{\mathrm{X}+2}$.

${ }^{\mathrm{c}}$ Stability constants are given for free $\mathrm{Hg}^{2+}$.

${ }^{\mathrm{d}} T=$ temperature in ${ }^{0} \mathrm{C}$ and $I=$ ionic strength in $\mathrm{mol} / \mathrm{l}$.

through 0.2 or $0.45 \mu \mathrm{m}$ filters and it is ubiquitous in aquatic system. Reduce organic sulfur is one of the most important components of DOM that can bind metal cations to form soluble complexes in aquatic environment.

It is widely accepted that the bioavailability, toxicity, and mobility of trace metals are highly dependent on complexation reactions with functional groups (in particular -SH containing groups) in natural organic matter (Buffer 1988). Among many toxic metals, mercury is of particular interest because its toxicity and widespread existence in the environment. Many studies have been conducted on the interactions of DOM and mercury. Significant and positive correlation between mercury and natural DOM has been observed in lake and river water systems (Mierle and Ingram 1991), suggesting that the interaction of mercury with DOM could play an important role in controlling the fate and transport of mercury in aqueous systems (Ravichandran 2004). The binding between mercury and DOM is so strong that the speciation of both inorganic and methylated mercury in freshwater may be largely dominated by mercury-DOM complexes (Cai et al. 1999). Lu and Jaffe studied the interaction between $\mathrm{Hg}(\mathrm{II})$ and DOM using fluorescence spectroscopy, including the conditional stability constants and the percentage of fluorophores participating in the complexation (Lu and Jaffe 2001).

The importance of ROS associated with natural organic matter in metal biogeochemistry has been well recognized (Ravichandran 2004). Although S-bearing 
ligands are less abundant compared to other binding functional groups in DOM, they may play dominant roles in forming DOM-metal complexes because of the stronger binding capability with heavy metal cations. Reduced sulfur functional groups are among the strongest binding sites for $\mathrm{Hg}(\mathrm{II})$, as demonstrated by synchrotron X-ray absorption spectroscopic measurements and related binding experiments (Xia et al. 1998; Xia et al. 1999; Skyllberg et al. 2000; Hesterberg et al. 2001; Hsu and Sedlak 2003; Lamborg et al. 2003; Waples et al. 2005). Because the concentration of DOM-bound thiols is generally much higher than the concentration of $\mathrm{Hg}$ in natural systems, strong interactions between Hg and DOM-bound thiols are expected under natural conditions (Haitzer et al. 2002). For example, results indicate that thiol groups are involved in the strong complexation of mercury with humic substances (Jackson et al. 1980; Lee and Hultberg 1990; Hintelmann and Wilken 1995; Hintelmann et al. 1997). Spectroscopic investigations have provided direct evidence of mercury binding to ROS groups in organic matter (Ravichandran 2004). Interactions between inorganic mercury (II) and ROS could directly affect mercury methylation. High methylation rates of mercury bound to cysteine by Geobacter sulfurreducens has been recently reported (Schaefer and Morel 2009).

The interactions between inorganic mercury and ROS in natural waters can be described as (Dyrssen and Wedborg 1991):

$$
\mathrm{Hg}^{2+}+\mathrm{RS}^{-} \leftrightarrow \mathrm{HgRS}^{+}
$$

Table 1.2 Stability constants of Hg-DOC complexes reported in literature. Data is adapted from Ravichandran (Ravichandran 2004). 


\begin{tabular}{|c|c|c|c|c|}
\hline Method & $\begin{array}{l}\text { Type of organic } \\
\text { mater }\end{array}$ & $\mathrm{pH}$ & $\begin{array}{l}\text { Conditional stability } \\
\text { constant }(k)\end{array}$ & Reference \\
\hline Ion exchange & $\begin{array}{l}\text { Marine sedimentary } \\
\text { humic acid, } \\
\text { commercial humic } \\
\text { acid }\end{array}$ & 5.0 & $10^{5.2}$ & $\begin{array}{l}\text { Strohel and Huljev } \\
\text { (Huljev 1971) }\end{array}$ \\
\hline $\begin{array}{l}\text { Iodide selective } \\
\text { electrode }\end{array}$ & Soil fulvic acid & $3.0-4.0$ & $10^{4.9}-10^{5.1}$ & $\begin{array}{l}\text { Chean and Gamble } \\
\text { (Chean 1974) }\end{array}$ \\
\hline $\begin{array}{l}\text { Gel filtration } \\
\text { chromatography }\end{array}$ & $\begin{array}{l}\text { Lake and river } \\
\text { humic substances }\end{array}$ & 8.0 & $10^{18.4}-10^{21.1}$ & $\begin{array}{l}\text { Mantoura and } \\
\text { Riley (Mantoura } \\
\text { and Riley 1975) }\end{array}$ \\
\hline Titration & $\begin{array}{l}\text { Bog water- } \\
\text { concentrated } \\
\text { organic matter }\end{array}$ & 4.0 & $10^{10.4}$ & $\begin{array}{l}\text { Lovgren and } \\
\text { Sjoberg (Lövgren } \\
\text { 1989) }\end{array}$ \\
\hline $\begin{array}{l}\text { Iodide selective } \\
\text { electrode }\end{array}$ & $\begin{array}{l}\text { Soil humic } \\
\text { substances }\end{array}$ & 4.5 & $10^{4.7}$ & $\begin{array}{l}\text { Yin et al. (Yin et } \\
\text { al. 1997) }\end{array}$ \\
\hline $\begin{array}{l}\text { Competitive } \\
\text { complexation }\end{array}$ & $\begin{array}{l}\text { Soil humic } \\
\text { substances }\end{array}$ & 3.2 & $10^{20.6}-10^{23.9}$ & $\begin{array}{l}\text { Skyllberg et al. } \\
\text { (Skyllberg 1997) }\end{array}$ \\
\hline $\begin{array}{l}\text { Sorption to peat } \\
\text { soil }\end{array}$ & Peat soil & - & $10^{31.1}-10^{32.2}$ & $\begin{array}{l}\text { Skyllberg et al. } \\
\text { (Skyllberg et al. } \\
2000 \text { ) }\end{array}$ \\
\hline $\begin{array}{l}\text { Competitive } \\
\text { ligand with } \\
\text { octanol-water } \\
\text { partitioning }\end{array}$ & $\begin{array}{l}\text { Aquatic humic } \\
\text { substances }\end{array}$ & Variable & $\begin{array}{l}10^{10.6}-10^{11.8} \text { (for } \\
\text { organic thiols) } \\
10^{22.4}-10^{23.8} \text { (for fully } \\
\text { ionized thiols in } \\
\text { DOM) }\end{array}$ & $\begin{array}{l}\text { Benoit et al. } \\
\text { (Benoit et al. } 2001 \\
\text { (b)) }\end{array}$ \\
\hline $\begin{array}{l}\text { Equilibrium } \\
\text { dialysis ligand } \\
\text { exchange }\end{array}$ & $\begin{array}{l}\text { Aquatic humic } \\
\text { substances }\end{array}$ & 7.0 & $\begin{array}{l}10^{23.2} \text { (at low } \\
\mathrm{Hg} / \mathrm{DOM} \text { ratio); } \\
10^{28.5} \text { for fully } \\
\text { ionized thiol in } \\
\text { DOM }\end{array}$ & $\begin{array}{l}\text { Haitzer et al. } \\
\text { (Haitzer et al. } \\
\text { 2002) }\end{array}$ \\
\hline $\begin{array}{l}\text { Adsorption to peat } \\
\text { and model fitting }\end{array}$ & $\begin{array}{l}\text { Aquatic humic } \\
\text { substances released } \\
\text { from peat during } \\
\text { adsorption } \\
\text { experiment }\end{array}$ & 6.0 & $\begin{array}{l}10^{25.8}-10^{27.2} \text { (strong } \\
\text { binding sites) } \\
10^{7.3}-10^{8.7} \text { (weak } \\
\text { binding sites) }\end{array}$ & $\begin{array}{l}\text { Drexel et al. } \\
\text { (Drexel et al. 2002) }\end{array}$ \\
\hline $\begin{array}{l}\text { Competitive } \\
\text { ligand exchange }\end{array}$ & $\begin{array}{l}\text { Organic matter in } \\
\text { stream and waster } \\
\text { water treatment } \\
\text { plant }\end{array}$ & - & $>10^{30}$ & $\begin{array}{l}\text { Hsu and Sellack } \\
\text { (Hsu and Sedlak } \\
\text { 2003) }\end{array}$ \\
\hline $\begin{array}{l}\text { "Reducible" } \\
\text { titration }\end{array}$ & $\begin{array}{l}\text { Dissolved organic } \\
\text { matter from lakes } \\
\text { and rivers }\end{array}$ & 7.5 & $10^{21}-10^{22.9}$ & $\begin{array}{l}\text { Lamborg et al. } \\
\text { (Lamborg et al. } \\
\text { 2003) }\end{array}$ \\
\hline
\end{tabular}


The stability constant of the above complex reaction has been estimated or measured many times with $\mathrm{K}$ values varying in a large range (Ravichandran et al. 1998; Ravichandran et al. 1999; Reddy and Aiken 2001). Drexel et al. (2002) studied the interaction of mercury with two Florida Everglades peat and found evidence for strong and weak binding and competition by dissolved organic matter released from the peat. The binding constants found in their ranged from $10^{25.8}$ to $10^{27.2}$ (Drexel et al. 2002). In a research studying the binding of mercury(II) to DOM, Haitzer et al. reported a binding constant of $10^{28.5}$ (Haitzer et al. 2002). Similarly, Skyllberg et al. calculated the binding constants ranging from $10^{31.6}$ to $10^{32.2}$ in a research studying binding of mercury (II) to reduced sulfur in soil organic matter along upland-peat soil transects (Skyllberg et al. 2000). These binding constants are important in predicting the role of reduced organic sulfur or DOM in general on the speciation, transport, and bioavailability of mercury in aquatic systems.

\subsection{Interactions of Methylmercury with Reduced Organic Sulfur}

Many studies have been conducted on the interactions between methylmercury (MeHg) and DOM (Hintelmann et al. 1997; Amirbahman et al. 2002) in the environment. Significant binding of MeHg by natural DOM in surface waters is suggested by the positive correlation between concentrations that have frequently been observed in both lake and river waters (Mierle and Ingram 1991; Hurley et al. 1995; Karlsson and Skyllberg 2003). Studies show that MeHg, in comparison with inorganic $\mathrm{Hg}(\mathrm{II})$, may tend to bind organic matter with low molecular weight in some natural waters, such as the surface water in the Florida Everglades (Cai et al. 1999). The strong interaction between $\mathrm{MeHg}$ and DOM is believed to occur through thiol functional sites present in DOM 
because methylmercury cation $\left(\mathrm{MeHg}^{+}\right)$, showing soft metal character (similar to $\mathrm{Hg}^{2+}$ ), also has high chemical affinity for thiol ligands (Rabenstein DL et al. 1982). The reaction depicted in the equation below is rapid and reversible:

$$
\mathrm{CH}_{3} \mathrm{Hg}^{+}+\mathrm{HS}-\mathrm{R} \leftrightarrow \mathrm{CH}_{3} \mathrm{Hg}-\mathrm{S}-\mathrm{R}
$$

The strong interaction of $\mathrm{MeHg}$ and ROS is also reflected in the speciation of mercury in biological sample. It is well known that more than $90 \%$ of mercury is in the form of $\mathrm{MeHg}$ in fish species collected in many natural waters. It has recently been demonstrated that methlymercury in fish is dominated by MeHg-ROS complexes (Harris et al. 2003). Zhang and his research group reported that thiols also play a significant role in $\mathrm{MeHg}^{+}$speciation in the extracellular environment, and the methylmercury-glutathione complex is the intracellular species responsible for transport out of the cell and the methylmercury-cysteine complex is the extracellullar species responsible for entry into the cell. but they reported the sum of reduced and oxidized thiols, not the reduced forms only (Zhang et al. 2004). As a matter of fact, all identified compounds of methylmercury in tissues are complexes with thiol containing molecules (Cernichiari et al. 2007). The methylmercury cation undergoes rapid exchange from one thiol to another depending on concentrations and different affinities for thiol ligands (Clarkson 1993; Cernichiari et al. 2007).

\subsection{Interactions of Mercury Sulfide with Reduced Organic Sulfur and DOM}

Mercury sulfide, $\mathrm{HgS}$, is a common and important $\mathrm{Hg}$ species in the environment. There are two common forms of $\mathrm{HgS}$, cinnabar $(\alpha-\mathrm{HgS}$, red) and metacinnabar $(\beta-\mathrm{HgS}$, black). Although cinnabar is more stable than metacinnabar at low temperatures $(<350$ $\left.{ }^{\circ} \mathrm{C}\right)$; metacinnabar can exist in various environmental settings. It is because of the 
stabilizing effect of impurities (e.g., $\mathrm{Fe}$ ) on the metacinnabar crystal structure. It has been postulated that $\mathrm{HgS}$ is one of the largest sinks for $\mathrm{Hg}$ in sediments, soils, and sulfidic waters (Barnett et al. 2001). Indeed, both spectroscopic determination and indirect extraction analyses have confirmed that $\mathrm{HgS}$ is the major fraction of $\mathrm{Hg}$ in sediments and soils in many $\mathrm{Hg}$ contaminated areas.

Both forms of mercury sulfide have extremely low solubility, with the solubility product $\left(K_{s p}\right)$ being $10^{-36.8}$ and $10^{-36.4}$ for cinnabar and metacinnabar, respectively (Ravichandran et al. 1999; He et al. 2006). As a result of its insolubility, HgS has thus been suggested to act as a repository for $\mathrm{Hg}$, limiting the cycling of $\mathrm{Hg}$ in the environment. However, under certain natural and anthropogenic perturbations of environmental conditions, solid mercury sulfide $\left(\mathrm{HgS}_{(\mathrm{s})}\right)$ can undergo enhanced dissolution, releasing dissolved and particulate (primarily colloid) $\mathrm{Hg}$ species into the pore water of sediments and soils (Ravichandran et al. 1998; Tossell 1999; Barnett et al. 2001; Waples et al. 2005; Holley et al. 2007). In fact, conditions within sediments (e.g., anaerobic and high organic matter) are conducive not only to the precipitation of insoluble $\mathrm{HgS}$, but also to the dissolution of $\mathrm{HgS}$, depending on concentration levels of sulfide and the specific environmental conditions (Paquette and Helz 1995; Paquette and Helz 1997; Merritt and Amirbahman 2007; Belzile et al. 2008; Han et al. 2008). In sediments, the precipitation and dissolution of $\mathrm{HgS}$ is usually a dynamic process.

The release of $\mathrm{Hg}$ to pore waters from soil and sediment $\mathrm{HgS}$ is often caused by ligand-promoted dissolution of $\mathrm{HgS}$ in the presence of such ligands as sulfide, polysulfides, ROS and DOM (e.g., humic substances) (Paquette and Helz 1995; Paquette and Helz 1997; Ravichandran et al. 1998; Ravichandran et al. 1999; Jay et al. 2000; Jay 
et al. 2002; Ravichandran 2004; Waples et al. 2005). Strong complexation of Hg (II) with DOM can impact the efficiency of $\mathrm{HgS}$ in immobilizing $\mathrm{Hg}$ (Ravichandran et al. 1998; Cai et al. 1999; Ravichandran et al. 1999; Barnett et al. 2001; Waples et al. 2005; He et al. 2007; Holley et al. 2007). In anoxic experiments, Ravichandran et al. showed that $\beta-\mathrm{HgS}$ precipitation was inhibited by DOM. Furthermore, dissolved organic matter enhances $\mathrm{Hg}$ release from cinnabar (Ravichandran et al. 1998; Waples et al. 2005), and measured Hg release rates in the presence of DOM ranged from $2.00 \times 10^{-2}$ to $6.19 \times 10^{-1} \mu \mathrm{mol}(\mathrm{Hg}) \mathrm{mg}$ $\left(\mathrm{C}^{-1} \mathrm{~m}^{-2}\right.$ day $^{-1}$ (Waples et al. 2005). A large increase in the solubility of cinnabar in the presence of polysulfides, which were formed through the reaction of $\mathrm{S}(-\mathrm{II})$ with $\mathrm{S}(0)$ at neutral to basic $\mathrm{pH}$, was observed, particularly at high $\mathrm{pH}$ (Jay et al. 2000).

The dissolved and colloidal $\mathrm{Hg}$ species released because of $\mathrm{HgS}$ dissolution may be available for $\mathrm{Hg}$ transport from soils to aquatic environments and, more importantly, for Hg methylation in sediments (Benoit et al. 2001 (a); Benoit et al. 2001 (b); Lowry et al. 2004; Slowey et al. 2005; Slowey et al. 2005). It was observed that the dissolution of $\mathrm{HgS}$ can release dissolved neutral $\mathrm{HgS}$ species, e.g., $\mathrm{Hg}(\mathrm{SH})(\mathrm{OH})$. The $\mathrm{Hg}$-sulfide complex has been presumed to be the dominant neutral dissolved complex in sulfidic sediments and the concentration of this complex can affect microbial uptake and methylation of $\mathrm{Hg}$ (Benoit et al. 1999). It should be noted that $\mathrm{Hg}(\mathrm{SH})(\mathrm{OH})$ was sometimes referred to as $\mathrm{HgS}^{0}$. However, physicochemical calculations have shown that $\mathrm{HgS}^{0}$ is unstable in the presence of $\mathrm{H}_{2} \mathrm{O}$, reacting to form $\mathrm{HgS}\left(\mathrm{H}_{2} \mathrm{O}\right)$ which subsequently isomerizes to $\mathrm{Hg}(\mathrm{SH})(\mathrm{OH})$ (Tossell 2001). The $\mathrm{pKa}$ of $\mathrm{Hg}(\mathrm{SH})(\mathrm{OH})$ is estimated to be 7 or higher, therefore, near neutral $\mathrm{pH}$ it exists as a neutral molecule. Also, as a result of its small hydration energy, $\mathrm{Hg}(\mathrm{SH})(\mathrm{OH})$ can partition into organic solvents, which makes it 
easily pass through the bacteria cell membrane and available for methylation (Tossell 2001). The neutral $\mathrm{Hg}$ species leached from $\mathrm{HgS}$ dissolution has been related to the increased $\mathrm{Hg}$ bioavailability, demonstrating the direct link between $\mathrm{HgS}$ dissolution and Hg methylation (Benoit et al. 1999; Benoit et al. 2001 (a); Benoit et al. 2001 (b); Jay et al. 2002; Lambertsson and Nilsson 2006; Miller et al. 2007).

Although previous studies have demonstrated the role of some ligands (e.g., polysulfides and DOM) in $\mathrm{HgS}$ dissolution, the effect of ROS, in particular small molecule ROS (e.g., thiol-containing amino acids), on $\mathrm{HgS}$ dissolution has not received much attention. Because of its strong affinity to complex Hg, ROS may be an important factor that can affect $\mathrm{HgS}$ dissolution. In previous studies investigating $\mathrm{HgS}$ dissolution in the presence of DOM, cysteine, which was used for the purpose of comparison, was found to be able to enhance $\mathrm{HgS}$ dissolution. Also, the enhancing effect of DOM on $\mathrm{HgS}$ dissolution could be mechanistically related to the strong complexation of $\mathrm{Hg}$ with thiol groups present within the DOM used there (Vairavamurthy et al. 1997). Despite the potentially important role of ROS in HgS dissolution, large remains unknown about the dissolution of $\mathrm{HgS}$ in the presence of ROS, in particular the speciation, reactivity, and bioavailability of the $\mathrm{Hg}$ released due to ROS-induced $\mathrm{HgS}$ dissolution.

\subsection{Objectives}

The objectives of this research are 1) to develop a sensitive and reliable method for preconcentration of small ROS in the environment using covalent affinity chromatography and analysis with HPLC coupled with UV-Vis or fluorescence detections and 2) to investigate the role of ROS and DOM, in particular small molecule thiol-containing amino acids such as cysteine and glutathione, on mercury sulfide 
dissolution, with a special focus on the speciation of the released mercury from $\mathrm{HgS}$ dissolution.

My study is guided by the following hypotheses formed on the basis of literature review and preliminary results produced in our laboratories.

1. Preconcentration of thiol-containing compounds using covalent affinity chromatography could prevent the oxidation of thiols, reduce interferences, and thus be applied in the analysis of thiols in environmental waters.

2. Because of its strong affinity towards mercury, ROS may promote the dissolution of $\mathrm{HgS}$, releasing dissolved and colloidal $\mathrm{Hg}$ species into the solutions and subsequently affecting transport and transformation of $\mathrm{Hg}$ in the environment. 


\section{Chapter II}

\section{ANALYSIS OF REDUCED ORGANIC SULFUR USING COVALENT AFFINITY CHROMATOGRAPHY COUPLED WITH HPLC-UV/Vis}

\subsection{Introduction}

Sulfur occurs in both combined and free states and is distributed widely over the earth's surface and represents approximately $1.9 \%$ of the total weight of the earth (USEPA 1991). It exists in nature in different oxidation states. The most active form is reduced organic sulfur containing thiol group (Chou et al. 2001). Examples of thiols in bimolecules include but are not limited to the amino acid cysteine (Cys), the non-protein forming amino acid homocysteine, and glutathione (GSH). Reduced organic sulfur (ROS) and organic sulfides are the most important sulfur species in controlling mercury cycling because ROS can be more than $50 \%$ of total sulfur in the water system, and has extremely high affinity to bind mercury. Among the numerous organic sulfur compounds, organic sulfhydryls (R-SH) are especially important in biogeochemical cycling of metals in marine and freshwater ecosystems because of the high reactivity of the sulfhydryl group toward metals (Patai 1974). Thiols have been shown to play an important role in controlling the bioavailability of trace metals and metalloids (Boulegue et al. 1982; Matrai 1988; Lee and Hultberg 1990; Leal et al. 1999; Harris et al. 2003) in aquatic environments through complexation reactions (Cullen et al. 1984; $\mathrm{Hu}$ et al. 2006). Glutathione, a tripeptide, and cysteine (Fig 2.1), the most abundant low molecular weight thiols in animals, plants and bacteria, are believed to play an important role in protecting cells against oxidative stress, and elevated levels of heavy metals (Giovanelli 1987). Theoretical calculations have shown that the thiol group is the primary complexation 
group of GSH with many trace metals (Krezel and Bal 1999). For example, reduced sulfur functional groups are among the strongest binding sites for $\mathrm{Hg}$ (II). Presence of the thiol-containing organic matter in the environment, such as in soil and water, often determines the fate and transport of $\mathrm{Hg}$ and many other transition metals (Ravichandran 2004).

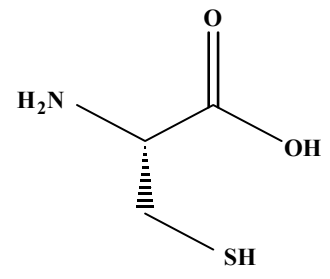

Cysteine

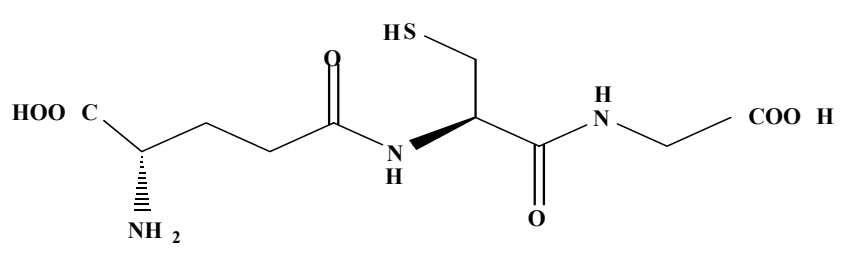

Glutathione

Figure 2.1 The structures of Cys and GSH.

Thiols undergo rapid oxidation in air, which makes storage and handling of the samples for thiol analysis very difficult. Analysis is often required on site or performed in a very short period of time upon sampling. It is one of the major problems in environmental studies where storage is often necessary prior to analysis. No satisfactory techniques have been yet developed to prevent this rapid oxidation. Thiol analysis in aquatic samples also suffers from the limitation of instrumental sensitivity and method detection limit since thiols exist in very low concentrations (nM or sub $\mathrm{nM}$ ) in aquatic environments (Tang et al. 2003; Zhang et al. 2004). In addition, strong matrix interferences are encountered without sample cleanup. These limitations have greatly hampered the measurement of reduced organic sulfur in aquatic environments particularly in freshwater ecosystems including surface and pore waters, therefore 
limiting our understanding of the role ROS played in metal biogeochemistry. Despite the critical role of ROS in mercury cycling and bioaccumulation, little is currently known about the distribution and extent of ROS, the interactions of ROS with mercury, and the effects of ROS on mercury cycling and bioaccumulation in the environment.

Various methods have been developed and applied to thiol detection in biological samples and natural aquatic systems. These include separation techniques (chromatography and electrophoresis) followed by electrochemical, fluorescence and postcolumn derivatization UV-Vis detection methods (Patai 1974; Vairavamurthy and Mopper 1990; Owens and LaCourse 1997; Kabzinski 1998; Wang et al. 1998; Tang et al. 2000; Tang et al. 2003; Zhang et al. 2004; Gong et al. 2005; Petrlova et al. 2006; Wang et al. 2006). Electrochemical methods, having detection limits at $\mu \mathrm{M}$ levels, are on the basis of thiol oxidization on the surface of working electrode and therefore inducing the catalytic response with the complexes of metal ions in the electrolyte. Relatively high sensitivity, easy operation, and low expense make electrochemical methods attractive techniques. However, these techniques suffer from oxide formations at the tip of the electrode used (usually gold) and adsorption of sulfur to the electrode surface (Owens and LaCourse 1997; Wang et al. 1998; Hiraku et al. 2002; Gong et al. 2005; Petrlova et al. 2006; Kim et al. 2009; Raoof et al. 2009). Derivatization of thiols using fluorescent reagent prior to HPLC separation has also found applications for thiol analysis. The commonly used fluorogenic reagents are ammonium 7-fluorobenzo-2-oxa-1, 3-diazole-4sulphonate (SBD-F), o-phthalaldehyde (OPA), and thiol-monobromobimane (mBBr) (Ivanov et al. 2000; Tang et al. 2000; Tang et al. 2003; Zhang et al. 2004). These derivative reactions are shown in Figures 3.2, 3.3 and 3.4 of Chapter III. The pre-column 
derivatization method offers high sensitivity and is therefore very useful for thiol analysis at trace level. However, multistep and off-line derivatization must be carried out before HPLC separation and fluorescence detection. Post-column derivatization technique coupled HPLC separation is also widely used for thiol analysis. First, thiols are separated by HPLC and then derivatized on-line prior to UV/Vis detection, therefore decreasing sample preparation time. The most commonly used reagent for post-column derivatization is 5, 5'-Dithiobis - (2-nitrobenzoic acid) (DTNB). Figure 2.2 illustrates the derivatization reaction. While oxidizing the thiol species, DTNB is reduced with the cleavage of the disulfide bond, producing a yellow color, which shows absorption at 412 nm (Vairavamurthy and Mopper 1990; Zhang et al. 2004). Another reagent, 2, 2'dithiobis (5-nitropyridine) (DTNP) is sensitive to UV-Vis light and shows a strong absorption at $320 \mathrm{~nm}$ (Patai 1974; Vairavamurthy and Mopper 1990) (Fig 2.3). The derivatives obtained from these two methods are both stable. One of the major disadvantages of the post-column derivatization methods is that the derivatized thiols are measured using UV-Vis absorption, therefore the detection limits are not as good as that obtained using pre-column fluorescence derivatization. In addition, environmental samples, such as, natural water, sediment porewater and biological samples often contain large numbers of absorbing compounds which could interfere with the determination of authentic thiols. The representative methods for thiol analysis are summarized in Table 2.1 . 


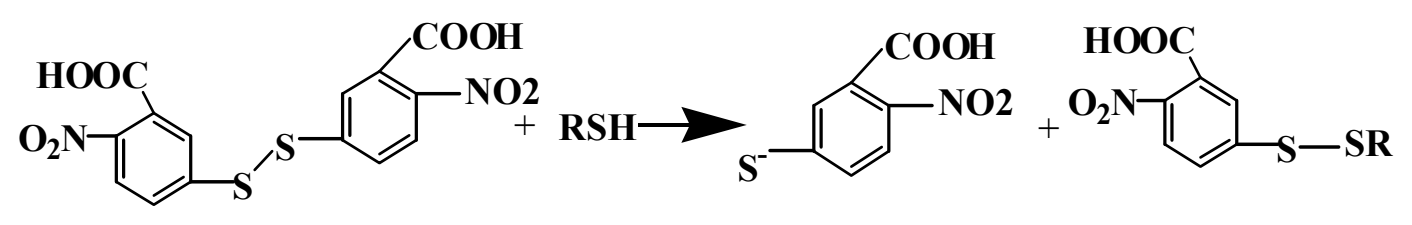

DTNB Nitromercaptobenzoic anion

Figure 2.2 The reaction scheme of DTNB with thiol species.

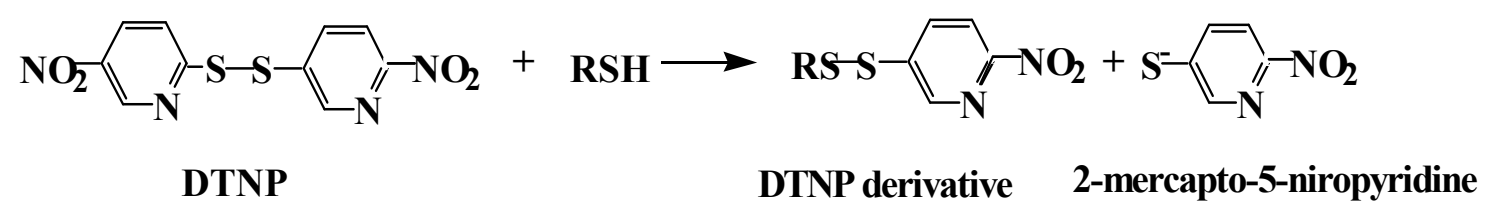

Figure 2.3 The reaction scheme of DTNP with thiol species.

Thiols are normally present in natural environmental samples at very low concentrations. For example, Al Farawati and Van Den Berg showed the concentrations of thiols in the western North Sea and English channel were in range of $0.7-3.6 \mathrm{nM}$ (AlFarawati and Van Den Berg 2001). Tang et al found that the GSH concentration was at $0.23-6.23 \mathrm{nM}$ in estuarine water of Galveston Bay, Texas (Tang et al. 2000). Due to the limited sensitivity offered by all aforementioned instrumental methods, preconcentration of thiols in natural water samples is often needed prior to analysis. Various sample preconcentration techniques for analyzing thiols in natural water have been developed. Solid phase extraction (SPE) (Huang et al. 2010), solid phase micro extraction (SPME) (Mestres et al. 1999; Hill and Smith 2000; Mestres et al. 2000; Mestres et al. 2002; Turkmen et al. 2004; Berijani et al. 2006; Wang et al. 2006) and affinity chromatography have been used for the analysis of biological samples. Lyophilization (Thing et al. 2010) 
and rotary evaporation were commonly used techniques for aquatic sample analysis (Zhang et al. 2004). The representtaive methods for thiol preconcentration are summarized in Table 2.2.

Table 2.1 Summary of the reprehensive methods for thiol analysis in environmental and biological samples.

\begin{tabular}{|c|c|c|c|}
\hline Method & Principle & $\begin{array}{c}\text { Derivatization } \\
\text { reagents }\end{array}$ & Advantages/disadvantages \\
\hline HPLC-UV/Vis & $\begin{array}{l}\text { Post column } \\
\text { derivatization }\end{array}$ & DTNP & $\begin{array}{l}\text { Sensitive to UV/Vis light at } \\
412 \mathrm{~nm} \text { and derivatization } \\
\text { occurred after separation } \\
\text { Sensitive to UV/Vis light at } \\
320 \mathrm{~nm} \text { and derivatization } \\
\text { occurred after separation }\end{array}$ \\
\hline HPLC- & Precolumn & SBD-F & $\begin{array}{l}\text { Highly sensitive and } \\
\text { derivatization need long } \\
\text { time period at high } \\
\text { temperature }\end{array}$ \\
\hline Fluorescence & derivatization & $\begin{array}{l}\mathrm{OPA} \\
\mathrm{mBBr}\end{array}$ & $\begin{array}{l}\text { Highly } \mathrm{pH} \text { dependent } \\
\text { No reaction below } \mathrm{pH} 9 \\
\text { Some interfering adducts, } \\
\text { time consuming and need } \\
\text { extra clean-up steps }\end{array}$ \\
\hline $\begin{array}{l}\text { HPLC- } \\
\text { Electrochemical } \\
\text { method }\end{array}$ & $\begin{array}{l}\text { Electrochemical } \\
\text { detection } \\
\text { redox reaction on } \\
\text { the surface of } \\
\text { working electrode }\end{array}$ & Gold electrode & $\begin{array}{c}\text { High sensitive, } \\
\text { Oxide formations and } \\
\text { absorption to the electrode } \\
\text { No derivatization is need. } \\
\text { High potential is required }\end{array}$ \\
\hline
\end{tabular}

Covalent affinity chromatography has found success in the analysis and purification of thiols in biological samples (Brocklehurst et al. 1974; Rydén 1981; Osakada et al. 1992; Glatz et al. 1997; Kabzinski 1997; Kabzinski 1998; Panda et al. 2008), however no applications have been found for environmental water samples. Because of the complex nature of environmental water samples, the analysis of thiol containing compounds in 
natural water system requires more specific and sensitive analysis methods. Covalent affinity chromatography has a potential to be employed as preconcentration technique prior to thiol analysis. Selectivity could be improved and matrix interferences might be Table 2.2 Summary of the representative methods for the preconcentration of ROS in water samples

Method Principle Advantages/Disadvantages

\begin{tabular}{|c|c|c|}
\hline Lyophilization & $\begin{array}{l}\text { Water sample is frozen } \\
\text { and water is removed by } \\
\text { sublimation under } \\
\text { vacuum }\end{array}$ & $\begin{array}{l}\text { Can handle large sample volumes. } \\
\text { Inorganics constituents concentrated } \\
\text { simultaneously. }\end{array}$ \\
\hline $\begin{array}{l}\text { Vacuum } \\
\text { distillation }\end{array}$ & $\begin{array}{l}\text { Water is evaporated at } \\
\text { reduced pressure and at } \\
\text { or near ambient } \\
\text { temperature }\end{array}$ & $\begin{array}{l}\text { Slow process when sample volumes are } \\
\text { large. Inorganic compounds are also } \\
\text { concentrated. Sample contamination is low } \\
\text { but sample may be modified }\end{array}$ \\
\hline Solvent extraction & $\begin{array}{l}\text { Aqueous sample is } \\
\text { partitioned with an } \\
\text { immiscible organic } \\
\text { solvent. Extraction } \\
\text { efficiency depends on the } \\
\text { affinity of the solute for } \\
\text { the organic solvent. }\end{array}$ & $\begin{array}{l}\text { Samples with a high affinity for water are } \\
\text { not extracted. Extractions can be performed } \\
\text { by a simple single equilibration or by } \\
\text { multiple equilibrations with fresh solvent. } \\
\text { Solvent impurities concentrated along with } \\
\text { sample. }\end{array}$ \\
\hline $\begin{array}{l}\text { Solid phase } \\
\text { extraction }\end{array}$ & Based on analyte polarity & $\begin{array}{l}\text { Solvent free. Extraction and } \\
\text { preconcentration are in one step. It will } \\
\text { encounter problems if some analytes have } \\
\text { similar polarity. }\end{array}$ \\
\hline $\begin{array}{l}\text { Covalent affinity } \\
\text { chromatography }\end{array}$ & $\begin{array}{l}\text { Covalent bond formed } \\
\text { between medium and } \\
\text { analytes }\end{array}$ & $\begin{array}{l}\text { Sensitive, selective and reduce interference. } \\
\text { The medium and analyte complex is stable. } \\
\text { Need reduced reagent to release the free } \\
\text { thiol. }\end{array}$ \\
\hline $\begin{array}{l}\text { Solid phase } \\
\text { microextraction }\end{array}$ & Based on analyte polarity & $\begin{array}{l}\text { Solvent free. Extraction and } \\
\text { preconcentration are in one step. } \\
\text { Competitive adsorption will cause } \\
\text { inaccurate. Need extra heat to release } \\
\text { analytes. }\end{array}$ \\
\hline
\end{tabular}


reduced in comparison to the traditional solid-phase extraction techniques. Most commonly used SPE methods preconcentrate analytes based on their polarity, which will create problems if other sample or reagent components have similar polarities. In covalent chromatography, on the other hand, covalent bonds are formed between the medium and analyte in the mobile phase. Moreover, the formation of the covalent bond can efficiently protect the redox sensitive species, such thiols, from oxidation during the preconcentration procedure.

\subsection{Objectives}

The objectives of this study were to develop a sensitive and reliable method for the preconcentration and analysis of small ROS (using Cys and GSH as representative compounds) in water samples using covalent affinity chromatographic concentration followed by reverse phase HPLC separation, on-line derivatization, and measurement with a UV/Vis detector. It was anticipated that in comparison with other techniques, the developed method could improve thiol analysis in waters in the following aspects:

1) reduce interferences, 2) improve detection limit, and 3) maintain the integrity of the thiols of interest by taking advantage of the covalent affinity chromatographic concentration.

\subsection{Experimental Section}

\subsubsection{Chemicals and Materials}

Sepharose $6 \mathrm{~B}$ in $20 \%$ ethanol with wet bead diameter 45 - $185 \mu \mathrm{m}$ was purchased from Sigma-Aldrich. Epichlorohydrin (99\%) was purchased from Acros Organics. Dithiothreitol (DTT), ethylenediaminetetraacetic acid (EDTA), 5,5'-Dithiobis-(2nitrobenzoic acid) (DTNB), sodium bicarbonate, sodium phosphate, 2, 2'-dipyridyl 
disulfide (98\%), acetonitrile (Optima, LC/MS), methanol (Optima, LC/MS), L-cysteine (99\% pure, Acros Organics), L-glutathione reduced (98 - 100\%, Sigma Ultra), and trifluoroacetic acid (TFA) were purchased from Fisher Scientific. Other chemicals were analytical grade or higher.

\subsubsection{Instrumentation}

A Thermo HPLC system including a gradient controller (SpectraSYSTEM P4000), an auto sampler (SpectraSYSTEM AS3000) and a UV-Vis detector (Spectra SYSTEM UV 1000) was employed for the study. A reversed phase $\mathrm{C}_{18}$ column (Thermo ODS HYPERSIL, $250 \times 4 \mathrm{~mm}$ particle size $5 \mu \mathrm{m}$ ) in combination with a guard column with same packing materials was used to separate thiolic compounds. A homemade postcolumn derivatization device consisting of a reaction coil and an isocratic pump (Acuflow Series1, Fisher) was used for postcolumn derivatization (Zhang and Cai 2003) Affinity chromatography columns were made of Flex columns $(0.7 \times 20 \mathrm{~cm}$ from Kimle Kontes LLC) with home made thiopropyl sepharose 6B. Barnstead Nanopure (Diamond Lab Water System) was used to produce deionized water (DIW). Touch Mixer model 232 (Fisher Scientific) was used to mix the samples. Air bath shaker (Orbital Shaker, VWR Scientific Products) was used to shake the sample. A sintered glass funnel (ASTM 25 $50 \mu \mathrm{m}$, ACE Glass Inc. USA) was used for filtration. Isometric pumps (Cole-Pamer Instrument Company, Chicago USA) were used to load samples. Mechanic stirring (Tline Laboratory 101 Stirrer Talboys Engineering Corp Emerson N.J) was employed to mix samples during synthesis. 


\subsubsection{Synthesis of Activated Thiopropyl Sepharose 6B}

Synthesis of activated thiopropyl gel was performed by following the method described by Axen et al. (Axen et al. 1975) and Zhang and Cai (Zhang and Cai 2003). Briefly, Sepharose 6B gel beads (45 g) were washed on a sintered glass funnel with DDI water. The obtained gel beads were mixed with $100 \mathrm{~mL}$ of $1 \mathrm{M}$ sodium hydroxide $(\mathrm{NaOH})$ solution in an Erlenmeyer flask. Epichlorohydrin $(45 \mathrm{~mL})$ was added slowly into above

solution at room temperature, and the reaction was allowed to develop at $60{ }^{\circ} \mathrm{C}$ in an air bath shaker for two hours. The obtained expoxide-activated gel was washed with DDI water to reach neutral $\mathrm{pH}$ and then washed with $0.5 \mathrm{M}$ phosphate buffer ( $\mathrm{pH}$ 6.3). The gel was suspended in the same buffer making a final volume of $100 \mathrm{~mL}$. Sodium thiosulfate $\left(\mathrm{Na}_{2} \mathrm{~S}_{2} \mathrm{O}_{3}\right)(50 \mathrm{~mL}, 2.0 \mathrm{M})$ was added immediately and the mixture was shaken in an air bath shaker for six hours at room temperature. The thiosulfate ester gel was washed free of sodium thiosulfate with DIW and then kept in $30 \mathrm{~mL}$ of sodium bicarbonate $\left(\mathrm{NaHCO}_{3}\right)$ solution $(0.1 \mathrm{M})$ containing $1.0 \mathrm{mM}$ EDTA. Dithiothreitol $(1 \mathrm{~g})$ was dissolved in $5 \mathrm{~mL}$ of EDTA $(1.0 \mathrm{mM})$ and then was added to reduce the gel to thiol agarose gel. The reaction was developed at room temperature for $30 \mathrm{~min}$ on an air bath shaker. The obtained gel was washed with $300 \mathrm{~mL}$ of $0.1 \mathrm{M} \mathrm{NaHCO}_{3}$ solution (containing $1 \mathrm{M}$ sodium chloride and $1.0 \mathrm{mM}$ ethylenediaminetetraacetic acid) and followed by $1000 \mathrm{~mL}$ of $1.0 \mathrm{mM}$ EDTA on a sintered glass funnel. Acetone $\left(500 \mathrm{~mL}, 60 \%\right.$ in $0.05 \mathrm{M} \mathrm{NaHCO}_{3}$ solution containing $1 \mathrm{mM}$ EDTA) was used to wash the gel and the gel was suspended in $30 \mathrm{~mL}$ same solvent. The above solution was mixed with 1 g 2, 2'-dipyridyl disulfide (dissolved in $20 \mathrm{~mL}$ of the above solvent) to activate the gel, at room temperature for 1 hour under stirring using a mechanic glass bar. Care should be taken to ensure the gel was 
homogenous. The product was washed with $500 \mathrm{~mL}$ of acetone $(60 \%$ in water) and followed by $1000 \mathrm{~mL}$ of $1.0 \mathrm{mM}$ EDTA. The activated gel was kept in EDTA (1.0 mM) solution containing $20 \%$ ethanol at $4{ }^{\circ} \mathrm{C}$ for storage. The reactions involved in the synthesis are summarized in Figure 2.4.

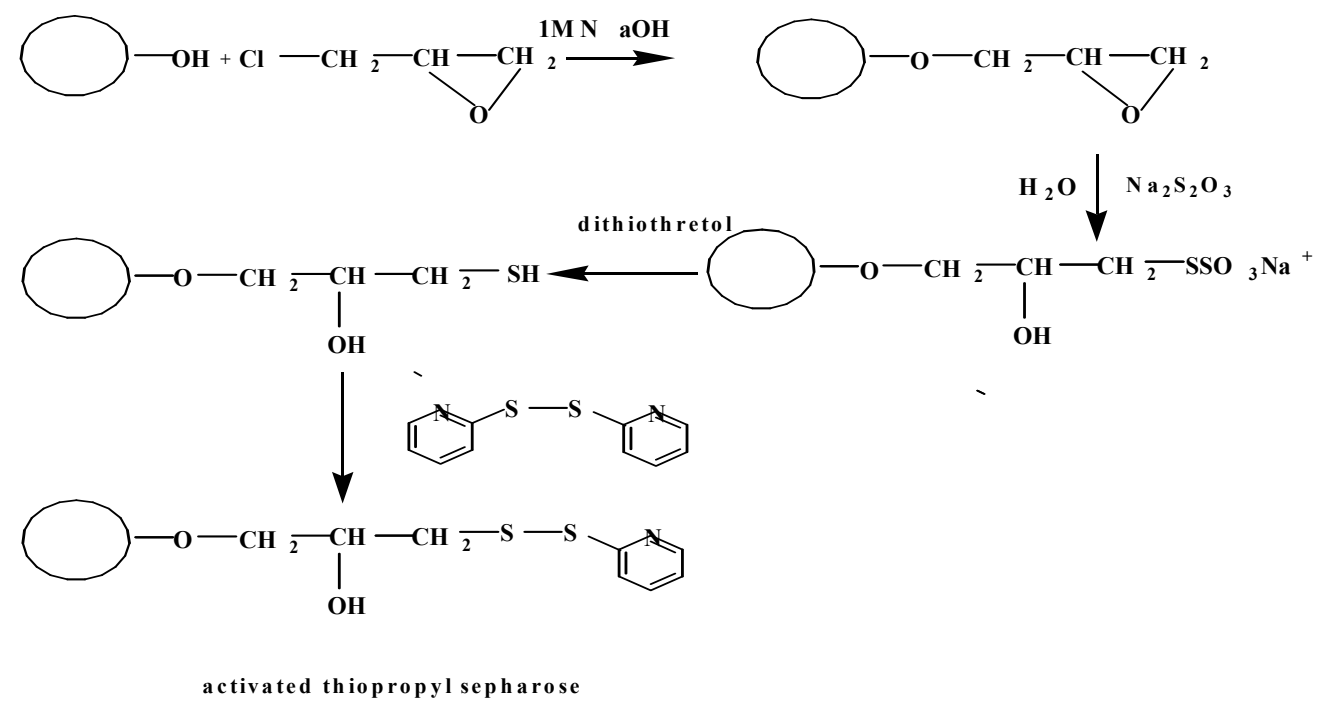

Figure 2.4 Reaction schemes showing the synthesis of activated thiopropyl sepharose $6 \mathrm{~B}$

\subsubsection{Procedures for Thiol Preconcentration and Analysis}

Thiol preconcentration system using affinity chromatography was set up in the laboratory. The system included two isometric pumps with one connected to the inlet of the Flex column and the other to the outlet. The thiol preconcentration was carried out as follows. The home made activated thiopropyl sepharose $6 \mathrm{~B}(3 \mathrm{~g})$ was mixed with $5 \mathrm{~mL}$ binding buffer (degassed before use with helium for $120 \mathrm{~min}$ at $2 \mathrm{ml} / \mathrm{min})(0.05 \mathrm{M}$ phosphate buffer with $\mathrm{pH}$ 7.4), to form a slurry. Before loading the gel, the column was filled with binding buffer to eliminate air. The slurry was slowly poured into the column 
while tapping the column using a glass stick to make the gel homogenous and tightly settled on the bottom of column. Tapping can also reduce the air trapped in the column. The column outlet was closed and the rest of column was filled with binding buffer. Prior to loading samples, the column was conditioned for 20 min using the binding buffer with flow rate of $1 \mathrm{~mL} / \mathrm{min}$ for inlet pump and $2 \mathrm{~mL} / \mathrm{min}$ for outlet. The inlet speed was half of the outlet speed because of the resistance caused by the gel in the column, which slowed down the flow of the passing solution. The column possibly would be overloaded if two speeds were set up the same. Sample was loaded into the column with the same pump speed settings. The column was then washed with $200 \mathrm{~mL}$ of $0.1 \mathrm{M} \mathrm{NaCl}$ and followed by $200 \mathrm{~mL}$ of $0.05 \mathrm{M}$ phosphate buffer ( $\mathrm{pH}$ 7.4) containing $2.0 \mathrm{mM}$ EDTA. The column was then eluted with $10 \mathrm{~mL}$ of $0.1 \mathrm{mg}$ DTT prepared in $0.05 \mathrm{M}$ phosphate buffer (pH 7.4). Eluent $(25 \mathrm{~mL})$ was taken for thiol analysis using HPLC with post-column derivatization. Figure 2.5 summarizes the steps involved for thiol preconcentration and elution. 


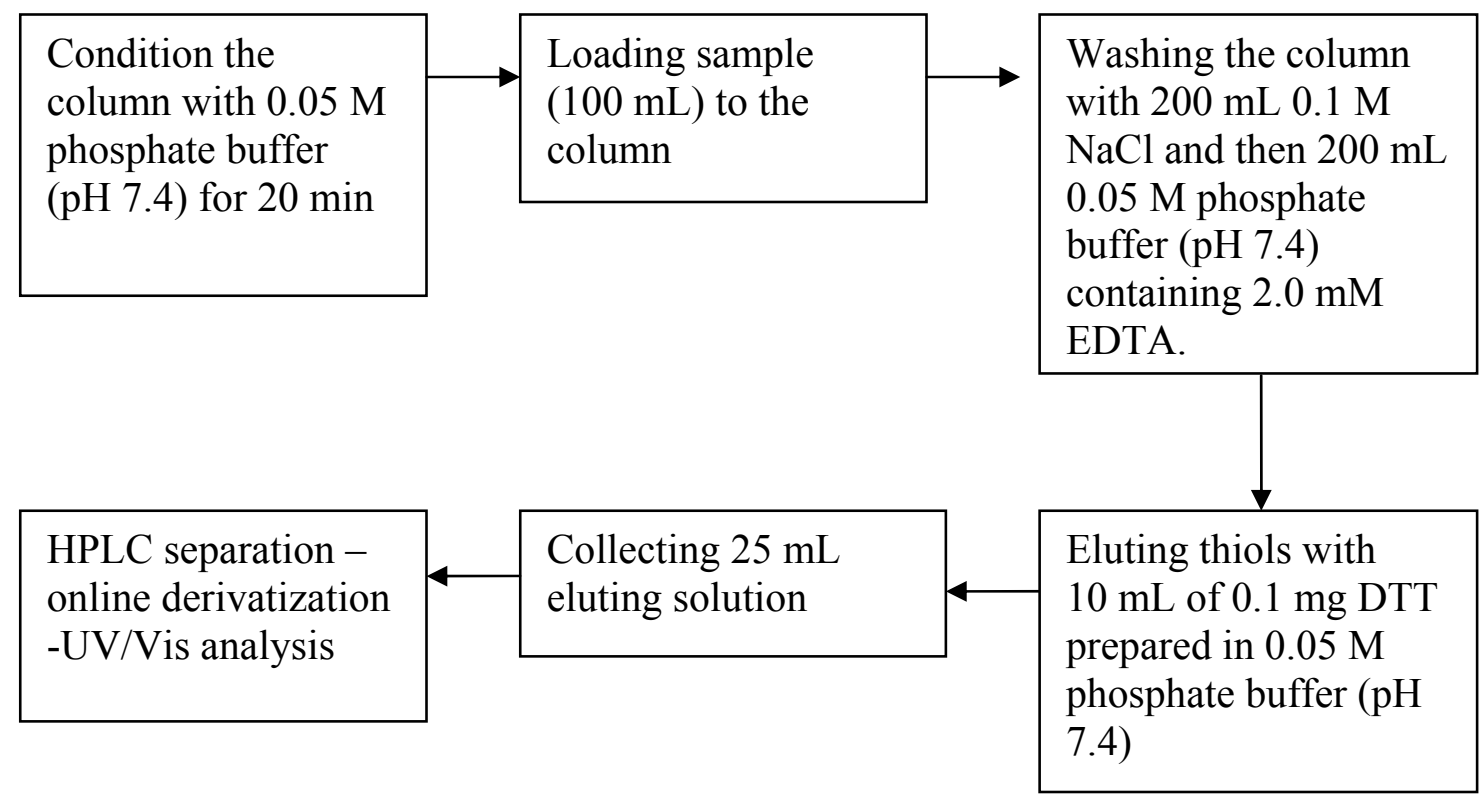

Figure 2.5 The schematic diagram showing the procedure for thiol preconcentration and elution using affinity covalent chromatography system

A homemade postcolumn derivatization device consisting of a reaction coil and an isocratic pump (Acuflow Series1, Fisher) was used for postcolumn derivatization. The reaction coil was made of Teflon tubing (10 ft, $0.5 \mathrm{~mm}$ i.d.). A $\mathrm{C}_{18}$ column (Thermo ODS HYPERSIL $250 \times 4 \mathrm{~mm}$, particle size $5 \mu \mathrm{m}$ ) and a guard column were used for thiol separation. Mobile phases $\mathrm{A}$ and $\mathrm{B}$ were $0.1 \%$ trifluroacetic acid and acetonitrile, respectively. The flow rate of the HPLC pump was $1 \mathrm{~mL} / \mathrm{min}$. A linear gradient of $0-20 \%$ acetonitrile was used for $20 \mathrm{~min}$ and followed by washing the column with $50 \%$ acetonitrile for an additional $5 \mathrm{~min}$. The postcolumn derivatization reagent was made of DTNB (1.8 mM) in $0.3 \mathrm{M}$ phosphate buffer (pH 8.0) containing $15 \mathrm{mM}$ EDTA. The solution was pumped at $0.5 \mathrm{~mL} / \mathrm{min}$. The thiol derivatives were monitored at $412 \mathrm{~nm}$ and the injection volume was $100 \mu \mathrm{L}$. 


\subsection{Results and Discussion}

\subsubsection{Synthesis and Storage of the Activated Thiopropyl Gel}

The activated thiopropyl sepharose gel was synthesized following a method reported in the literature (Axen et al. 1975; Zhang and Cai 2003) with minor modification. The synthesis process had several critical steps. The original sepharose $6 \mathrm{~B}$ was stored in $20 \%$ ethanol. It is necessary to remove the ethanol by washing the gel beads with distilled deionized (DDI) water before the synthesis process. The reaction with epichlorohydrin was initially carried out on an air bath shaker at $37^{\circ} \mathrm{C}$ at $200 \mathrm{rpm}$ in order to obtain expoxideactivated gel. The thiosulfate ester gel was synthesized by reacting expoxide-activated gel with sodium thiosulfate on an air bath shaker under room temperature for 6 hours at 200 rpm. It was observed that the gel synthesized under the aforementioned conditions was not homogenous. During the last step it was observed that some larger particles formed as well.. The gel with big particles was found to be ineffective for covalent affinity chromatographic enrichment of thiols from water. After several trials, two experimental conditions were found to be critical in order to synthesize a homogenous activated thiopropyl gel. The temperature of the air bath shaker was adjusted from 37 to $60{ }^{\circ} \mathrm{C}$ for the reaction with epichlorohydrin. The speed of stirring was optimized at $70 \mathrm{rpm}$ in order to make the gel homogenous. Finally, a homogenous activated thiopropyl sepharose gel was obtained.

The synthesized activated thiopropyl sepharose gel needed to be stored in a proper way for an extended period (longer than 30 days). Sodium azide $\left(\mathrm{NaN}_{3}\right)(0.02 \%)$ was initially used to prevent bacterial growth during storage of the synthesized gel. In a trial where Cys recovery was tested using the activated thiopropyl sepharose gel preserved in 
$\mathrm{NaN}_{3}$, it was found that more than $60 \%$ Cys was present in the filtrate with a limited amount enriched on the column. The active site of the thiopropyl sepharose $6 \mathrm{~B}$ is a 2pridyl disulphide group, which could react with azide ions (Biotech 1998). The activated thiopropyl gel was deactivated in the presence of $\mathrm{NaN}_{3}$. The activated thiopropyl sepharose gel was then tested for storage in $20 \%$ ethanol. A trial was conducted by mixing $50 \mathrm{~mL}$ of $10 \mathrm{mM}$ Cys with $5 \mathrm{~g}$ activated thiopropyl gel. Cysteine was not detected in the filtrate, indicating efficient enrichment of Cys on the column. The results indicate that this method can preserve the gel for at least 2 months

\subsubsection{Preconcentration of Thiols using Affinity Chromatographic Column}

A scheme showing the reaction between the activated thiopropyl sepharose $6 \mathrm{~B}$ and the reduced organic sulfur is illustrated in Figure 2.6. Thiopropyl sepharose 6B active group 2-pyridyl disulfide reacts with ROS to form a mix disulfide and 2-thiopyridone (Fig 2.6). The disulfide bond can be split by a reducing reagent and release the thiol, which maintain its full activity. It makes the separation of thiol from non-thiol compounds possible and protects the thiol from oxidation.

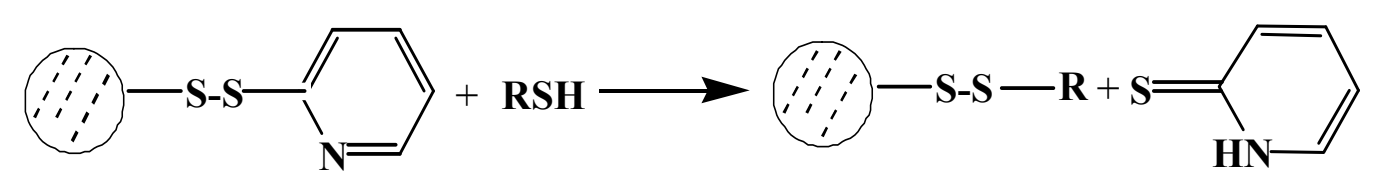

Figure 2.6 Covalent affinity reactions between activated thiopropyl sepharose $6 \mathrm{~B}$ and reduced organic sulfur.

The slurry containing the activated thiopropyl sepharose gel should be loaded on the column with great care. Air bubbles must be avoided during the loading and the gel 
should be settled tightly on the bottom of the column. It could be done with the assistance of tapping the column with a rubber wrapped glass stick while the slurry was slowly loaded into the column. The loading rate was controlled at approximately $10 \mathrm{~cm} / \mathrm{h}$. The amount of gel loaded was $3 \mathrm{~g}$ or approximately $5 \mathrm{~cm}$ height in the column.

Sample loading rate was found to be another important factor. The effects of sample loading speed on the enrichment/recovery of Cys and GSH were tested using DDI water spiked with these two thiols at $100 \mu \mathrm{M}$. The sample loading speed was investigated at 2 and $1 \mathrm{ml} / \mathrm{min}$. Cysteine and glutathione were detected at 43 and $56 \mu \mathrm{M}$ in the filtrate at 2 $\mathrm{mL} / \mathrm{min}$, indicating $43 \%$ and $56 \%$ were not retained by the column. However, with the reduced loading speed, Cys and GSH were not detectable in the filtrate, suggesting these thiols were efficiently enriched on the column. Sample loading speed of $1 \mathrm{~mL} / \mathrm{min}$ was selected in the following experiments to provide sufficient time for the thiols to react with the activated thiolpropyl sepharose gel.

Thiols are redox sensitive chemical species and therefore their integrity should be preserved during the process of sample preparation and loading onto the column. Oxygen, which could oxidize thiols (Bagiyan et al. 2003) should be reduced or eliminated from the water solution before thiols are spiked. It was done by purge the DIW with helium (He) for at least two hours at $2 \mathrm{~mL} / \mathrm{min}$. All buffer and standard solutions were prepared with the degassed DIW. The presence of metals in water solutions could facilitate the oxidation of thiols because the catalytic effect of metals (Bagiyan et al. 2003), and/or reduce the enrichment efficiency on the column due to the interactions of metals with the thiols of interest (Krezel and Bal 1999). By adding $1 \mathrm{mM}$ ethylenediaminetetraacetic acid 
(EDTA) as complex agent for metals, the thiol groups were made more accessible to thiopropyl gel (Baden and Mende 1982).

\subsubsection{Release of Thiols from the Affinity Chromatographic Column}

Once sample loading was accomplished, the column was washed with $200 \mathrm{~mL} 0.1 \mathrm{M}$ $\mathrm{NaCl}$ and then $200 \mathrm{~mL} 0.05 \mathrm{M}$ phosphate buffer ( $\mathrm{pH}$ 7.4) containing $2.0 \mathrm{mM}$ EDTA, to remove the substances either present in the sample (e.g. metals) or formed (e,g., 2-pridyl disulfide) during the enrichment reaction. The presence of these impurities could affect the HPLC separation and the on-line derivatization that followed the preconcentration step. The thiols enriched on the column were then eluted with $10 \mathrm{~mL}$ of $0.1 \mathrm{mg}$ DTT prepared in $0.05 \mathrm{M}$ phosphate buffer ( $\mathrm{pH}$ 7.4). Figure 2.7 shows the chemical reactions for the elution of thiols from the column.

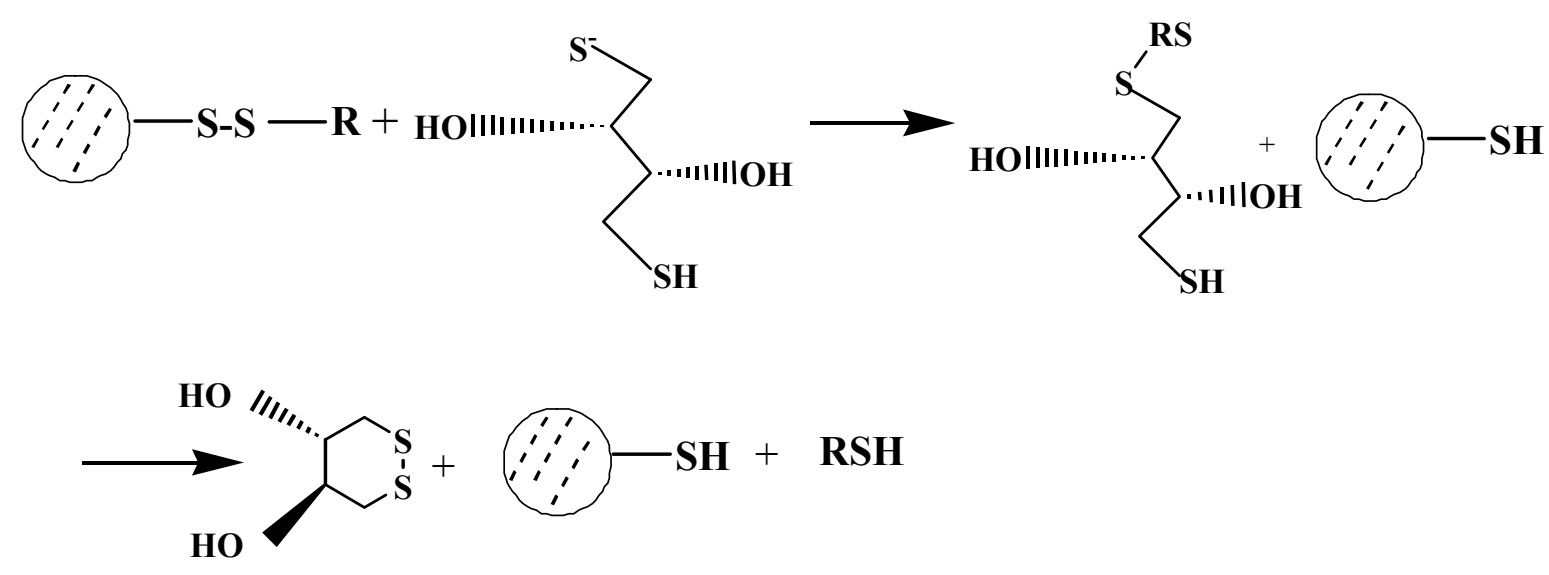

Figure 2.7 Reactions showing the free thiol (RSH) released by DTT from affinity chromatographic column. 


\subsubsection{HPLC Separation-online Derivatization and UV/Vis Detection}

Fraction of the released sample $(100 \mu \mathrm{L})$ was subjected to HPLC analysis. The separation was performed by following a method reported in the literature (Axen et al. 1975; Zhang and Cai 2003) with some modification. Mobile phase A and B were $0.1 \%$ trifluroacetic acid and acetonitrile. The mobile gradient program was an important parameter for the separation of Cys and GSH. Figure 2.8 shows a typical chromatogram obtained for the analysis of the two thiols using a mobile phase gradient reported in the literature (Zhang and Cai 2003), which employed a linear gradient of $0-20 \%$ acetonitrile for $20 \mathrm{~min}$ and followed by washing column with $50 \%$ acetonitrile for additional 5 minutes. Using this gradient, Cys and GSH can be well separated, while one of the two peaks originated from DTT interfered with GSH. The ratio of acetonitrile and water in mobile phase were evaluated for its effect on HPLC separation. It was found that a reasonable separation was achieved for Cys, GSH, and the two interfering peaks, when a linear gradient of $0-5 \%$ acetonitrile (instead of $0-20 \%$ ), for $20 \mathrm{~min}$ and followed by washing the column with 50\% acetonitrile for additional 5 min (Fig. 2.9).

The post column derivatization was carried out in a reaction coil made of 10 feet of Teflon tubing. Initially, a coil with $0.3 \mathrm{~mm}$ i.d. was used. I discovered that the diameter of Teflon tubing was too narrow, causing high pressure, and consequently leaching. Ideal reaction can be performed by using $0.5 \mathrm{~mm}$ i.d. tubing. The reaction coil should be washed by pumping DIW through the coil for $20 \mathrm{~min}$ after daily sample analysis to maintain for future use. 


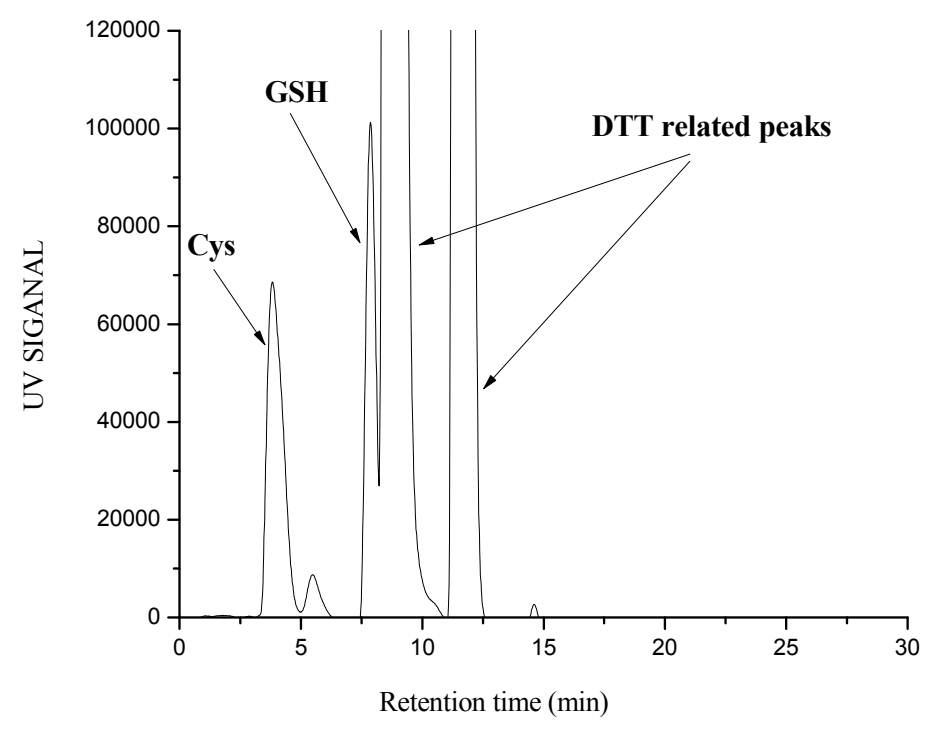

Figure 2.8 The chromatogram of a mixture solution of Cys and GSH separated by HPLC with a linear gradient of $0-20 \%$ acetonitrile for $20 \mathrm{~min}$ and followed by washing the column with $50 \%$ acetonitrile for an additional $5 \mathrm{~min}$.

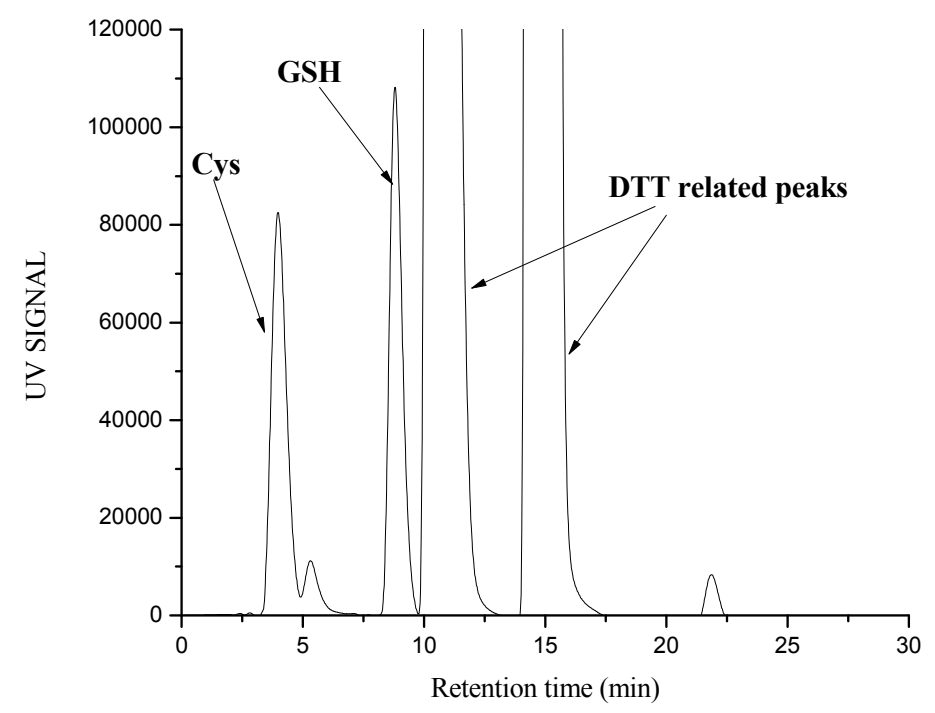

Figure 2.9 The chromatogram of a mixture solution of Cys and GSH separated by HPLC 
with a linear gradient of $0-5 \%$ acetonitrile for $20 \mathrm{~min}$ and followed by washing the column with $50 \%$ acetonitrile for an additional $5 \mathrm{~min}$.

\subsubsection{Figures of Merit of the Developed Method}

Cysteine and GSH were prepared in DDI water and analyzed directly with HPLC and on-line derivatization without preconcentration. The calibration curves for the tested thiol compounds were made in the range 25 to $150 \mu \mathrm{M}$ under the optimum conditions and showed excellent linearity for both Cys and GSH (Fig 2.10). The coefficients of correlation $\left(\mathrm{R}^{2}\right)$ were 0.9993 and 0.9943 for Cys and GSH, respectively.

The limits of detection (LODs) of the instrument were calculated as 3 times the standard deviation of $25 \mu \mathrm{M}$ Cys and GSH standard solution injected directly onto the high performance liquid chromatography. The LODs were 3.0 and $5.1 \mu \mathrm{M}$ for Cys and GSH, respectively. Taking the preconcentration ratio for water sample analysis into consideration, which was from 500 to $25 \mathrm{~mL}$, the LODs of the method were 0.15 and $0.26 \mu \mathrm{M}$ (Table 2.3). 


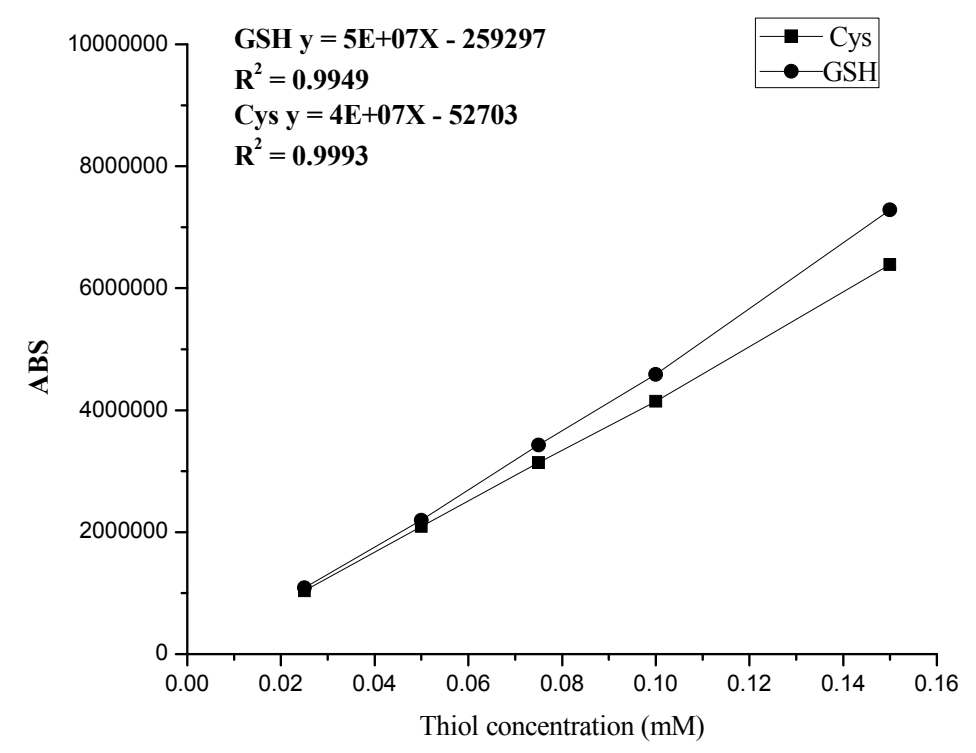

Figure 2.10 The standard of Cys and GSH calibration curve.

Table 2.3 Limits of detection for Cys and GSH calculated based on 3 times the standard deviation of $25 \mu \mathrm{M}$ Cys and GSH standard solution injected directly onto HPLC $(\mathrm{N}=6)$. For the calculation of method LODs, sample was concentrated from 500 to $25 \mathrm{~mL}$.

\begin{tabular}{ccc}
\hline & Cys & GSH \\
\hline Instrumental LODs $(\mu \mathrm{M})$ & 3.0 & 5.1 \\
Method LODs $(\mu \mathrm{M})$ & 0.15 & 0.26 \\
\hline
\end{tabular}

Accuracy and precision of above method for the analysis of Cys and GSH were evaluated. Dionized water solution (100 mL) spiked with Cys and GSH at $25 \mu \mathrm{M}$ levels was preconcentrated using affinity thiopropyl sepharose column and analyzed by HPLCUV/Vis under previous optimized conditions $(\mathrm{N}=5)$. The volume of the eluted solution 
was $25 \mathrm{~mL}$, meaning the thiols were concentrated 4 times. The recoveries of Cys were in the range of 83 to $93 \%$ with an average of $89 \pm 5 \%$ and were in the range of 71 to $78 \%$ and averaged at $81 \pm 9 \%$.for GSH. The relative standard deviation (RSD) was 5 and $9 \%$ for Cys and GSH, respectively (Table 2.4).

Table 2.4 Recoveries and relative standard deviation for the analysis of Cys and GSH, 25 $\mu \mathrm{M}$ spiked in DIW, using activated thiopropyl sepharose gel preconcentration (4 times) and analysis using HPLC-UV/Vis $(\mathrm{N}=5)$.

\begin{tabular}{cccccc}
\hline \multicolumn{3}{c}{ Cys } & & \multicolumn{3}{c}{ GSH } \\
\hline $\begin{array}{c}\text { RSD } \\
(\%)\end{array}$ & Recovery (\%) & $\begin{array}{c}\text { Average } \\
\text { recovery (\%) }\end{array}$ & $\begin{array}{c}\text { RSD } \\
(\%)\end{array}$ & Recovery (\%) & $\begin{array}{c}\text { Average } \\
\text { recovery (\%) }\end{array}$ \\
\hline 5 & $83-93$ & 89 & 9 & $71-88$ & 81 \\
\hline
\end{tabular}

\subsubsection{Real Sample Analysis}

Water samples (2 L) were collected from a small pond at FIU and from the Florida Everglades at depth of approximately $20 \mathrm{~cm}$ using a $2 \mathrm{~L}$ Teflon bottle containing $500 \mu \mathrm{L}$ of 2 mM EDTA. Upon arrival at the laboratory, the water samples were filtering with a $0.45 \mu \mathrm{m}$ membrane. The water sample $(500 \mathrm{~mL})$ was preconcentrated using the column under optimized conditions. The column was eluted with $10 \mathrm{~mL}$ of $10 \mathrm{mM}$ DTT and 25 $\mathrm{mL}$ of eluted solution was analyzed by HPLC coupled with UV/Vis detection. Thiols could not be detected from the water samples, even after 20 folds of concentration, indicating Cys and GSH were below the detection limits of the method. 
Table 2.5 Analysis of water samples collected from the Everglades and a small pond at FIU. The samples were spiked with Cys and GSH at $10 \mu \mathrm{M}$ and preconcentrated using activated thiopropyl sepharose gel for 20 folds and analyzed by HPLC-UV/Vis $(\mathrm{N}=5)$.

\begin{tabular}{ccccccc}
\hline \multicolumn{3}{c}{ Cys } & & GSH \\
\hline Matrix & $\begin{array}{c}\text { RSD } \\
(\%)\end{array}$ & $\begin{array}{c}\text { Recovery } \\
(\%)\end{array}$ & $\begin{array}{c}\text { Average } \\
\text { recovery } \\
(\%)\end{array}$ & $\begin{array}{c}\text { RSD } \\
(\%)\end{array}$ & $\begin{array}{c}\text { Recovery } \\
(\%)\end{array}$ & $\begin{array}{c}\text { Average } \\
\text { recovery } \\
(\%)\end{array}$ \\
$\begin{array}{c}\text { Pond } \\
\text { water }\end{array}$ & 7 & $80-95$ & 89 & 8 & $84-97$ & 93 \\
$\begin{array}{c}\text { Everglade } \\
\text { water }\end{array}$ & 10 & $96-110$ & 103 & 12 & $84-108$ & 95 \\
\hline
\end{tabular}

The recoveries of Cys and GSH from real environmental water samples were evaluated by spiking Cys and GSH into $500 \mathrm{~mL}$ of these samples at $10 \mu \mathrm{M}$. The recoveries were in the range of $80-110 \%$ for Cys and $84-108 \%$ for GSH (Table 2.5). A typical chromatogram for the analysis of Cys and GSH in these environmental surface waters is shown in Figure 2.9. In addition to the Cys and GSH peaks, a few peaks originated from DTT also appeared on the chromatogram. However, these peaks did not interfere with the separation and quantification of Cys and GSH. It was reported in a previous study that a strong interference from natural organic matter with Cys analysis in lake water was observed without using covalent affinity preconcentration (Hu et al. 2006). Our results indicate that the covalent affinity chromatographic technique not only enriched thiols but also eliminated the interferences present in the water samples. However, application of this method for the analysis of thiols present in real 
environmental water samples at trace levels is limited because of the poor detection limits of UV/Vis detector.

\subsection{Conclusions}

Activated thiopropyl sepharose gel was successfully synthesized. A method of using affinity covalent chromatographic preconcentration coupled with HPLC separation, online derivatization, and UV/Vis detection was developed for analyzing reduced organic sulfur (using Cys and GSH and representatives) in water samples. Factors affecting the column packing, thiols enrichment and elution from the column, on-line derivatization, and separation and analysis with HPLC and UV/Vis were evaluated and optimized. Figures of merits were evaluated. The detection limits for water samples were 0.15 and $0.26 \mu \mathrm{M}$ for Cys and GSH, respectively, with concentration factor of 20 , indicating the difficulty of using this method for analyzing real environmental water samples, which usually contain thiols at low nM levels. The good recoveries observed for both Cys and GSH and the lack of interferences for real water sample analysis demonstrate that the developed covalent affinity chromatographic preconcentration method is indeed an efficient technique for thiol enrichment and interference elimination. This method could be potentially developed into a reliable and useful technique for thiol analysis in water samples with a more sensitive detection, such as a fluorescence detector. 


\section{Chapter III}

\section{ANALYSIS OF REDUCED ORGANIC SULFUR IN WATER SAMPLES USING AFFINITY CHROMATOGRAPHIC PRECONCENTRATION COUPLED WITH HPLC-FLUORESCENCE DETECTION}

\subsection{Introduction}

Sulfur occurs in both combined and free states and is distributed widely over the Earth's surface and represents approximately $1.9 \%$ of the total weight of the earth (USEPA 1991). It exists in nature at different oxidation states such as: sulfides $\left(\mathrm{S}^{2-}\right)$,

sulfites $\left(\mathrm{SO}_{3}{ }^{2-}\right)$, sulfates $\left(\mathrm{SO}_{4}{ }^{2-}\right)$, thiosulfates $\left(\mathrm{S}_{2} \mathrm{O}_{3}{ }^{2-}\right)$ etc. Among the numerous organic sulfur compounds, reduced organic sulfur compounds (R-SH) are especially important in biogeochemical reactions of the marine and freshwater ecosystem because of the high reactivity of the sulfhydryl group (Patai 1974). Thiols have been shown to play an important role in controlling the bioavailability of trace metals (Boulegue et al. 1982; Matrai 1988; Lee and Hultberg 1990; Leal et al. 1999; Harris et al. 2003) and other toxic compounds in aquatic environments through complexation reactions (Cullen et al. 1984; $\mathrm{Hu}$ et al. 2006). Reduced organic sulfur (ROS) is more abundant than mercury found in most aquatic environments (Xia et al. 1999). Reduced organic sulfur can strongly interact with many metals present in aquatic systems. It is well known that the reactivity of thiol to mercury is strong compared to other transition metal ions (Cestari and Airoldi 1997; Xia et al. 1998) because of the strong complexation between Hg and ROS (Benoit et al. 2001). The methylmercury cation $\left(\mathrm{MeHg}^{+}\right)$also has high affinity for thiol ligands (Rabenstein et al. 1982). Among many reduced organic sulfur compounds, cysteine (Cys) and glutathione (GSH) have been reported as the most frequently detected thiols in 
aquatic environments (Mopper and Taylor Barrie 1986; Tang et al. 2000; Al-Farawati and Van Den Berg 2001).

A sensitive and reliable technique is necessary for the detection of thiols in aquatic environment, particularly in fresh water systems (Tang et al. 2003). Thiols undergo rapid oxidation in air, which puts limitations on the storage and handling of the samples. Analysis is required on site or performed within very short periods of time upon sampling. Appropriate storage prior to analysis is one of the major problems in real environment studies Up to date, satisfactory techniques have not been developed to prevent this rapid oxidation process. Thiol analysis in aqueous samples also suffers from the limitation in instrumental sensitivity and method detection limit since thiols exist at very low concentrations (nM or sub nM) in aquatic environments (Tang et al. 2003; Zhang et al. 2004). In addition, strong matrix interferences are encountered without sample cleanup (Hu et al. 2006). These limitations have greatly hampered the measurement of reduced organic sulfur in aquatic environments, particularly in freshwater ecosystems including surface and pore waters. Limitations in thiol analysis have hindered our further understanding of the role of ROS played in metal biogeochemistry.

A reliable analysis method to detect thiol would be very helpful for us to understand the fate and transportation of sulfur and trace metals and their interaction in aquatic environment. Various sample preconcentration techniques have been developed and utilized for analyzing thiols. Solid phase extraction (SPE), solid phase microextraction (SPME) and covalent affinity chromatography techniques have been found to be successful in the analysis and purification of thiols in biological samples (Glatz et al. 
1997; Kabzinski 1997; Kabzinski 1998), while no applications have been found for environmental water samples.

Covalent affinity chromatography has the potential to be employed as a preconcentration technique prior to thiols analysis in water samples because its selectivity and capability of reducing interferences in comparison to the traditional solid-phase extraction techniques. Most common solid phase extractions retain analytes on basis of their polarity, creating problems if other components in the sample or in the reagents have similar polarities. In covalent chromatography, on the other hand, covalent bonds formed between the medium and analytes in the mobile phase (Fig 3.1). This makes the separation of thiols from non-thiol compounds possible and protects thiols from oxidation; however, this technique has not been applied for the analysis of thiols in environmental water samples.

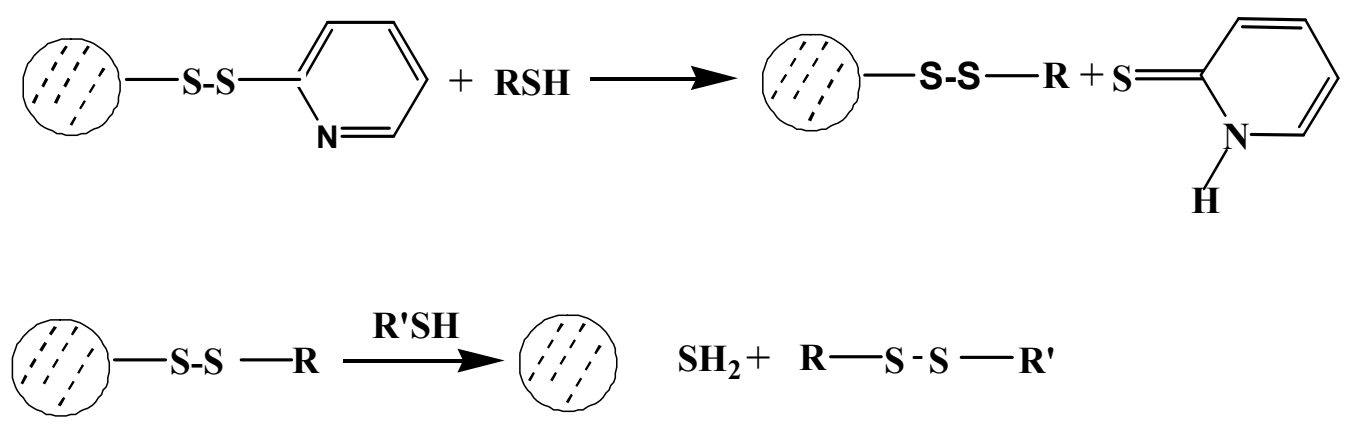

Figure 3.1 Scheme showing the reaction between reduced organic sulfur and activated thiopropyl sepharose 6B. RSH is the low molecular weight thiol, such as Cys or GSH, while R'SH represents another thiol-containing compound, such as dithiothreitol (DTT), used to release RSH from the column. 
Methods have been developed for thiols analysis using high performance liquid chromatography (HPLC) coupled with UV/Vis or fluorescence (FL) detectors. Some of the methods employ post-column derivatization and HPLC-UV/Vis, while others utilize pre-column derivatization followed by HPLC-FL detection. Postcolumn derivatization requires additional pumps to dispense the derivatization reagent. Moreover, it may lead to peak broadening and decreasing sensitivity (Capitan-Vallvey et al. 2002). The major advantage of precolumn derivatization, in comparison with the postcolumn method is that it provides a much better sensitivity. The fluorescence reagents, ammonium 7fluorobenzo-2-oxa-1, 3-diazole-4-sulphonate (SBD-F) (Toyo'oka et al. 1988; Garcia and Apitz-Castro 2002; Santa et al. 2006; Ichinose et al. 2009), 4-aminosulfonyl-7-fluoro2,1,3-benzoxadiazole (ABD-F) (Lin Ling et al. 1989; Whittle et al. 2000; Santa et al. 2006; Takeda et al. 2007), o-phthalaldehyde (OPA) (Gardner and Miller 1980; MolnarPerl 2001) and monobromobimane (mBBr) (Luo et al. 1995; Ivanov et al. 2000; Chou et al. 2001; Ivanov et al. 2001) are commonly used (Joys and Kim 1979; Tang et al. 2000; Tang et al. 2003; Zhang et al. 2004). These derivatization reactions are illustrated in Figs 3.2, 3.3 and 3.4. The reaction with o-phthalaldehyde is highly $\mathrm{pH}$ dependent and at $\mathrm{pH}$ values below 9, no reaction occurs. Derivatization with $\mathrm{mBBr}$ is characterized by the formation of interfering adducts and time consuming clean-up steps required to remove the hydrolysis products. Benzofurazan reagents such as SBD-F and ABD-F were most often used because of their higher reaction selectivity toward thiols. The derivatives of SBD-F and ABD-F with thiols have strong fluorescence response. The reagents themselves are not fluorescent. Therefore, the interferences from the excess reagent can be avoided (Imai et al. 1994; Daskalakis et al. 1996; Oe et al. 1998; Rizzo et al. 1998; 
Pfeiffer et al. 1999; Uchiyama et al. 2001; Abukhalaf et al. 2002; Yoshida et al. 2003). The derivatives of SBD-F are highly soluble in water since the sulfonate group of SBD-F ionizes in water (Okabe et al. 2002).

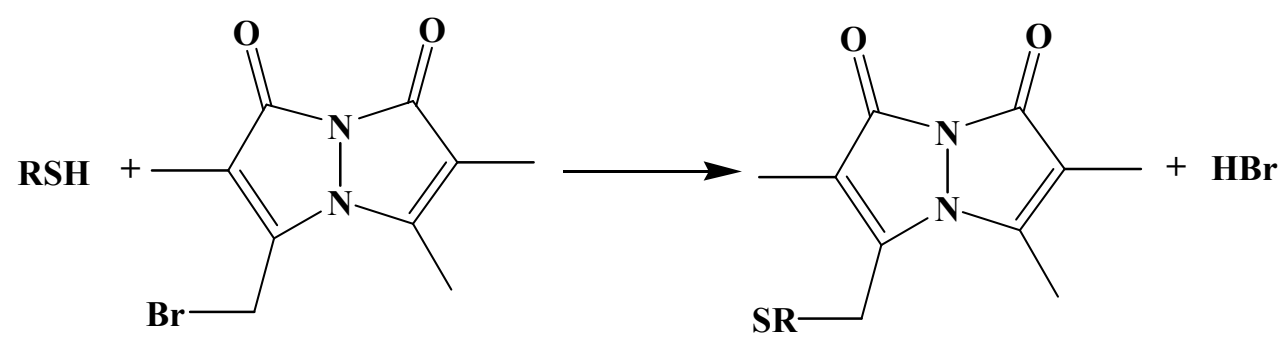

Figure 3.2 Derivatization reactions of thiols with monobromobimane.

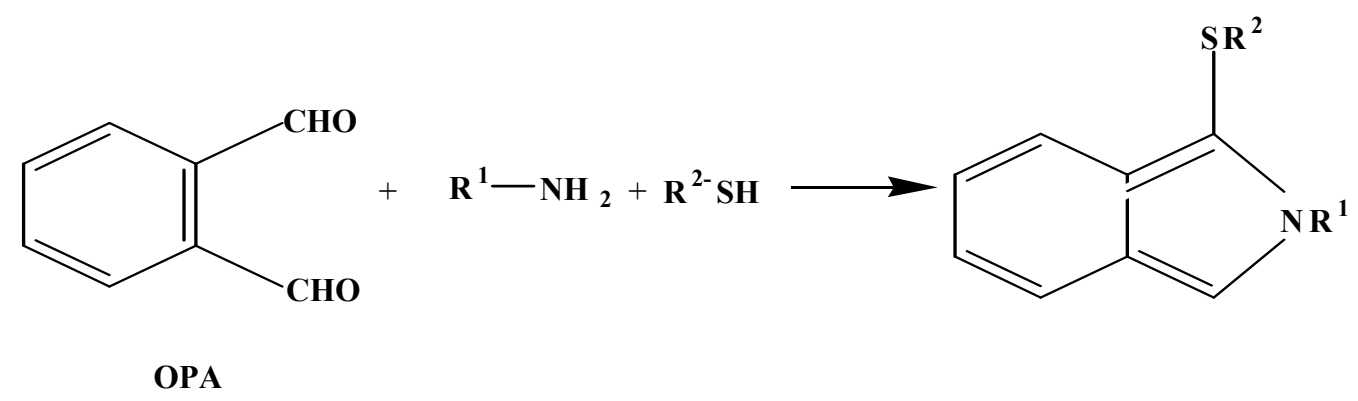

Figure 3.3 Derivatization reactions of thiols with o-phthalaldehyde.
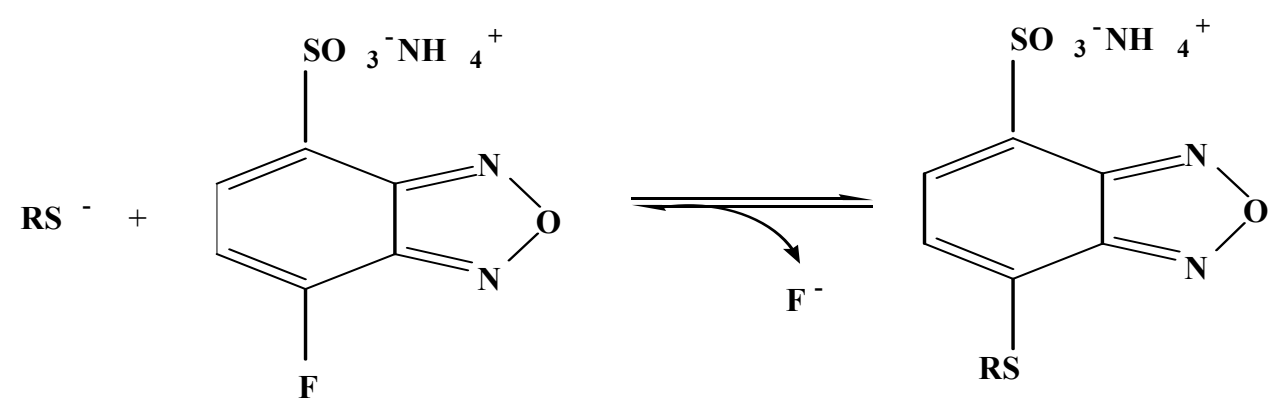

Figure 3.4 Derivatization reactions of thiols and 4-fluoro-7-sulfobenzofurazan, ammonium salt. 


\subsection{Objectives}

The objective of this research was to develop a sensitive and reliable method for preconcentration of small ROS in the aquatic environment especially in fresh water samples using covalent affinity technique and analysis with a reverse phase chromatographic method coupled with a fluorescence detector. It was expected that such method would improve the detection limits enabling the analysis of thiols in freshwater samples. The enrichment technique using covalent affinity chromatography would provide longer storage times prior to for analysis, easy handling of the sample, and reduce interferences.

\subsection{Experimental Section}

\subsubsection{Chemicals and Materials}

Acetonitrile (Optima, LC/MS), methanol (Optima, LC/MS), cysteine (99\% pure, Acros Organics), glutathione reduced (98 - 100\%, Sigma Ultra), dithiothreitol (DTT), sodium bicarbonate, sodium phosphate, 2,2'-dipyridyl disulfide (98\%), 4-fluoro-7sulfobenzofurazan, ammonium salt (SBD-F), tris 2-carboxyethyl phosphine (TCEP) and trifluoroacetic acid (TFA) were purchased from Fisher Scientific. Sepharose 6B in 20\% ethanol wet bead diameter $45-185 \mu \mathrm{m}$ was purchased from Sigma-Aldrich. Epichlorohydrin (99\%) was obtained from Acros Organics. Other chemicals were analytical grade or higher.

\subsubsection{Instrumentation}

A Thermo HPLC system including a gradient controller (SpectraSYSTEM P4000), an auto sampler (SpectraSYSTEM AS3000) and a fluorescence detector (Spectra SYSTEM FL 3000) was used. Flex-columns $(0.7 \times 10 \mathrm{~cm}$ KIMLE KONTES LLC) were 
employed for affinity chromatographic enrichment. A guard column coupled with a reversed phase $\mathrm{C}_{18}$ column (Thermo ODS HYPERSIL $250 \times 4 \mathrm{~mm}$ Particle size $5 \mu \mathrm{m}$ ) was utilized to separate derivatives of the thiol compounds. Barnstead Nanopure (Diamond Lab Water System) was used to produce de-ionized water. Touch Mixer model 232 (Fisher Scientific) was used for mixing purpose. Air orbital shaker (Orbital Shaker, VWR Scientific Products) was used to shake samples. A sintered glass funnel (ASTM 25 - $50 \mu \mathrm{m}, \mathrm{ACE}$ Glass Inc. USA) was employed for filtration. Isometric pumps (ColePamer Instrument Company, Chicago USA) were utilized to load samples onto the enrichment columns. Mechanic stirring (Tline Laboratory 101 Stirrer Talboys Engineering Corp Emerson N.J) was employed to stir samples during synthesis. Bransonic 1510 R-MTH $(50-60 \mathrm{HZ})$ was used for ultrasonication. The water bath was purchased from NESLAB and was used for temperature control $\left(60^{\circ} \mathrm{C}\right)$ for SBD-F derivatization.

\subsubsection{Covalent Affinity Chromatographic Enrichment}

\subsubsection{Synthesis of Activated Thiopropyl Sepharose 6 B}

Synthesis of activated thiopropyl sepharose $6 \mathrm{~B}$ was performed using a method described previously (Axen et al. 1975; Zhang and Cai 2003) with minor modifications. Briefly, Sepharose 6B gel was washed on a sintered glass with distilled water and then suspended in $100 \mathrm{~mL}$ of $0.1 \mathrm{M}$ sodium hydroxide $(\mathrm{NaOH})$ in an Erlenmeyer flask. Epichlorohydrin $(45 \mathrm{~mL})$ was added at room temperature, and the reaction was developed at $60{ }^{\circ} \mathrm{C}$ on an air bath shaker for two hours. The expoxide-activated gel was washed with DDI water on a sintered glass funnel until reaching neutral $\mathrm{pH}$ was reached and then washed with $0.5 \mathrm{M}$ phosphate buffer $(\mathrm{pH}$ 6.3). The gel was sucked free from interstitial 
buffer and suspended in the same buffer to a final volume of $100 \mathrm{~mL}$. Sodium thiosulfate $50 \mathrm{~mL}(2.0 \mathrm{M})$ was added and the mixture was shaken in an orbital shaker for six hours at room temperature. The S-alkyl thiosulfate agarose gel was washed free of sodium thiosulfate with DIW then suspended in $30 \mathrm{~mL}$ of $0.1 \mathrm{M}$ sodium bicarbonate $\left(\mathrm{NaHCO}_{3}\right)$ containing $1.0 \mathrm{mM}$ EDTA, DTT $(1.0 \mathrm{~g})$, dissolved in EDTA $(0.1 \mathrm{mM}, 5 \mathrm{~mL})$, was immediately added to reduce the gel to thiols agarose gel for $30 \mathrm{~min}$. The gel was then washed on a sintered funnel with $300 \mathrm{~mL}$ of $\mathrm{NaHCO}_{3}(0.1 \mathrm{M})$ containing $1 \mathrm{M}$ sodium chloride and $1.0 \mathrm{mM}$ EDTA and followed by $1000 \mathrm{~mL}$ of $1.0 \mathrm{mM}$ EDTA and $500 \mathrm{~mL}$ of acetone ( $60 \%$ in $0.05 \mathrm{M} \mathrm{NaHCO}_{3}$ solution containing $1 \mathrm{mM}$ EDTA) and suspended in 30 $\mathrm{mL}$ same solvent. $1 \mathrm{~g}, 2$, 2'-dipyridyl disulfide in $20 \mathrm{~mL}$ of the above solvent was immediately added to activate the gel, at room temperature for $1 \mathrm{~h}$ under direct drive stirring. The product was washed with $500 \mathrm{~mL}$ of acetone $(60 \%$ in water) and finally with $1000 \mathrm{~mL}$ of EDTA $(1.0 \mathrm{M})$. The activated gel was kept in EDTA $(1.0 \mathrm{mM})$ solution (containing $20 \%$ alcohol) at $4{ }^{\circ} \mathrm{C}$. The purpose of adding $20 \%$ alcohol was to prevent bacterial growth in the gel.

\subsubsection{Peconcentration of Thiols Using Covalent Affinity Columns}

The column set up for thiol preconcentration using covalent affinity technique was similar to the one described in Chapter II. The system included two isometric pumps, four plastic flex-columns $(0.7 \times 10 \mathrm{~cm}$ Kimle Kontes LLC $)$ and Teflon tubing for all connections (Fig 3.5). 


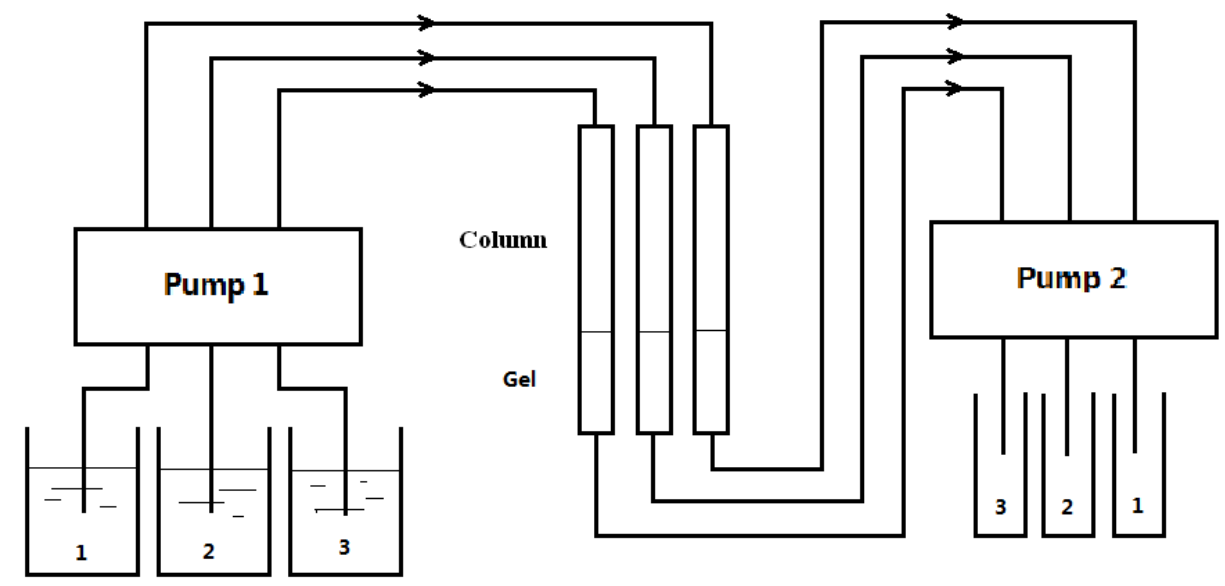

Figure 3.5 Schematic diagram is showing the thiol preconcentration system by covalent affinity chromatography. Pump 1 was used to load samples into the column, while pump 2 was used to draw effluent.

Briefly, the home made thiopropyl sepharose $6 \mathrm{~B}(1 \mathrm{~g})$ was mixed with $5 \mathrm{~mL} 0.05 \mathrm{M}$ phosphate buffer ( $\mathrm{pH} 7.4$ ) containing $2 \mathrm{mM}$ EDTA, (degassed before use) to form a slurry. Column was first filled with binding buffer in order to eliminate air. The slurry was slowly poured into the column meanwhile the column was tapped using a rubber wrapped glass bar to make sure the gel was homogenous and tightly settled down at bottom of the column. The tapping also helped to avoid air being trapped in the column. The column was conditioned for 20 min with the sample binding buffer, and then the sample was pumped into the column. The column was washed with $200 \mathrm{~mL}$ of $0.1 \mathrm{M}$ $\mathrm{NaCl}$ and $200 \mathrm{~mL}$ of $0.05 \mathrm{M}$ phosphate buffer (pH 7.4) containing $2 \mathrm{mM}$ ethylenediaminetetraacetic acid. The thiols enriched on the gel were eluted with releasing reagents (TBP or TCEP). Alternatively, the gel in the column with the preconcentrated thiols was taken out and incubated with $500 \mu \mathrm{L}$ of $10 \%$ TCEP for $30 \mathrm{~min}$ and the mixture 
was then diluted to $25 \mathrm{~mL}$. A fraction of the supernatant $(500 \mu \mathrm{L})$ was used for derivatization using SBD-F and analysis using HLC-FL. Figure 3.6 shows the reaction of releasing free thiols from the thiol enriched gel.

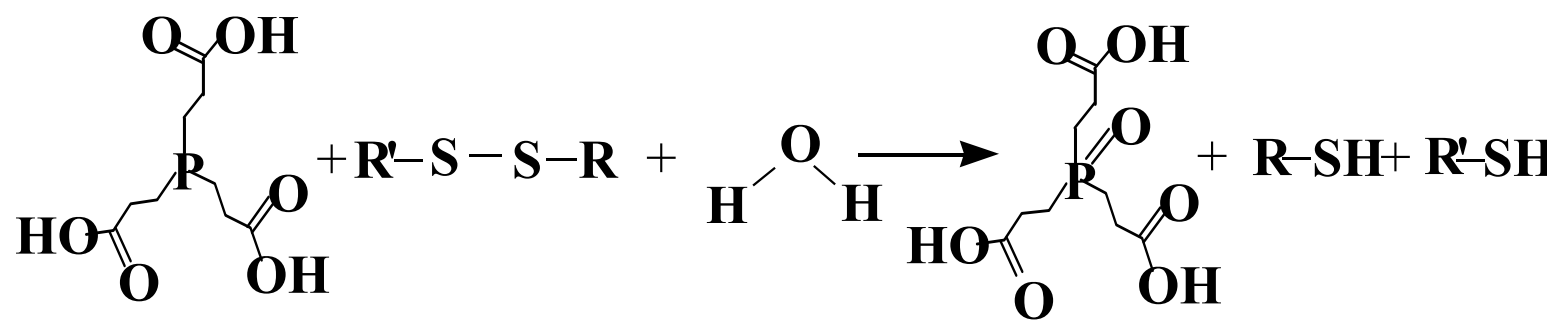

Figure 3.6 Reaction showing the release of the thiol of interest (R-SH) by TCEP from the affinity column with enriched thiols on thiopropyl sepharose gel.

\subsubsection{Preconcentration of Thiols Using Covalent Affinity Solid Phase Extraction without Being Loaded on a Column}

Instead of using an affinity column, the preconcentration of thiols was conducted in a $15 \mathrm{~mL}$ plastic centrifuge tube in the presence of thiopropyl sepharose gel. In order to distinguish this procedure from the affinity column set up as described above, we name this method as affinity solid phase extraction in the following discussion. To the test tubing, $10 \mathrm{mg}$ of thiopropyl sepharose gel was added followed by the addition of $12.5 \mathrm{ml}$ of sample or thiols standard. The mixture was shaken for 40 minutes. The test tube was centrifuged for $10 \mathrm{~min}$ at $10000 \mathrm{rpm}$ and the supernatant was decanted to another test tube. The reducing reagent, TCEP $(50 \mu \mathrm{L})$, was added into the centrifuge tube containing thiol enriched gel. The mixture was under vortex for 60 seconds and then shaken on an orbital shaker for 30 minutes at $300 \mathrm{rpm}$. The mixture was centrifuged for $10 \mathrm{~min}$ at 
$10,000 \mathrm{rpm}$ and the supernatant $(500 \mu \mathrm{L})$ was sampled and derivatized by 4-fluoro-7sulfobenzofurazan, ammonium salt.

\subsubsection{Derivatization of the Enriched Thiols with SBD-F}

The derivatization reaction was performed in a $2 \mathrm{~mL}$ centrifuge tube. Solution (500 $\mu \mathrm{L}$ ) containing the released thiols from thiopropyl sepharose gel was mixed with $200 \mu \mathrm{L}$ of $0.1 \mathrm{M}$ borate buffer ( $\mathrm{pH} 9.5$ ), $40 \mu \mathrm{L}$ of $1 \mathrm{mg} / \mathrm{mL}$ SBD-F (prepared in $0.1 \mathrm{M}$ borate buffer, pH 9.5 containing $2 \mathrm{mM}$ EDTA), and $20 \mu \mathrm{L}$ of $1 \mathrm{M} \mathrm{NaOH}$. After vortex mixing for $20 \mathrm{~s}$, the derivatization reaction was carried out in a water bath at $60{ }^{\circ} \mathrm{C}$ for 1 hour. The reaction was then stopped by adding $20 \mu \mathrm{L}$ of $4 \mathrm{M} \mathrm{HCl}$. The thiol derivatives were stored at $4{ }^{\circ} \mathrm{C}$ under dark for later HPLC separation and fluorescence detection.

The reaction times of SBD-F derivatization with Cys and GSH were optimized. Samples were collected at different time interval $(0,60,90$, and 120, 180 and 240 minutes). The derivatives of Cys and GSH were analyzed by HPLC with fluorescence detector. The concentration of SBD-F used in the derivatization reactions was also optimized in order to increase fluorescence response. A series of concentrations of SBDF were used for Cys and GSH derivatization $(0.25,0.5,1.0$ and $2.0 \mathrm{mg} / \mathrm{L})$. The derivatives of Cys and GSH were analyzed by HPLC coupled with fluorescence detection.

\subsubsection{HPLC-FL Analysis}

Thiol analysis was performed using reversed-phase HPLC-FL following a method previously described (Tang et al. 2000; Zhang and Cai 2003) A HPLC system (Thermo Separation Products, TSP) with an auto sampler (AS3000) and fluorescence detector (Spectra SYSTEM FL 3000) was employed (excitation wavelength $\lambda_{\mathrm{ex}} 386 \mathrm{~nm}$ and emission wavelength $\left.\lambda_{\mathrm{em}} 516 \mathrm{~nm}\right)$. A $\mathrm{C}_{18}$ column $(250 \times 4 \mathrm{~mm}, 5 \mu \mathrm{m}$ particle size, ODS 
Hypersil, Thermo) was used for the separation of SBD-F derivatized thiols. Mobile phases $\mathrm{A}$ and $\mathrm{B}$ were $0.1 \%$ trifluroacetic acid and acetonitrile respectively. The flow rate of the mobile phase was $1 \mathrm{~mL} / \mathrm{min}$, with a program as follows: 0 - $1 \mathrm{~min}$, isocratic $10 \% \mathrm{~B}$; 1 - 12 min, 10 - 15\% B; 12 - 25 min, 15 - 35\% B; 25 - 28 min, 35 - 100\% B; 28 - 32 min, isocratic $100 \% \mathrm{~B}$; and $32-40 \mathrm{~min}, 100-0 \% \mathrm{~B}$. The SBD-F derivatized thiols were monitored at $\lambda_{\text {em }} 516 \mathrm{~nm}$.

\subsection{Results and Discussion}

\subsubsection{Selection of Reducing Reagents to Release Thiols on Thiopropyl Sepharose Gel}

It is common to use a reducing reagent in order to determine all the thiols including the oxidized thiols (disulfides). In this case, the disulfide bond is broken and the thiols of interest are eluted from the column for derivatization and analysis. The common reducing reagents used to cleave the -s-s- bond are TCEP, DTT and TBP (Figs 3.6, 3.7, and 3.8). Dithiothreitol itself is a thiol compound and thus may generate problems for the determination of other thiol species. Some works showed that TBP could decrease fluorescence signals (Rizzo et al. 1998). Therefore, an extra extraction step using nhexane is usually required before derivatization (Kok et al. 1997). Tributylphosphine is not soluble in water and has an unpleasant odor. It should be dissolved in dimethylformamide (DMF). Using TCEP as reducing reagent avoids the problem of interference. It is soluble in water and does not have unpleasent odor. Therefore, TCEP was selected in this study. 


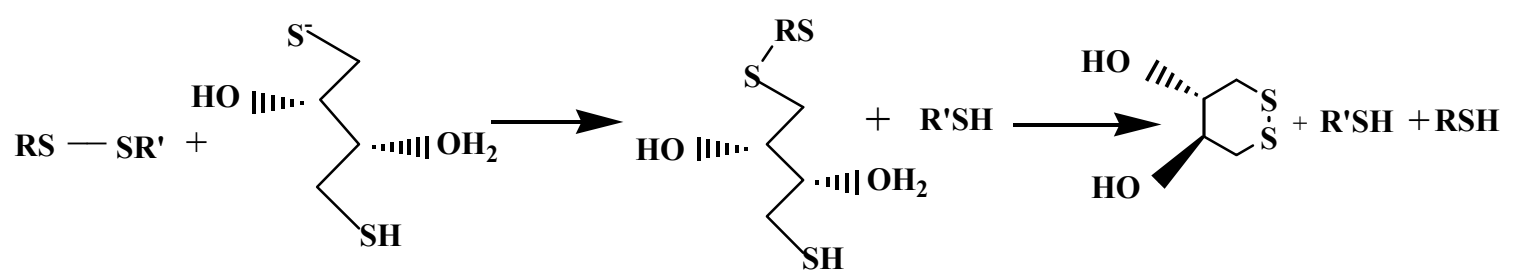

Figure 3.7 Reduction of organic disulfide by dithiothreitol.

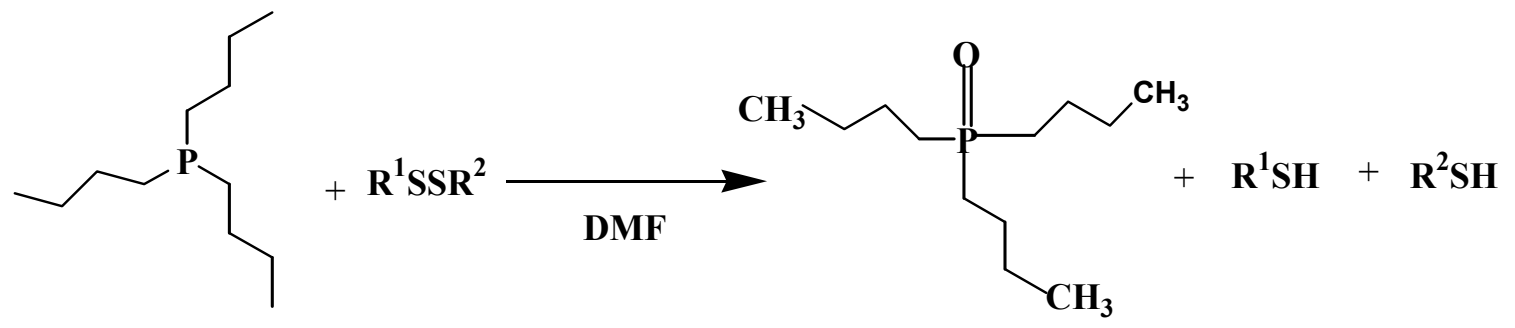

Figure 3.8 Organic disulfide is reduced by tributylphosphine. Dimethylformamide is used as the solvent.

\subsubsection{SBD-F Derivatization and HPLC-FL Analysis}

Experiments were conducted to optimize the conditions for thiols derivatization using SBD-F. The thiol standard solutions were prepared daily to avoid thiol oxidation. Two thiol standards, cysteine and glutathione were chosen for this study because they are the most frequently detected thiols in natural water (Mopper and Taylor 1986; Tang et al. 2000; Al-Farawati and Van Den Berg 2001). For quantitative analysis, hydrochloride acid $(20 \mu \mathrm{L}, 4 \mathrm{M})$ was added to terminate the SBD-F derivatization reaction. The derivatives were found to be stable during the HPLC analysis.

In order to improve the method detection limit, experimental conditions were optimized for fluorescence signals for the two SBD-F derivatives, Cys and glutathione. The concentrations of SBD-F used and the derivatization reaction time were investigated. 
Reaction times needed for the SBD-F derivatization varied among the reported research work (Oe et al. 1998; Okabe et al. 2002; Yoshida et al. 2003; Santa et al. 2006), because of the differences in sample matrices and the thiol species involved. The peak heights of the derivatives of Cys and GSH were plotted against the reaction time. The peak heights increased rapidly within the initial 40 minutes and then remained relatively constant for up to 240 min for both Cys and GSH (Fig 3.9). Therefore, the reaction time of 60 minutes was chosen as the reaction time for the following experiments.

The concentration of SBD-F used for thiol derivatization was tested in a range of 0.25 to $2 \mathrm{mg} / \mathrm{mL}$. The peak height of the GSH derivative reached maximum value at 1 $\mathrm{mg} / \mathrm{mL}$ of SBD-F, while the signal for Cys-SBD derivative continued to increase about $20 \%$ with $2 \mathrm{mg} / \mathrm{ml}$ of SBD-F. However, the SBD-F concentration of $1 \mathrm{mg} / \mathrm{mL}$ was chosen for all experiments by taking into consideration the expensive price of 4-fluoro-7sulfobenzofurazan, ammonium salt (Fig 3.10). A broad range of SBD-F concentration used for the derivatization can be found from the literature. Some were comparable to the one utilized in this study (Rizzo et al. 1998; Frick et al. 2003; Nolin et al. 2007), while others were much higher. For example, $0.6 \%$ was used by Yoshida (Yoshida et al. 2003), $0.3 \%$ used by Oe (Oe et al. 1998) and $0.6 \mathrm{mg} / \mathrm{ml}$ by Dashalakis (Daskalakis et al. 1996). On the other hand, a concentration of SBD-F at $0.25 \mathrm{mg} / \mathrm{ml}$ has also been used (Tang et al. 2000). This difference in the amount of SBD-F needed could be partially attributed to the different derivatization conditions employed. For instance, TBP was present in the solution for some of the studies. 


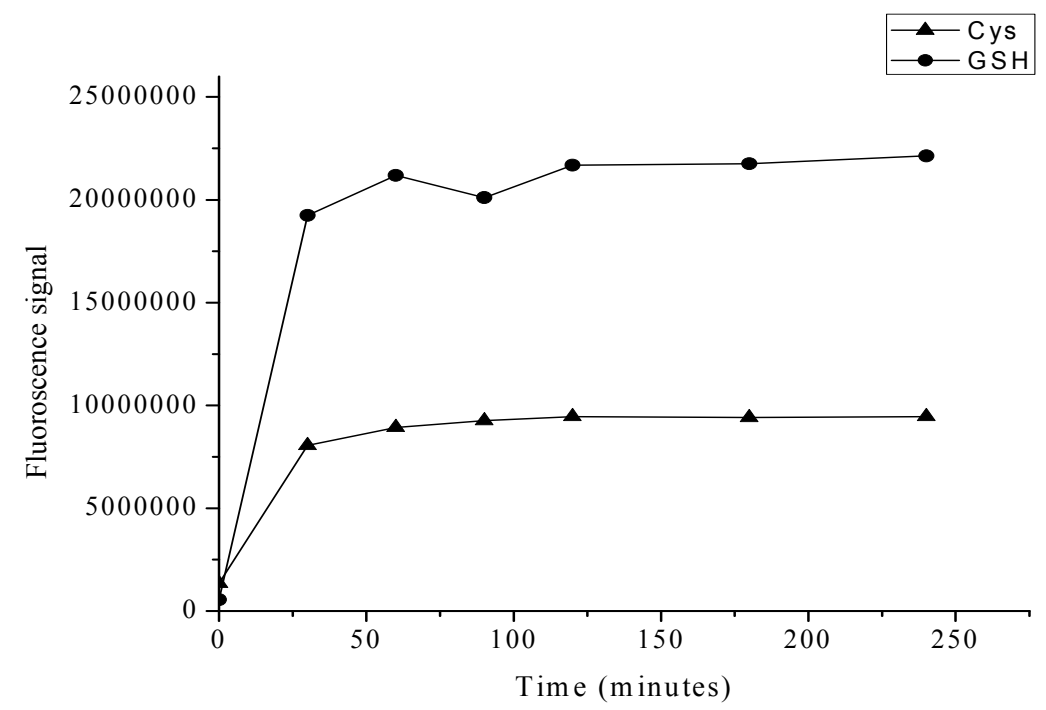

Figure 3.9 Optimization of the reaction time for SBD-F derivatization of Cys and GSH $(10 \mu \mathrm{M})$.

The stability of the SBD-F derivatives of Cys and GSH was tested. No significant changes in fluorescence response of the SBD-thiol derivatives for both Cys and GSH were observed during a storage period of 2 weeks at $4{ }^{\circ} \mathrm{C}$ in a refrigerator. It was in agreement with previous research work (Oe et al. 1998; Hu et al. 2006).

Under the optimized experimental conditions, the detection limits of the developed HPLC-FL method for ROS model compounds, cysteine and glutathione standards, were 4.5 and $3.6 \mathrm{nM}$ respectively (Table 3.1). These results were better compared to that 23 nM obtained in other researcher's work (Tang et al. 2000). 


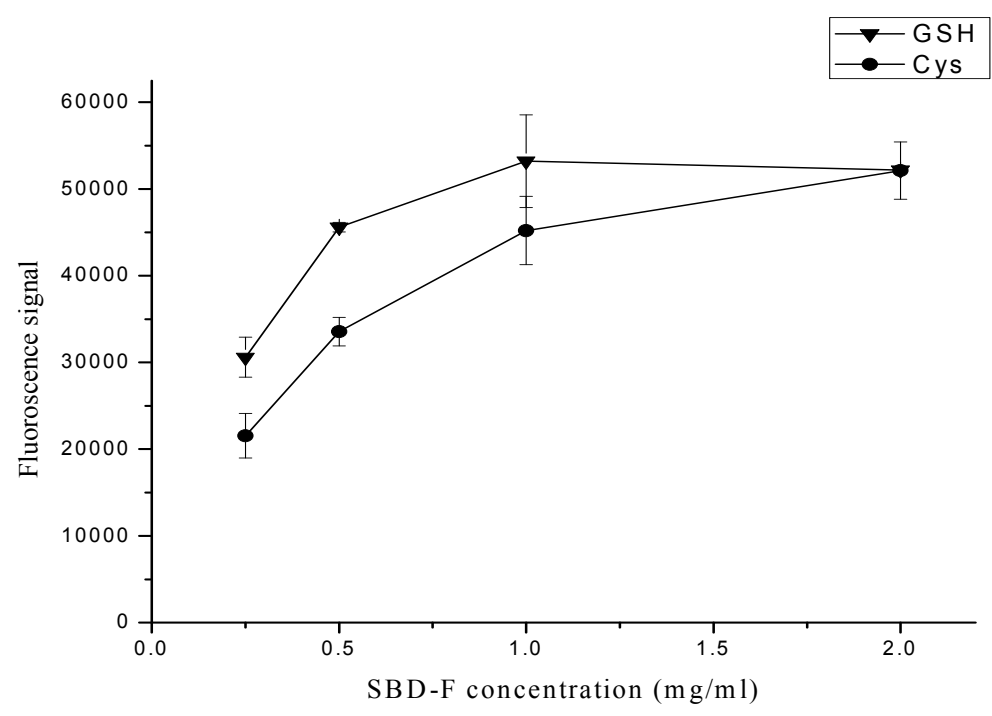

Figure 3.10 Effects of the concentration of SBD-F on the fluorescence signals of Cys and GSH derivatives. Concentration of Cys and GSH used was $1.0 \mu \mathrm{M}$.

\subsubsection{Optimization of the TCEP Concentration Using to Release Thiols from}

\section{Thiopropyl Sepharose Gel}

Tris 2 carboxyethyl phosphine was used to release thiols enriched on the thiopropyl gel. It was observed during the HPLC-FL analysis that some interfering peaks appeared at similar retention times to that of Cys-SBD and GSH-SBD derivatives when certain concentrations of TCEP were used. Figure 3.11 (a) is a chromatogram of a blank solution containing $80 \mu \mathrm{L}$ of $10 \%$ TCEP, indicating two peaks eluted at the retention time of Cys and GSH. Therefore, the effects of TCEP concentration on the chromatographic separation of the Cys and GSH derivatives were carried out under optimized conditions for other parameters, such as the SBD-F concentration and derivatization time. The results indicate that these interference peaks appeared only when mole ratio of TCEP (1\% 
TCEP in DIW or binding phosphate buffer) and SBD-F was more than $1 / 5$ during the SBD-F derivatization. It is currently unclear why such interferences could be observed only at this condition.

\subsubsection{Thiol Stability under Room Temperature and Ice Condition}

To evaluate the stability of the tested thiols during the experiments, stabilities of Cys and GSH at $300 \mathrm{nM}$ were compared by keeping the thiol standards either at room temperature or on ice (Figs 3.12 and 3.13). Cysteine was oxidized very quickly at room temperature with only $30 \%$ left after 9 hours. In comparison, GSH is more stable at room temperature, showing no significant changes in concentration within 9 hours of testing. These results suggest that the operation of the preconcentration procedure for some thiols (such as Cys) at room temperature may not be able to maintain the integrity of the tested compounds. Loading sample or standard onto the affinity column could easily take a few hours during which time some thiols may be oxidized. Stability tests for both Cys and GSH were performed by keeping the thiols in ice during the course of experiments. There were no significant changes in thiols concentrations were observed after 8 hours of storage under ice (Fig. 3.13). Eight hours are sufficient for loading the thiol-containing sample into the covalent affinity column. 

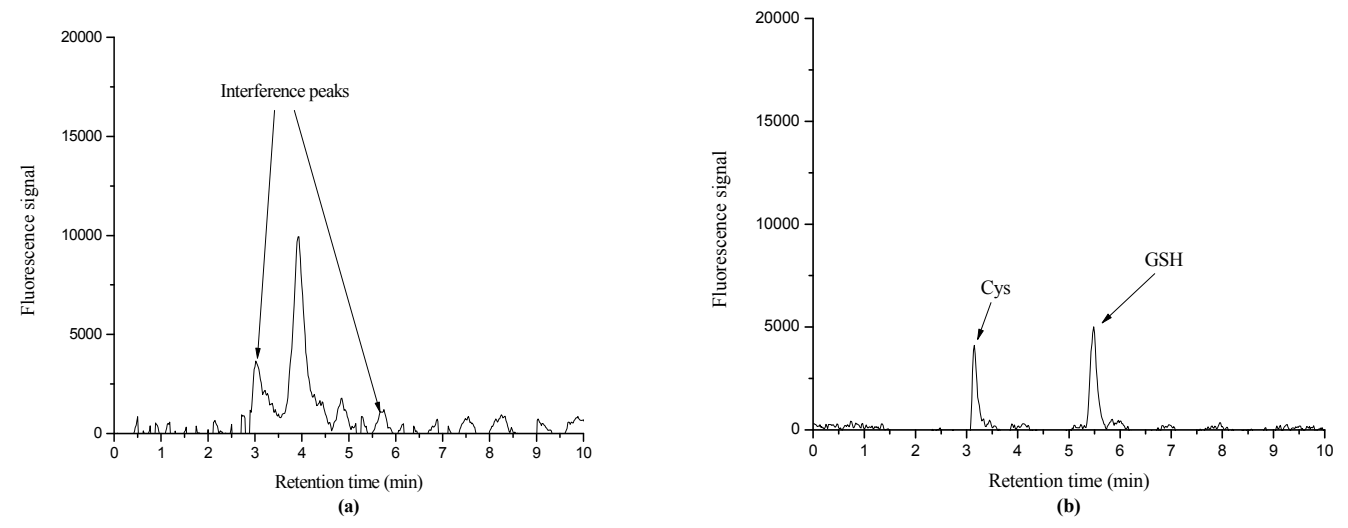

Figure 3.11 Chromatogram of a blank solution containing $80 \mu \mathrm{L} 10 \%$ TCEP (a), showing two of the interference peaks having similar retention times with $100 \mathrm{nM}$ Cys and GSH derivatives (b).

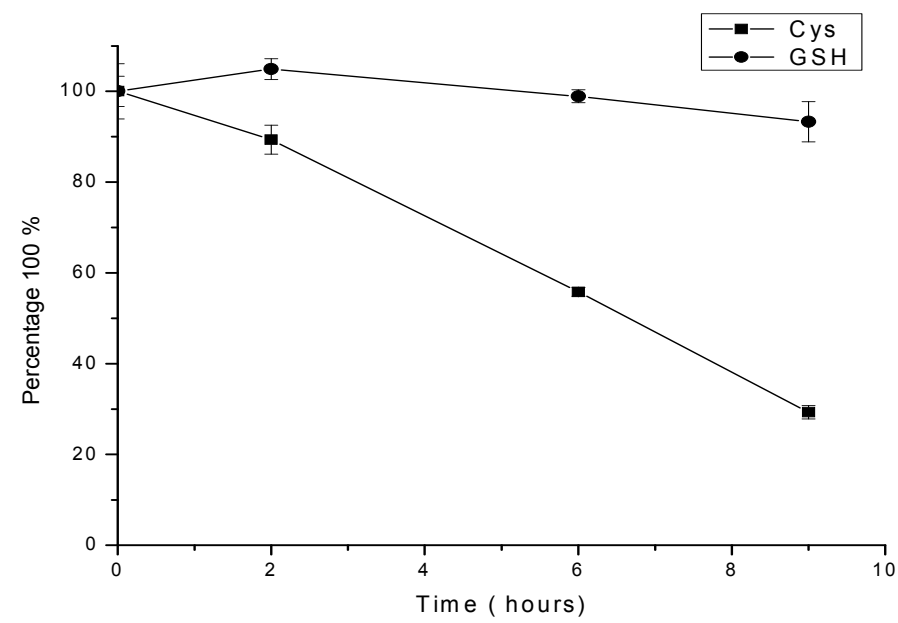

Figure 3.12 Stability tests of Cys and GSH (300 nM spiked in DDI water) under room temperature. 


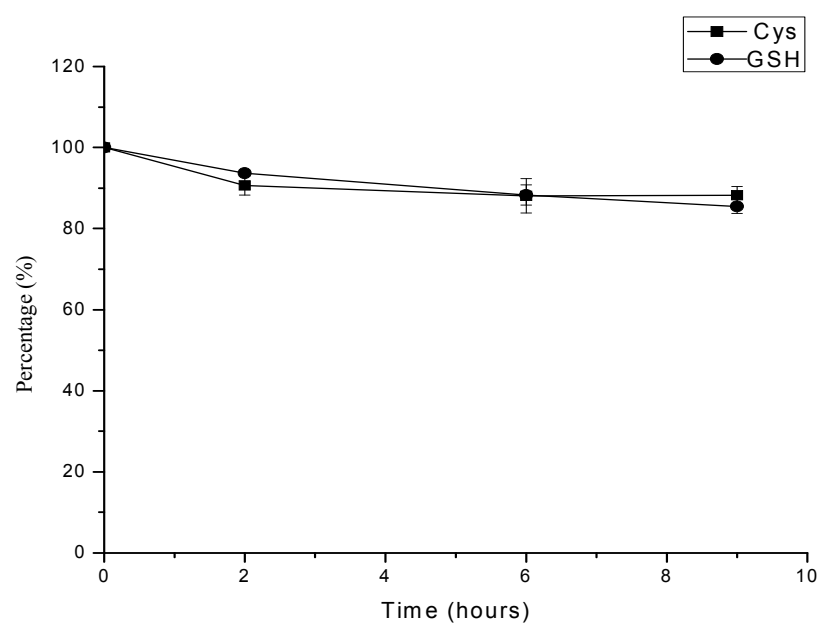

Figure 3.13 Stability tests of Cys and GSH (300 nM spiked in DDI water) under ice condition.

\subsubsection{Preconcentration Using Covalent Affinity Column}

Preconcentration of thiols was first performed by using a covalent affinity column packed with thiopropyl sepharose gel. The sample loading rates were set up at 0.5 and 1 $\mathrm{mL} / \mathrm{min}$ for inlet and outlet, respectively. The different flow rate settings were required because of the resistance caused by the presence of gel in the column. The reducing reagent used to release thiols from column was TCEP. Preconcentration for Cys spiked at $200 \mathrm{nM}$ in DIW using covalent affinity column was compared at room temperature and under ice condition. It seems that the recovery obtained under ice condition was higher than that at room temperature $(67 \%$ under room temperature and $75 \%$ under ice condition), suggesting that Cys might be partially oxidized during the preconcentration step.

Typical chromatograms of the method blank and the SBD-F derivatives of Cys and GSH using covalent affinity column preconcentration were showed in Figure 3.14. A 
large interference peak was observed at retention time of 4 to $4.5 \mathrm{~min}$ for the blank (Fig. 3.14 a). The interference is believed to come from the byproduct of the reaction between activated thiopropyl sepharose 6B and TCEP. The 2-pridyl disulfide produced during the reaction (Fig. 3.15a) could react with SBD-F, form a new compound (Fig.3.15b), which could have fluorescence at similar excitation and emission wavelengths as the derivatives of Cys and GSH. Since the appearance of this peak did not interfere with the analysis of Cys and GSH, efforts were not made to further figure out the identity of the interference using molecular mass spectrometry (Fig 3.15).

The mixed solution of Cys and GSH $(200 \mathrm{nM})$ was preconcentrated by covalent affinity column and eluted with $5 \mathrm{~mL}$ of $1 \%$ tris 2-carboxyethyl phosphine. Recoveries obtained were 56\% for Cys and 53\% for glutathione. The low recoveries for both Cys and GSH were largely resulted from the inefficient bonding of thiols on the column. It could be confirmed by the presence of significant amount of thiols $(\sim 50 \%)$ in the sample after passing through the column. Several efforts were made to improve the bonding efficiency. Cysteine and GSH were prepared in the bonding buffer (0.05 M phosphate buffer, $\mathrm{pH}$ 7.4) instead of DIW in order to maintain a consistent $\mathrm{pH}$ during the course of the experiments. Standard loading speed was changed from 1 to $0.5 \mathrm{~mL} / \mathrm{min}$ in an effort to increase the contact time of thiols with the gel. However, recoveries of thiols were not significantly improved. 

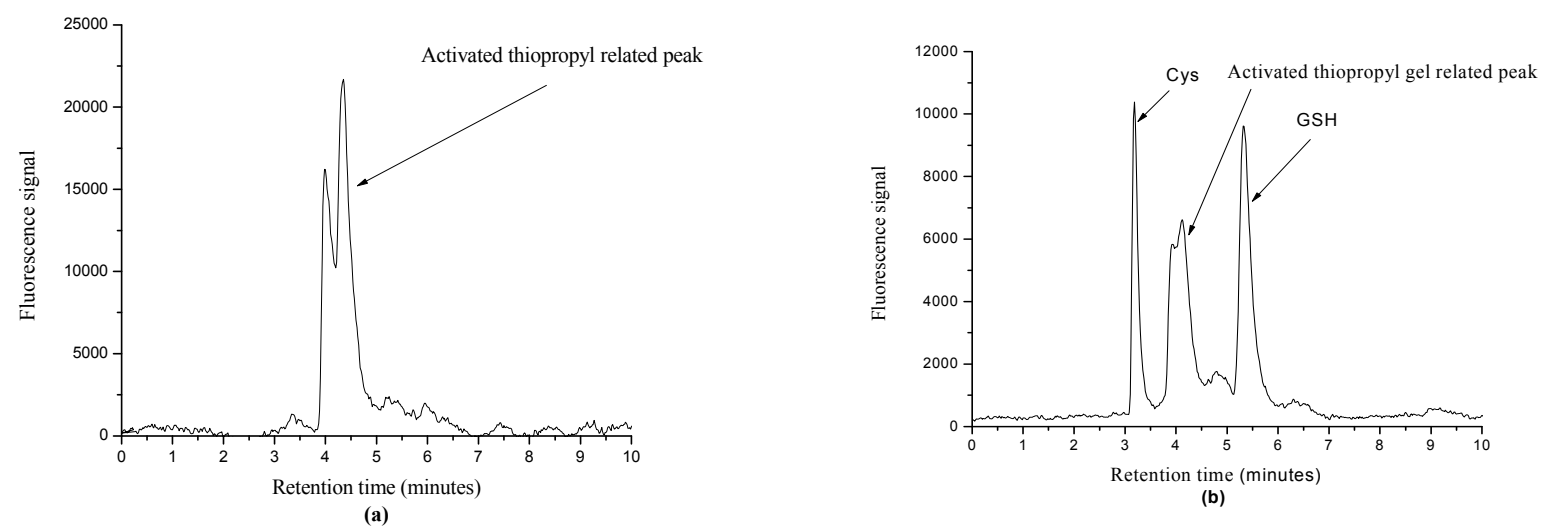

Figure 3.14 Typical chromatograms of the procedure blank (a), and Cys and GSH spiked in DIW at $200 \mathrm{nM}$ (b), followed by covalent affinity column preconcentration, elution with TCEP, SBD-F derivatization, and HPLC-FL detection.<smiles>CC(C)CP(=O)(CC(=O)O)CC(=O)O</smiles>

(a)

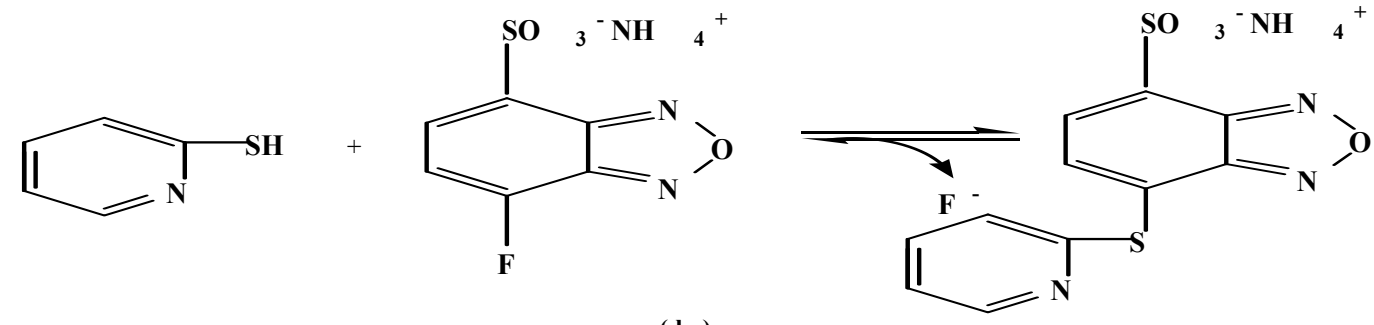

(b )

Figure 3.15 The schemes for the reactions (a) between TCEP and activated thiopropyl sepharose gel, and (b) the proposed reaction between SBD-F and 2-pridyl disulfide produced in scheme (a). 


\subsubsection{Preconcentration of Thiols Using Covalent Affinity Solid Phase Extraction}

The major purpose of using the affinity solid phase extraction instead of the affinity column setting was to improve the recovery of thiols. The procedure of using affinity solid phase extraction is also more suitable for field application, where rapid sampling and preconcentration is crucial. Samples were mixed with the activated thiopropyl gel immediately when using affinity solid phase extraction, while loading the samples onto the affinity column could take a few hours. In order to efficiently elute thiols, the recoveries of Cys and GSH spiked in DIW at $200 \mathrm{nM}$ were compared using vortex for 5 min, ultrasonication for $30 \mathrm{~min}$, and orbital shaking for $30 \mathrm{~min}$ (Table 3.1). The recovery can reach $64 \%$ for $\mathrm{GSH}$ and $44 \%$ for Cys by using $250 \mu \mathrm{L}$ of $2 \%$ TCEP using orbital shaking. Lower recoveries were obtained for both GSH and Cys when vortex and ultrasonication were used. The orbital shaking was chosen in the following experiments.

The amount of TCEP used to release thiols from the gel is determined by the thiol releasing efficiency and the ratio of TCEP and SBD-F during the derivatization step. In other words, sufficient amount should be used to make sure thiols are released, while at the same time maintaining TCEP as low as possible to reduce the interference caused by the presence of TCEP for the HPLC analysis. Listed in Table 3.6 are the results for the analysis of Cys spiked in DIW at $200 \mathrm{nM}$ using $500 \mu \mathrm{L}$ of $1 \%$ or $50 \mu \mathrm{L}$ of $10 \%$ TCEP (different concentration, but same amount of TCEP) as releasing reagent. The results showed that similar results were obtained for 10 or $1 \%$ TCEP (Table 3.2). Higher concentration and low volume were preferred because a small volume of solution was obtained during the thiol releasing step, which could provide more options in terms of selecting dilution factors used in the following derivatization reaction with SBD-F. 
Using the optimized parameters, the recoveries of Cys and GSH (10 nM spiked in DIW) were evaluated using the covalent affinity solid phase extraction method. The volume of the initial solution containing Cys and GSH was $12.5 \mathrm{~mL}$ and the final volume after elution using TCEP was $2.5 \mathrm{~mL}$, meaning that the concentration factor was 5 . The thiol enriched gel was mixed with $50 \mu \mathrm{L} 10 \%$ TCEP under vortex for 2 min and then were shaken on the orbital shaker for $30 \mathrm{~min}$. The supernatant was separated and the residue was mixed with $50 \mu \mathrm{L} 10 \%$ TCEP again and the same elution procedure was reapplied. The overall recoveries of Cys and GSH were 84 and 91\%, respectively after eluting twice (Table 3.3). Satisfactory recoveries obtained for both Cys and GSH from spiked DIWusing the covalent affinity solid phase extraction method suggested that this method has the potential to be used for thiol preconcentration in real environmental water samples.

Table 3.1 Comparisons of using $2 \%$ TCEP $(250 \mu \mathrm{L})$ and different shaking methods (vortex, ultrasonic, and orbital shaking) to elute GSH and Cys enriched with affinity solid phase extraction $(\mathrm{N}=3)$.

\begin{tabular}{ccc}
\hline & \multicolumn{2}{c}{$\begin{array}{c}\text { Recovery } \\
(\%)\end{array}$} \\
\hline Eluting method & Cys & GSH \\
\hline Orbital shaking & $44 \pm 4$ & $64 \pm 5$ \\
Ultrasonic & $35 \pm 4$ & $44 \pm 7$ \\
Vortex & $41 \pm 2$ & $58 \pm 2$ \\
\hline
\end{tabular}


Table 3.2 Recoveries of Cys spiked in DIW at $200 \mathrm{nM}$ using 1\% TCEP (500 $\mu \mathrm{L})$ or 10\% TCEP $(50 \mu \mathrm{L})$ as releasing reagent $(\mathrm{N}=3)$. The sample was preconcentrated with $0.1 \mathrm{~g}$ activated thiopropyl gel from 10 to $2 \mathrm{~mL}$.

\begin{tabular}{ccc}
\hline $\begin{array}{c}\text { TCEP concentration } \\
(\%)\end{array}$ & $\begin{array}{c}\text { Volume } \\
(\mu \mathrm{L})\end{array}$ & $\begin{array}{c}\text { Recovery } \\
(\%)\end{array}$ \\
\hline 10 & 50 & $66 \pm 8$ \\
1 & 500 & $60 \pm 5$ \\
\hline
\end{tabular}

Table 3.3 Recoveries of thiols in DIWspiked with $10 \mathrm{nM}$ Cys and GSH using activated thiopropyl gel preconcentrated and analyzed by HPLC-FL $(\mathrm{N}=3)$. Two consecutive

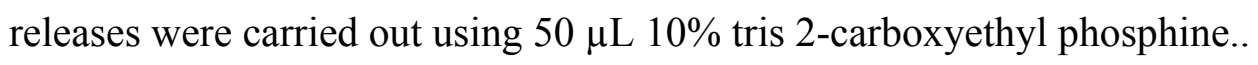

\begin{tabular}{ccccc}
\hline \multicolumn{2}{c}{ Cys } & \multicolumn{2}{c}{ GSH } \\
\hline & $\begin{array}{c}\text { Recovery } \\
(\%)\end{array}$ & $\begin{array}{c}\text { Total recovery } \\
(\%)\end{array}$ & $\begin{array}{c}\text { Recovery } \\
(\%)\end{array}$ & $\begin{array}{c}\text { Total recovery } \\
(\%)\end{array}$ \\
First & $40 \pm 4$ & 84 & $42 \pm 3$ & 91 \\
Second & $44 \pm 5$ & & $49 \pm 4$ & \\
\hline
\end{tabular}

\subsubsection{Figures of Merit}

The calibration curves showed good linearity for both Cys and GSH in the range of 25 to $500 \mathrm{nM}$ (Fig 3.16). The coefficients of correlation $\left(\mathrm{R}^{2}\right)$ between the amounts of the thiol-SBD derivatives and observed peak heights were 0.9988 and 0.9998 for Cys and GSH, respectively. The sensitivity of SBD-GSH derivatives was higher than SBD-Cys, 
agreeing with some earlier published results (Andrews et al. 1982; Tang et al. 2000). It could be attributed to the fact that GSH is much more stable than Cys at room temperature (see 3.4.4 for more details). A typical chromatogram for $50 \mathrm{nM}$ standard derivatives is shown in Fig 3.17. Each SBD-thiol derivative exhibited a sharp and symmetric peak and good separation from each other.

The method limits of detection (LODs) were calculated based on 3 times of the standard deviation for the analysis of $10 \mathrm{nM}$ Cys and GSH standards. The standard solution was preconcentrated by affinity chromatography solid extraction from 25 to 2.5 $\mathrm{mL}$ and analyzed by HPLC-FL $(\mathrm{N}=6)$. The LODs achieved were 0.45 and $0.36 \mathrm{nM}$ for Cys and GSH, respectively (Table 3.4). These LODs were much better than those obtained using HPLC-UV/Vis method.

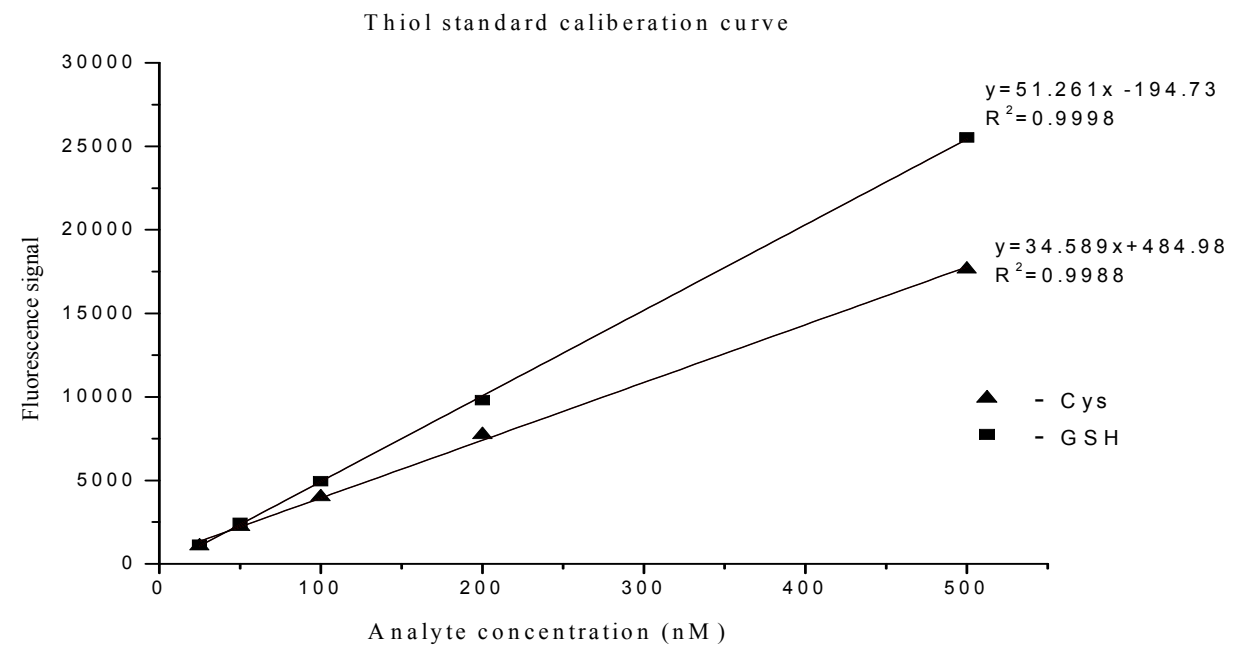

Figure 3.16 Calibration curves of Cys and GSH using HPLC-FL after derivatization with SBD-F. 


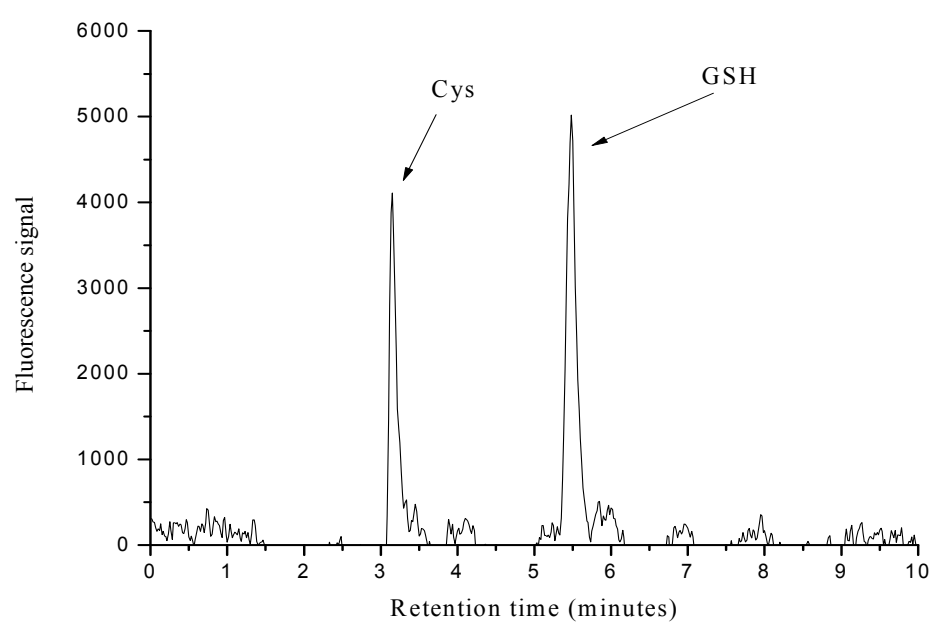

Figure 3.17 A typical chromatogram of the SBD-F derivatives of Cys and GSH analyzed by HPLC-FL. Thiol concentration was $100 \mathrm{nM}$.

Table 3.4 Limits of detection (LODs) calculated based on 3 times standard deviation for the analysis of $10 \mathrm{nM}$ Cys and GSH spiked in DDI water $(\mathrm{N}=6)$. The volume of the original standard solution was $25 \mathrm{~mL}$ and the final volume was $2.5 \mathrm{ml}$.

\begin{tabular}{ccc}
\hline & Cys & GSH \\
\hline $\begin{array}{c}\text { Instrumental detection limit } \\
(\mathrm{nM})\end{array}$ & 4.5 & 3.6 \\
$\begin{array}{c}\text { Method detection limit } \\
(\mathrm{nM})\end{array}$ & 0.45 & 0.36 \\
\hline
\end{tabular}

\subsubsection{Application for Real Sample Analysis Using Covalent Affinity Solid Phase}

\section{Extraction}

A surface water sample was collected at the depth of $\sim 20 \mathrm{~cm}$ from the surface from a small pond located at FIU using a $1 \mathrm{~L}$ Teflon bottle. In the laboratory, approximately 10 minutes, $12.5 \mathrm{~mL}$ was transferred into a $15 \mathrm{~mL}$ centrifuge tube containing $20 \mathrm{mg}$ of 
activated thiopropyl sepharose gel. The pond surface water was mixed with thiopropyl gel immediately by vortexing for $2 \mathrm{~min}$ and then shaken on an orbital shaker for 30 minutes. The tube was centrifuged under $10,000 \mathrm{rpm}$ for $10 \mathrm{~min}$ and supernatant was discarded. Tris 2-carboxyethyl phosphine $(50 \mu \mathrm{L} 10 \%)$ was added into the centrifuge tube and the mixture was vortexing for $2 \mathrm{~min}$ and then shaken for $30 \mathrm{~min}$. The resulted slurry was then diluted by adding $2.5 \mathrm{~mL}$ DIW and mixed homogenously by vortexing for 2 minutes. The mixture was centrifuged under $10,000 \mathrm{rpm}$ for $10 \mathrm{~min}$. The supernatant $(500 \mu \mathrm{L})$ was derivatized with SBD-F and analyzed by HPLC-FL following the procedures discussed above.

Both Cys and GSH were not detectable in the lake sample tested. In order to evaluate the recoveries for Cys and GSH in lake water, the water sample was spiked at 200 and 5 $\mathrm{nM}$ with Cys and GSH. The results indicate that the recoveries of Cys and GSH at $200 \mathrm{M}$ levels from the lake water sample were $70 \pm 4$ and $84 \pm 1 \%$, respectively. A lower recovery for Cys was observed due likely to the faster oxidation in comparison with GSH. Further experiments were conducted by spiking GSH in the lake water at $5 \mathrm{nM}$, a more realistic concentration level of thiols present in the environment. It was found that only $49 \pm 2.5 \%$ was recovered (Table 3.5 ). The low recovery was possibly attributed to the fact that GSH was not quantitatively eluted from the gel, similar to the results obtained with thiol standards. 
Table 3.5 Recoveries of Cys and GSH spiked at 0, 5, and $200 \mathrm{nM}$ in a pond water sample collected at FIU. The samples were processed with activated thiopropyl gel solid phase preconcentration and followed by TCEP elution and HPLC-FL analysis $(\mathrm{N}=3)$.

\begin{tabular}{ccc} 
& \multicolumn{2}{c}{ Recovery (\%) } \\
\cline { 2 - 3 } Thiol Concentrations Spiked & Cys & GSH \\
\hline No spike & UDL & UDL \\
$200 \mathrm{nM}$ & $70 \pm 4$ & $84 \pm 1$ \\
$5 \mathrm{nM}$ & NA & $49 \pm 2.5$ \\
\hline
\end{tabular}

UDL: below detection ( 0.45 and $0.36 \mathrm{nM}$ for Cys and GSH, respectively).

NA: experiment was not conducted.

\subsection{Conclusions}

A method was developed for thiols preconcentration in water samples using affinity covalent chromatographic column or solid phase extraction and analysis using HPLC-FL method. Thiopropyl sepharose 6B is very efficient for enrichment of Cys and GSH from water due to its unique affinity with thiols. Several reducing reagents have been evaluated for their application to release thiols from the thiopropyl sepharose gel. Tris 2carboxyethyl phosphine was found to be the more useful reagent for this purpose because it does not introduce interference for the separation and analysis of Cys and GSH. Compared to the column enrichment method, solid phase extraction offered some advantages, including fast complexation, enhanced elution, and easy application in the 
field. Under the optimized conditions, the detection limits of the method for Cys and GSH were 0.45 and $0.36 \mathrm{nM}$, respectively. The limitation of using chromatographic column for preconcentration of thiols is its low enrichment efficiency for thiols at low concentration. The limitation of solid phase extraction is that two consecutive elution steps with TCEP are required to obtain a reasonable recovery for both Cys and GSH. In addition, the maximum enrichment factor achieved in this study was 10 for both Cys and GSH, limiting its use for thiol analysis at trace levels. 


\section{Chapter IV}

\section{EFFECTS OF REDUCED ORGANIC SULFUR ON DISSOLUTION OF MERCURY SULFIDE}

\subsection{Introduction}

\subsubsection{Mercury Sulfide}

Mercury can occur in a variety of species (e.g., $\mathrm{HgS}, \mathrm{Hg}(\mathrm{II}), \mathrm{MeHg}, \mathrm{HgO}$ ) in the environment, among which mercury sulfide $(\mathrm{HgS})$ is a common and important species. As shown in Figure 4.1, under mildly reducing environments (e.g., in sediments), insoluble $\mathrm{HgS}$ can be readily formed and may be present as a dominant $\mathrm{Hg}$ species, because of the strong affinity of sulfide towards dissolved inorganic Hg (USEPA 2001). The most common forms of mercury sulfide in the natural environment are cinnabar (red) and metacinnabar (black) (Burkstaller et al. 1975). Although cinnabar is more stable than metacinnabar, metacinnabar can exist in various environmental settings. This is because of the stabilizing effect of impurities (e.g., Fe) on the metacinnabar crystal structure. Both forms of mercury sulfide have extremely low solubility, with the solubility product $\left(K_{s p}\right)$

being $10^{-36.8}$ and $10^{-36.4}$ for cinnabar and metacinnabar, respectively (Ravichandran et al. 1999; He et al. 2006). 


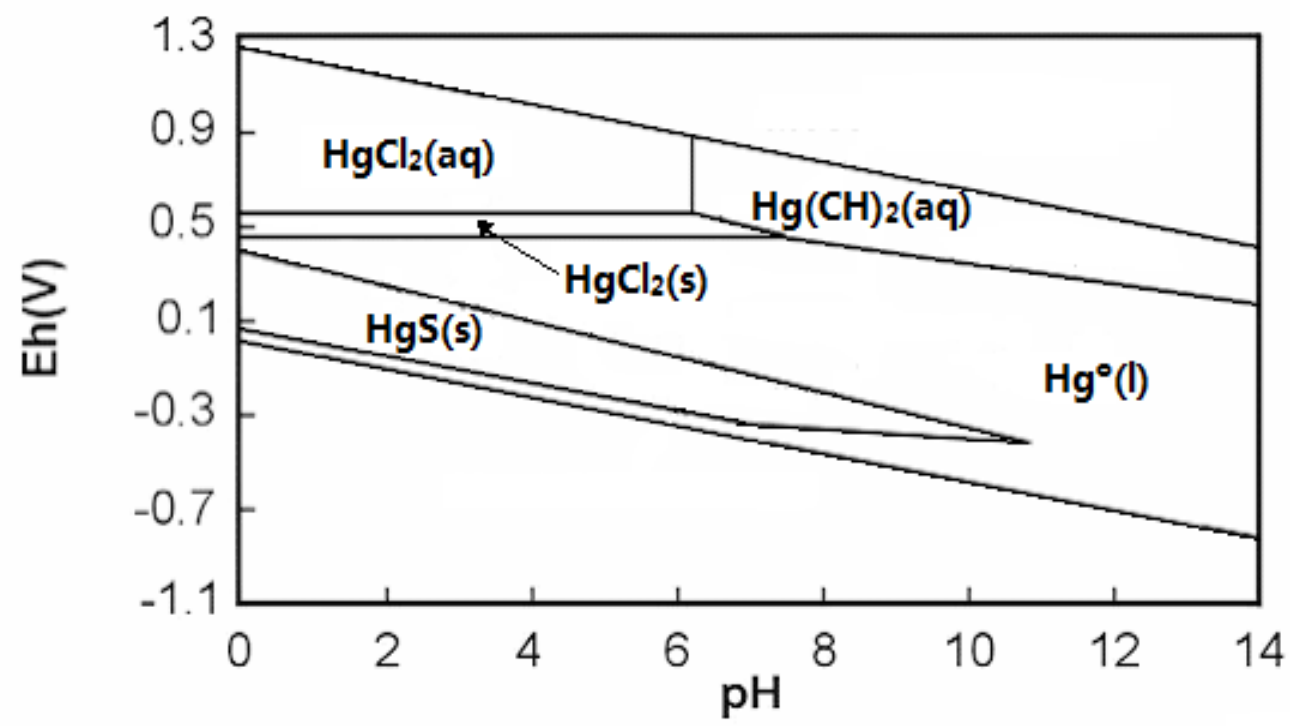

Figure 4.1 Mercury speciation under different Eh/pH conditions (adapted from a USEPA report) (USEPA 2001).

It has been postulated that $\mathrm{HgS}$ is one of the largest sinks for $\mathrm{Hg}$ in sediments, soils, and sulfuric waters (Barnett et al. 2001). Indeed, both spectroscopic determination and indirect extraction analyses have confirmed that $\mathrm{HgS}$ is the major fraction of $\mathrm{Hg}$ in sediments and soils in many Hg contaminated areas (Barnett et al. 1995; Barnett et al. 1997; Slowey et al. 2005). For instance, in Hg-contaminated flood plains and soils of the East Fork Poplar Creek (EFPC) in the Oak Ridge Reservation (ORR) area, where large amounts of $\mathrm{Hg}$ were historically discharged, metacinnabar occurs in primary deposits (NCEDR 1996; Han et al. 2006). Likewise, the predominant Hg species in wastes at $\mathrm{Hg}$ mine sites are primary cinnabar in discarded low-grade ore, and secondary metacinnabar in tailings (Kim et al. 2000; Kim et al. 2003; Kim et al. 2004). At the Carson River Superfund Site, Nevada, $\mathrm{Hg}$ dissolved out of anthropogenic $\mathrm{Hg}-\mathrm{Au}$ amalgams that were formed during gold mining can reprecipitate as authigenic metacinnabar (Holley et al. 
2007). Even in the Florida Everglades which receives $\mathrm{Hg}$ input primarily from atmospheric deposition rather than industrial $\mathrm{Hg}$ discharge, precipitation of metacinnabar has been documented (Ravichandran et al. 1999). Because of its insolubility, HgS in these areas has been suggested to act as a repository for $\mathrm{Hg}$, limiting the cycling of $\mathrm{Hg}$ in the environment.

\subsubsection{Dissolution of Mercury Sulfide}

Although the solubility products of $\mathrm{HgS}$ are extremely low, under certain natural and anthropogenic perturbations of environmental conditions, solid mercury sulfide ( $\mathrm{HgS})$ can undergo enhanced dissolution, releasing dissolved and particulate (primarily colloid) Hg species into the pore water of sediments and soils (Ravichandran et al. 1998; Tossell 1999; Barnett et al. 2001; Waples et al. 2005; Holley et al. 2007). These dissolved and colloidal $\mathrm{Hg}$ species may be available for $\mathrm{Hg}$ methylation in sediments and for $\mathrm{Hg}$ transport from soils to aquatic environments (Benoit et al. 2001 (a); Benoit et al. 2001 (b); Lowry et al. 2004; Slowey et al. 2005; Slowey et al. 2005). Therefore, cinnabar dissolution critically affects the fate and risks of $\mathrm{Hg}$ on ecosystems and humans.

The release of $\mathrm{Hg}$ to porewater from soil and sediment $\mathrm{HgS}$ is often caused by ligand-promoted dissolution of $\mathrm{HgS}_{(\mathrm{s})}$ in the presence of such ligands as sulfide, polysulfides, and dissolved organic matter (DOM, e.g. humic substances) (Paquette and Helz 1995; Paquette and Helz 1997; Ravichandran et al. 1998; Ravichandran et al. 1999; Jay et al. 2000; Jay et al. 2002; Ravichandran 2004; Waples et al. 2005). Strong complexation of $\mathrm{Hg}(\mathrm{II})$ with DOM can impact the efficiency of $\mathrm{HgS}_{(\mathrm{s})}$ in immobilizing Hg (Ravichandran et al. 1998; Cai et al. 1999; Ravichandran et al. 1999; Barnett et al. 2001; Waples et al. 2005; He et al. 2007; Holley et al. 2007). In anoxic experiments, 
Ravichandran et al. (1999) showed that $\beta-\mathrm{HgS}$ precipitation was inhibited by DOM. Furthermore, DOM enhances Hg release from cinnabar (Ravichandran et al. 1998; Waples et al. 2005), and measured Hg release rates in the presence of DOM ranged from $2.00 \times 10^{-2}$ to $6.19 \times 10^{-1} \mu \mathrm{mol}(\mathrm{Hg}) \mathrm{mg}\left(\mathrm{C}^{-1} \mathrm{~m}^{-2} \mathrm{day}^{-1}\right)$ (Waples et al. 2005). A large increase in the solubility of cinnabar in the presence of polysulfides, which were formed through the reaction of $\mathrm{S}(-\mathrm{II})$ with $\mathrm{S}(0)$ at neutral to basic $\mathrm{pH}$, was observed, particularly at high pH (Jay et al. 2000).

In addition to (poly) sulfide and DOM, other factors, such as Fe(III), chloride $\left(\mathrm{Cl}^{-}\right)$, and dissolved oxygen (DO), may also induce $\mathrm{HgS}$ dissolution. In the presence of $\mathrm{Fe}(\mathrm{III})$ (hydr)oxides, S(-II) is rapidly oxidized, with the dominant product being elemental sulfur [S(0)] (Pyzik and Sommer 1981; Poulton et al. 2004). The oxidative dissolution of HgS can significantly release Hg into solution from cinnabar (Burkstaller et al. 1975). The presence of $\mathrm{FeCl}_{3}$ was observed to enhance solubility of both cinnabar and metacinnabar (Mikac et al. 2002; Mikac et al. 2003). The enhancing effect of $\mathrm{FeCl}_{3}$ on $\mathrm{HgS}$ dissolution could be caused either by $\mathrm{Fe}(\mathrm{III})$, or by $\mathrm{Cl}^{-}$, which can form dissolved complexes with $\mathrm{Hg}$, or by both (Mikac et al. 2003). Indeed, the addition of very low levels of chloride to concentrated $\mathrm{HNO}_{3}$ provoked partial $\left(\mathrm{Cl}^{-}>10^{-4} \mathrm{M}\right)$ or even total dissolution $\left(\mathrm{Cl}^{-}>10^{-2} \mathrm{M}\right)$ of $\mathrm{HgS}_{(\mathrm{s})}$, confirming that chloride enhances dissolution of $\mathrm{HgS}$ (Mikac et al. 2003). The effect of DOM on enhanced dissolution of $\mathrm{HgS}$ has also been observed previously (Barnett et al. 2001; Holley et al. 2007).

\subsubsection{Role of Reduced Organic Sulfur in HgS Dissolution}

Reduced organic sulfur (organic compounds containing thiol group (-SH), ROS) is the most active form of sulfur in biological systems as well as in the environment. It was 
estimated that ROS could contribute up to $50-80 \%$ of total organic sulfur in organic-rich waters (Skyllberg 2008) and this fraction is expected to be higher in pore waters where conditions are conducive to ROS formation. Reduced organic sulfur has high affinity for mercury and can form strong complexes with mercury species, as evidenced by experimental data and theoretical calculations (Cestari and Airoldi 1997; Krezel and Bal 1999; Benoit et al. 2001 (a); Zhang et al. 2004). The strong interactions of ROS with mercury play an important role in controlling the speciation, mobility, bioavailability and reactivity of mercury in aqueous system (Ravichandran 2004; Wu et al. 2004; Miller et al. 2009).

Because of its strong affinity to complex $\mathrm{Hg}$, reduced organic sulfur may be an important factor that can affect $\mathrm{HgS}$ dissolution. In previous studies investigating $\mathrm{HgS}$ dissolution in the presence of DOM, cysteine, which was used for the purpose of comparison, was found to be able to enhance $\mathrm{HgS}$ dissolution. Also, the enhancing effect of $\mathrm{DOM}$ on $\mathrm{HgS}$ dissolution could be mechanistically related to the strong complexation of Hg with thiol groups present within the DOM used there (Vairavamurthy et al. 1997) . Despite the potentially important role of ROS in $\mathrm{HgS}$ dissolution, the effect of small ROS species on $\mathrm{HgS}$ dissolution has not been systematically investigated.

\subsection{Objective}

The objective of this research is to investigate the role of reduced organic sulfur, in particular low molecular weight thiol-containing amino acids (LMWTs) such as cysteine (Cys) and glutathione (GSH), and DOM on mercury sulfide dissolution. Two specific aims are to 1) quantify the (enhancing or inhibitory) effects of LMWTs and DOM on 
$\mathrm{HgS}$ dissolution, and 2) determine the distribution of mercury species during $\mathrm{HgS}$ dissolution in the presence of LMWTs or DOM.

\subsection{Experimental Section}

\subsubsection{Chemicals}

Cinnabar (red HgS, certified to be $>99.5 \%$ pure) was purchased as a natural mineral powder from Sigma-Aldrich. Before dissolution experiments, cinnabar was pretreated using a simple cleaning procedure. The surface of the cinnabar was cleaned by soaking with $1 \mathrm{M}$ hydrochloride acid (trace metal grade, Fisher) for 3 days and the solids were separated using a $0.45 \mu \mathrm{m}$ Millipore filter, followed by subsequent washing with distilled de-ionized (DDI) water. The solids were dried at $60{ }^{\circ} \mathrm{C}$ in the oven overnight and stored dry for later use.

Two LWMTs, L-Cysteine (> 99\%) and L-Glutathione (reduced, 98 - 100\%), were purchased from Sigma-Aldrich. Different types of dissolved organic matter were prepared by dissolving solid organic matter from different sources. Lignite-extracted humic acid was purchased from Sigma-Aldrich (AHA). Soil humic acid (1R107H, WHA) and fulvic acid (1R107F, WFA) extracted from Waskish peat were purchased from the International Humic Substances Society (IHSS).

Analytical grade potassium bromide $(\mathrm{KBr})$, potassium bromate $\left(\mathrm{KBrO}_{3}\right)$, stannous chloride and hydroxylamine hydrochloride were purchased from Sigma-Aldrich. All other chemicals used were analytical reagent-grade or higher. Argon (ultra high purity), helium gas and compressed air (ultra zero grade) were purchase from Airgas. Total mercury standard from Fisher was used as the primary standard to prepare calibration curves and mercury standard from AccuStandard was used as the secondary standard for 
instrumental performance check. Glass beads $(6 \mathrm{~mm}$ diameter) were purchased from Fisher Scientific.

\subsubsection{Instrumentation}

Cold vapor atomic fluorescence spectrometry (CVAFS, PS Analytical, 10.035 Millennium Merlin System) was used to analyze total mercury. A Barnstead Nanopure Diamond Lab Water System was used to produce DIW. Other ancillary equipment includes a water bath (NESLAB), an orbital shaker (Hernry Troemner LLC), a centrifuge (Fisher Scientific), a heating block (Environmental Express), an analytical balance (AG 204, Mettler Toledo), and an oven (PRECISION Economy, Precision Scientific). FluoroMax-3 (Jovin Yuon Horiba) was used for thiol detection.

\subsubsection{Procedures}

\subsubsection{Preliminary Experiments}

The dissolution experiments were designed to be performed by mixing HgS solids with solutions containing ROS or DOM. Preliminary experiments were first conducted to select appropriate methods for separation of $\mathrm{HgS}$ particles from solutions. Ten centrifugal tubes containing cinnabar $(20 \mathrm{mg}$ ) and glass beads (10 beads, $6 \mathrm{~mm}$ diameter) in $50 \mathrm{~mL}$ DDI water were wrapped with aluminum foil and continuously shaken for 144 hours. For separation of undissolved $\mathrm{HgS}$ particles from the solution, five tubes were centrifuged for $20 \mathrm{~min}$ at $9400 \mathrm{~g}$, while the suspensions $(10 \mathrm{~mL})$ from the other five tubes were filtrated through $0.22 \mu \mathrm{m}$ filters. The supernatants and filtrates were digested and analyzed for total $\mathrm{Hg}(\mathrm{THg})$ (see 4.3.3.5 for $\mathrm{THg}$ analysis procedures).

We planned to monitor the changes of thiol concentrations with time during the process of $\mathrm{HgS}$ dissolution. In consideration of the presence of possibly high 
concentrations of $\mathrm{Hg}$ (from $\mathrm{HgS}$ dissolution), we conducted experiments to check if the presence of $\mathrm{Hg}$ influences thiol analysis. We prepared $\mathrm{Hg}$-containing solutions by adding $20 \mathrm{mg}$ of $\mathrm{HgS}$ solids and glass beads into $50 \mathrm{~mL}$ of DDI water, shaking the suspensions for 144 hours, and filtering the suspensions through a 0.22 um filter. The concentrations of THg in the filtrates were determined. The filtrates were used to prepare a series of Cys ad GSH standards (from 0.2 to $10 \mu \mathrm{M}$ ). These thiol standards were derivatized by SBD-F and analyzed by fluorescence detection (see 3.3.3.3 for procedures) for thiol concentrations. Additional experiments were conducted by preparing thiol standards in $200 \mu \mathrm{g} / \mathrm{L}$ of $\mathrm{Hg}\left(\mathrm{NO}_{3}\right)_{2}$ solutions. Control experiments were performed using thiol standard prepared in DIW.

After checking the effect of $\mathrm{Hg}$ on thiol determination, experiments were conducted to monitor the changes of thiol concentrations with time during the process of $\mathrm{HgS}$ dissolution, as thiols (Cys and GSH) are not stable at room temperature. Glass beads and $\mathrm{HgS}$ solids (20 mg) were added to $50-\mathrm{ml}$ centrifugal tubes containing $10 \mu \mathrm{M}$ of Cys (or GSH) solutions and the tubes were shaken continuously. At regular intervals, an aliquot of suspension was collected, filtered, and analyzed for thiol concentration.

\subsubsection{Effect of ROS and DOM on HgS Dissolution (with Glass Beads)}

After preliminary experiments, I systematically conducted a series of experiments (see below) to investigate the effects of small ROS and DOM on HgS dissolution and the speciation of $\mathrm{Hg}$ species during $\mathrm{HgS}$ dissolution. The dissolution experiments were conducted under two different conditions: in the presence of glass beads, which were designed to represent the environmental conditions where severe perturbations (e.g., hurricanes and dredging) occur, and in the absence of glass beads, which represented 
natural conditions without vigorous mixing processes at the water-sediment interface. For all experiments, unless stated otherwise, the general operations included adding $20 \mathrm{mg}$ of $\mathrm{HgS}$ solids into $50 \mathrm{ml}$ of solutions, aluminum-foil wrapping to avoid light, keeping the suspensions continuously shaken at $200 \mathrm{rpm}$ under room temperature and approximately neutral $\mathrm{pH}$ (without adjustment), and filtration through a $0.22 \mu \mathrm{m}$ PVDF filter using a plastic syringe to separate the undissolved $\mathrm{HgS}$ solids from the solutions. All experiments were conducted in triplicate or duplicate (separated tubes).

For $\mathrm{HgS}$ dissolution in the presence of glass beads, 10 beads $(6 \mathrm{~mm}$ diameter) were added to each tube. The effect of GSH on $\mathrm{HgS}$ dissolution was investigated at $3 \mathrm{GSH}$ levels $(10,1$, and $0.2 \mu \mathrm{M})$, while two Cys concentrations (10 and $0.2 \mu \mathrm{M})$ were selected. The effect of DOM on HgS dissolution was studied by using AHA solutions with a DOC concentration of $22.5 \mathrm{mg} / \mathrm{L}$. A series of tubes containing $\mathrm{HgS}$, ROS (or DOM), and glass beads were prepared and placed on a shaker. At desired time intervals $(0,2,4,8,10,24$, $30,48,96,120$ and 144 hour), two tubes (as duplicate) were removed from the shaker and an aliquot of suspension $(10 \mathrm{~mL})$ was immediately taken from the tubes and filtered to stop the dissolution reaction. The filtrates were determined for THg. Control experiments were conducted by adding HgS to DIWand by using only DIW or ROS solutions, following the same procedures.

\subsubsection{Effect of ROS and DOM on HgS Dissolution (without Glass Beads)}

For $\mathrm{HgS}$ dissolution in the absence of glass beads, the experiments were conducted by mixing $\mathrm{HgS}$ solids with ROS or DOM solutions and shaking the suspensions for 72 hours, as prior experiments show that the dissolution of $\mathrm{HgS}$ (without or with ROS) could reach equilibrium approximately at 72 hours. The other procedures were basically same 
with the experiments in the presence of glass beads. The concentrations of Cys and GSH were set as 50,200,1000,5000, and $10000 \mathrm{nM}$, while the AHA was tested at 0.1125, 0.45, $2.25,11.25$, and $22.5 \mathrm{mgC} / \mathrm{L}$.

Additional experiments were performed to study the effect of DOM source on $\mathrm{HgS}$ dissolution, by using three different types of DOM, namely AHA, WHA, and WFA, following the same procedures. All DOM was prepared at the DOC concentration of 22.5 $\mathrm{mgC} / \mathrm{L}$.

\subsubsection{Speciation of Hg Species during HgS Dissolution}

The dissolved Hg determined in prior experiments was referring to $\mathrm{Hg}$ passing through a $0.22 \mu \mathrm{m}$ filter and it could include colloidal $\mathrm{Hg}$ (e.g., $\mathrm{HgS}$ colloids formed during ROSenhanced HgS dissolution) and truly dissolved Hg (e.g., Hg-ROS complexes formed through the complexation of the dissolute $\mathrm{Hg}$ and thiol groups). In order to further distinguish between these $\mathrm{Hg}$ species, a Microsep centrifugal filtration device with $3 \mathrm{kDa}$ molecular weight cutoff (MWCO) (Fig 4.2) was used to separate the dissolution sample into three fractions: colloidal $(0.22 \mu \mathrm{m}>$ colloidal $>3 \mathrm{kDa})$, colloids on the filter, truly dissolved $(<3 \mathrm{kDa})$. Truly dissolved mercury was defined as the mercury species that can pass through $3 \mathrm{kDa}$ membranes. 


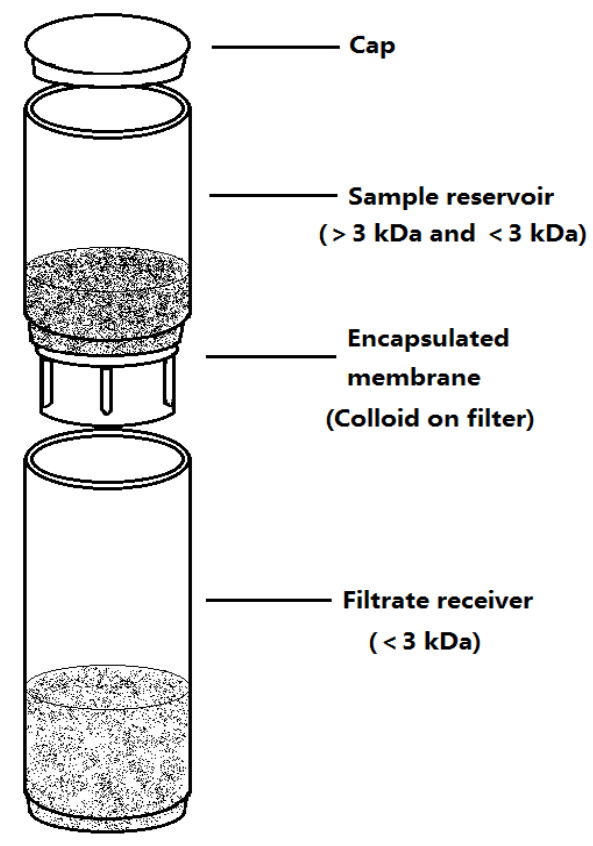

Figure 4.2 The separation of different dissolved fraction by using microsep centrifugal devices. Colloidal fraction is retained in sample reservoir and truly dissolved fraction $(<3$ $\mathrm{kDa})$ is retained in filtrate receiver.

The solutions obtained from the $\mathrm{HgS}$ dissolution in the presence of Cys $(10 \mu \mathrm{M})$, GSH $(10 \mu \mathrm{M})$, or AHA $(22.5 \mathrm{mgC} / \mathrm{L})$ without the addition of glass beads were examined using the centrifugal filtration devices for $\mathrm{Hg}$ speciation. After taking $10 \mathrm{~mL}$ of sample at 72 hours from the dissolution experiments and filtering the sample by using a $0.22 \mu \mathrm{m}$ syringe filter, $3 \mathrm{~mL}$ of the solutions were put into the sample reservoir of the microsep centrifugal devices and then centrifuged for 20 minutes at $7000 \times \mathrm{g}$. The volumes of the solutions remained in the sample reservoir and entering into the filtrate receiver were obtained by weighing the samples. After filtration, the solutions remained in the sample reservoirs were digested and analyzed for THg (see 4.3.3.5 for procedures), which represented the concentrations of colloidal and truly dissolved Hg. The solutions entering the filtrate receivers were digested 
and analyzed for the truly dissolved $\mathrm{Hg}$. The concentrations of the colloidal $\mathrm{Hg}$ were determined by the differences between these two fractions. In addition, some colloidal $\mathrm{Hg}$ particles could be deposited onto the encapsulated membranes of the centrifugal filtration devices during centrifugation. In order to determine the $\mathrm{Hg}$ colloids absorbed on the membranes, the whole filter was digested with aqua regia by adding $2 \mathrm{~mL}$ of aqua regia into the sample reservoir and the filtrate receiver, followed by placing the filter into a 50$\mathrm{mL}$ digest tube and shaking on an air bath shaker overnight ( $200 \mathrm{rpm}$, room temperature). After digestion, the solution was diluted with $1 \% \mathrm{HCl}$ and analyzed for THg.

In order to further characterize the speciation of the $\mathrm{Hg}$ dissoluted from $\mathrm{HgS}$, a series of additional experiments were conducted. These experiments include 1) solutions obtained from the GSH-enhanced $\mathrm{HgS}$ dissolution without glass beads were examined for $\mathrm{Hg}$ species, for the purpose of comparison; 2) Hg standards (100 ppb) were reacted with GSH (10 $\mu \mathrm{M})$ or AHA (22.5 $\mathrm{mgC} / \mathrm{L})$ and the mixtures were examined for $\mathrm{Hg}$ species using the similar procedures to check whether Hg-GSH (or Hg-AHA) complexes could pass through the 3 kDa MWCO membrane; 3) the solutions from HgS dissolution experiments (in the presence of GSH without glass beads) were separated for $\mathrm{Hg}$ species under $9400 \times \mathrm{g}$ centrifuge force, in addition to $7000 \times \mathrm{g}$; and 4) the reactivity of $\mathrm{Hg}$ species separated from cinnabar dissolution experiments were tested by directly analyzing (without digestion) the solutions for THg.

\subsubsection{Total Mercury Analysis}

In consideration of the presence of colloidal $\mathrm{Hg}$ and $\mathrm{Hg}$-complexes with ROS or DOM during $\mathrm{HgS}$ dissolution experiments, digestion procedures were performed before instrumental analysis of mercury. For the experiments studying the effects of ROS on 
$\mathrm{HgS}$ dissolution, a brominating digestion procedure was used. In this digestion procedure, $5 \mathrm{~mL}$ of sample solution (filtrates that passed through $0.22 \mu \mathrm{m}$ filters) were acidified (to $1 \% \mathrm{HCl}$ ) and placed in a $125-\mathrm{mL}$ Teflon bottle, which was placed in an ultraviolet cabinet for 12 hours and then allowed to cool. An aliquot of sample (usually $100 \mu \mathrm{L}$ ) was diluted with $1 \% \mathrm{HCl}$ to $40 \mathrm{~mL}$, to which $0.8 \mathrm{ml}$ of brominating reagent $(0.1 \mathrm{M} \mathrm{KBr}+$ $0.05 \mathrm{M} \mathrm{KBrO}_{3}$ ) were added for oxidation of $\mathrm{Hg}$ species. After one hour, $160 \mu \mathrm{L}$ of hydroxylamine hydrochloride aqueous solution $(12 \%, w / v)$ were added and the samples were allowed to settle for at least $10 \mathrm{~min}$ before analysis. For the experiments investigating the $\mathrm{Hg}$ speciation during $\mathrm{HgS}$ dissolution, an aqua regia digestion procedure was used, because of the limited sample volume for brominating digestion. In this aqua regia procedure, $0.5 \mathrm{~mL}$ of sample solution was digested with $0.5 \mathrm{~mL}$ of aqua regia for 20 min under intermittent shaking (room temperature) and the mixture was then diluted with $1 \% \mathrm{HCl}$ to $40 \mathrm{ml}$ for $\mathrm{Hg}$ analysis (additional dilutions were made, if necessary). I did not observe any systematic disparities between these two digestion procedures in $\mathrm{THg}$ analysis, when analyzing the same sample.

Total mercury concentration was analyzed by cold vapor atomic fluorescence spectrometry (CVAFS) (Bloom and Crecelius 1983; Bloom and Fitzgerald 1988), following the reduction of $\mathrm{Hg}^{2+}$ to $\mathrm{Hg}^{0}$ using stannous chloride and purging $\mathrm{Hg}^{0}$ into the detector with argon. Stannous chloride (2\% w/v) was prepared by adding $40 \mathrm{~g}$ of $\mathrm{SnCl}_{2}$ into $2000 \mathrm{~mL}$ DDI water containing $50 \mathrm{~mL}$ of $12 \mathrm{~N} \mathrm{HCl}$, followed by purging with argon for 20 minutes before analysis. The instrument was calibrated by a six-point mercury standard curve $(0,5,10,20,50$ and $100 \mathrm{ppt})$. All standards were prepared in $1 \% \mathrm{HCl}$ solution. All standards and samples were measured in duplicate. A second source working 
standard (50 ppt QC check solution) was measured in duplicate immediately after the standard curve. For the calibration range used here $(0-100 \mathrm{ppt})$, a good linear calibration curve was always obtained (Fig 4.3).

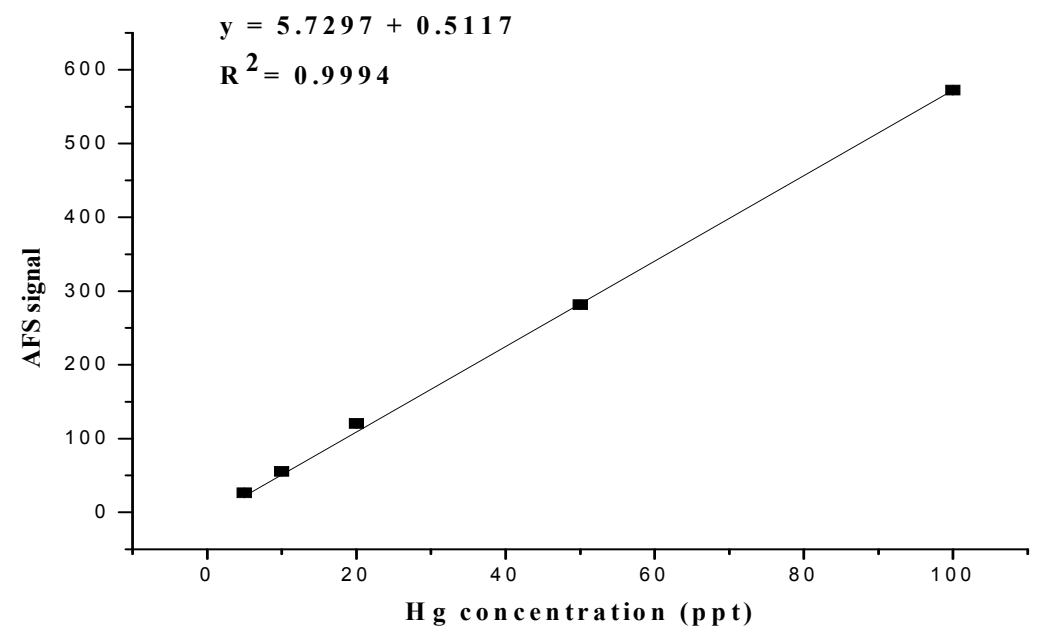

Figure 4.3 Typical calibration curve for mercury analysis using CVAFS.

\subsection{Results and Discussion}

\subsubsection{Preliminary Experiments}

Separation of HgS Solids from Solutions. There is no uniform definition for the dissolved $\mathrm{Hg}$ in the solutions of $\mathrm{HgS}$ dissolution, with filtration and centrifugation being two common methods for separation of dissolved $\mathrm{Hg}$ from undissolved $\mathrm{HgS}$ solids. I tested both methods and found that the $\mathrm{Hg}$ concentrations in the supernatants of centrifugation were about 30 -fold higher than in the filtrates of filtration $(0.22 \mu \mathrm{m})$ (Table 4.1). Filtration of $\mathrm{Hg}^{2+}$ standard solutions revealed that the adsorption of dissolved $\mathrm{Hg}^{2+}$ on the PVDF filters used here was negligible, indicating that the disparities in 
dissolved $\mathrm{Hg}$ concentrations between centrifugation and filtration were unlikely caused by the filter adsorption of Hg. Filtration of the supernatants obtained in the centrifugation step obtained similar results with the direct filtration of the original suspensions (Table 4.1). From these data, it appears that the centrifugation method used here (20 min at 9400 g) could not have some Hg-containing particles (larger than $0.22 \mu \mathrm{m}$ ) precipitated, leaving these $\mathrm{Hg}$-containing particles in the supernatants and resulting in much higher $\mathrm{Hg}$ concentrations in the supernatants, in comparison to the filtration. Therefore, the filtration method was adopted in this study.

Effect of $\mathrm{Hg}$ on Thiol Determination. The effect of $\mathrm{Hg}$ presence on thiol determination using SBD-F derivatization - fluorescence detection method was investigated by preparing thiol standards in the filtrates obtained from $\mathrm{HgS}$ dissolution, in the $\mathrm{Hg}^{2+}$ standard solutions, and in DIW. It was observed that the presence of $\mathrm{Hg}$ from $\mathrm{HgS}$ dissolution (at 115 or $338 \mathrm{ppb}$ ) had basically no effect on the determination of either Cys or GSH in the range 0.2 to $15 \mu \mathrm{M}$ (Fig 4.4 and 4.5). However, when thiols were prepared in the $\mathrm{Hg}^{2+}$ standard solutions, remarkable decreases in fluorescence responses were observed. In the presence of $1 \mu \mathrm{M}$ of $\mathrm{Hg}^{2+}$, thiols could not be detected when the concentrations of thiols were $1 \mu \mathrm{M}$ or lower (Table 4.2). At higher thiol concentrations (3 or $10 \mu \mathrm{M}$ ), thiols could be detected, but a large fraction of thiol (about $1.4 \mu \mathrm{M}$ for GSH and $2.2 \mu \mathrm{M}$ for Cys) was consumed by $\mathrm{Hg}$ and could not be accounted for. 
Table 4.1 Concentration of released mercury of cinnabar $(400 \mathrm{mgC} / \mathrm{L})$ in DDI water by different sampling method was compared. One group was sampled by $0.22 \mu \mathrm{m}$ filter; the other was centrifuged under $9400 \times \mathrm{g}$ for $20 \mathrm{~min}$ and stand still for next 8 hours then took supernatant.

\begin{tabular}{ccc}
\hline $\mathrm{N}=5$ & $\begin{array}{c}\text { Conc. } \\
(\mathrm{ppb})\end{array}$ & $\begin{array}{c}\text { RSD } \\
(\%)\end{array}$ \\
\hline Centrifuge & $4671 \pm 781$ & 16 \\
Filtration & $120 \pm 18$ & 14 \\
$200 \mathrm{ppb} \mathrm{Hg} \mathrm{STD} \mathrm{filtration}$ & $227 \pm 0.4$ & 0.2 \\
\hline
\end{tabular}

Because of its extremely high affinity towards thiols, $\mathrm{Hg}^{2+}$ is expected to form strong complexes with thiols. These Hg-thiol complexes could remain inert during the SBD-F derivatization step and prevent the release and detection of thiols, resulting in lower response of thiols in the $\mathrm{Hg}^{2+}$ standard solutions, as we observed here. The result was in agreement with previous studies which have reported thiol-metal complexes might not react with the fluorescent tag in the absence of reducing reagent tributylphosphine (TBP) (Tang et al. 2000). The dissolved $\mathrm{Hg}$ from $\mathrm{HgS}$ dissolution had no influence on thiol determination, probably because it was not in the form of $\mathrm{Hg}^{2+}$. From the solubility product of $\mathrm{HgS}$, it is unlikely that the dissolution of $\mathrm{HgS}$ in DIW would produce the dissolved $\mathrm{Hg}^{2+}$ at the concentrations we determined ( $\left.>100 \mathrm{ppb}\right)$. The dissolved $\mathrm{Hg}$ we determined from $\mathrm{HgS}$ dissolution could be in the form of colloidal particles rather than 
truly dissolved $\mathrm{Hg}^{2+}$ form (as evidenced in 4.4.4, see below). This colloidal $\mathrm{Hg}$ could not react with thiol to form strong complex and thus did not affect thiol analysis (Fig 4.4 and 4.5).

Table 4.2 Cysteine and glutathione reacted with 200 ppb Hg standard were analyzed by SBD-F derivatization with fluorescence detection

\begin{tabular}{|c|c|c|c|}
\hline & $\begin{array}{l}\text { Thiol conc. } \\
\text { (nM) }\end{array}$ & $\begin{array}{l}\text { Detected conc. } \\
(\mathrm{nM})\end{array}$ & $\begin{array}{l}\text { Consumed conc. } \\
(\mathrm{nM})\end{array}$ \\
\hline \multirow[t]{4}{*}{$\mathrm{GSH}+\mathrm{Hg}$} & 500 & No & 500 \\
\hline & 1000 & No & 1000 \\
\hline & 3000 & 1589 & 1411 \\
\hline & 10000 & 8547 & 1453 \\
\hline \multirow[t]{4}{*}{$\mathrm{Cys}+\mathrm{Hg}$} & 500 & No & 500 \\
\hline & 1000 & No & 1000 \\
\hline & 3000 & 700 & 2300 \\
\hline & 10000 & 7552 & 2448 \\
\hline
\end{tabular}

Changes of Thiol Concentrations during HgS Dissolution. When monitoring the thiol concentrations during $\mathrm{HgS}$ dissolution, it was found that Cys (10 $\mu \mathrm{M}$ levels) was depleted quickly and almost undetectable at 120 hours (Fig 4.6). For the GSH experiment, we added another $10 \mu \mathrm{M}$ of GSH at 72 hours (in addition to the initial addition of $10 \mu \mathrm{M}$ ). The depletion of GSH was observed following both additions of GSH (Fig 4.7). The 
depletion of thiols could be caused by the oxidization of thiols during the experiment time interval, since both thiols were observed unstable, even when prepared in DDI water only. These results suggested the importance of documenting the concentrations of thiols and/or specifying the methods for thiol addition (initial, multiple, or continuous).

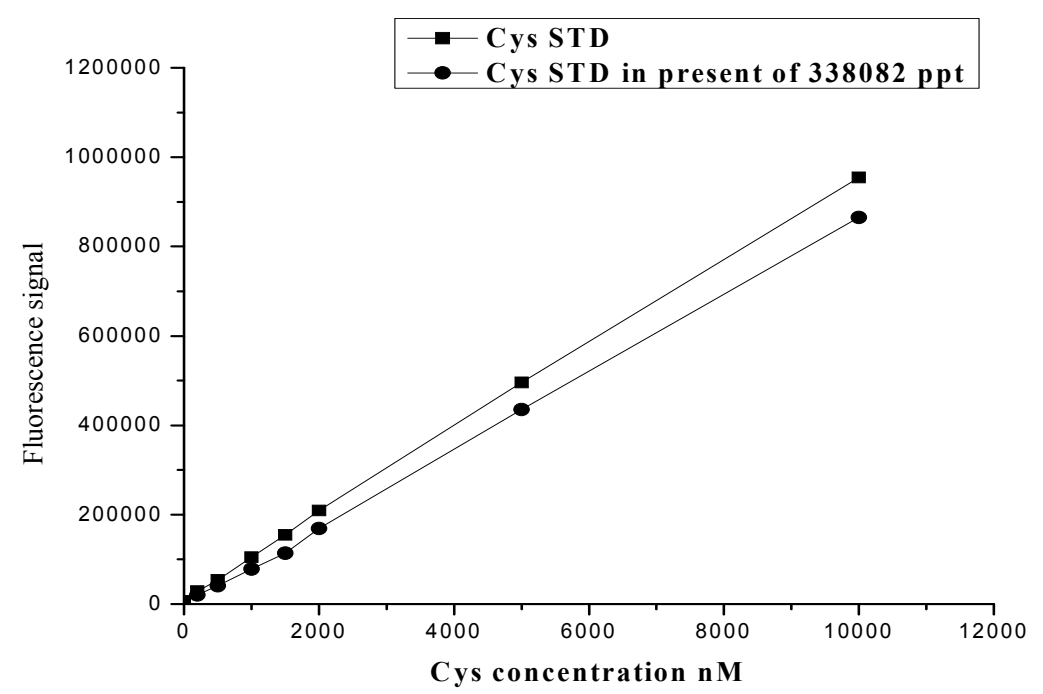

Figure 4.4 Cysteine STD and mix solution of cysteine STD and $338 \mathrm{ppb} \mathrm{Hg}$ ( $\mathrm{HgS}$ dissolution) analyzed by SBD-F derivatization with fluorescence detection. 


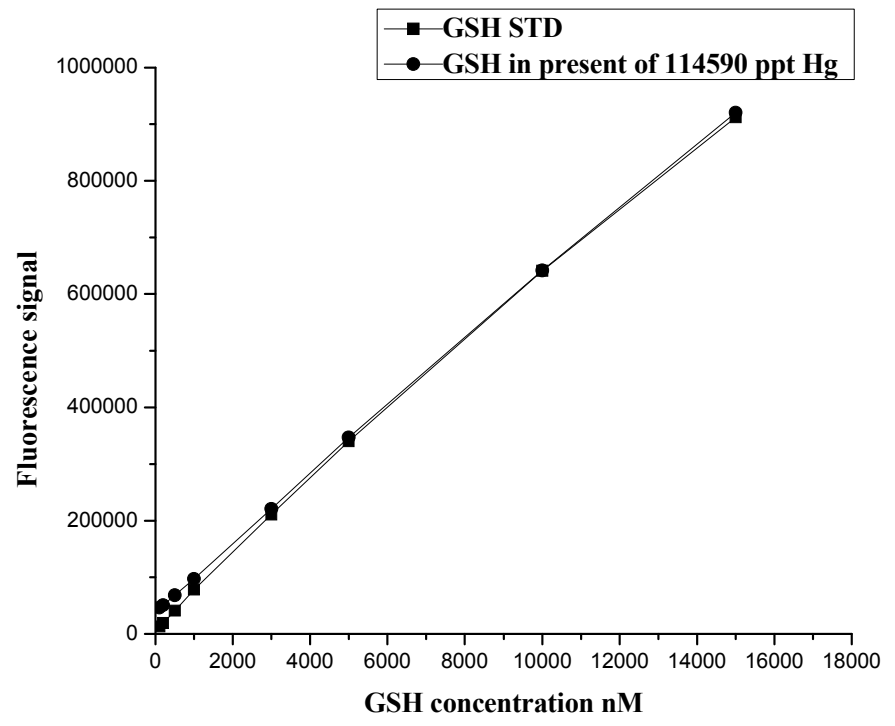

Figure 4.5 Glutathione STD and mix solution of glutathione STD and $115 \mathrm{ppb} \mathrm{Hg}(\mathrm{HgS}$ dissolution) analyzed by SBD-F derivatization with fluorescence detection.

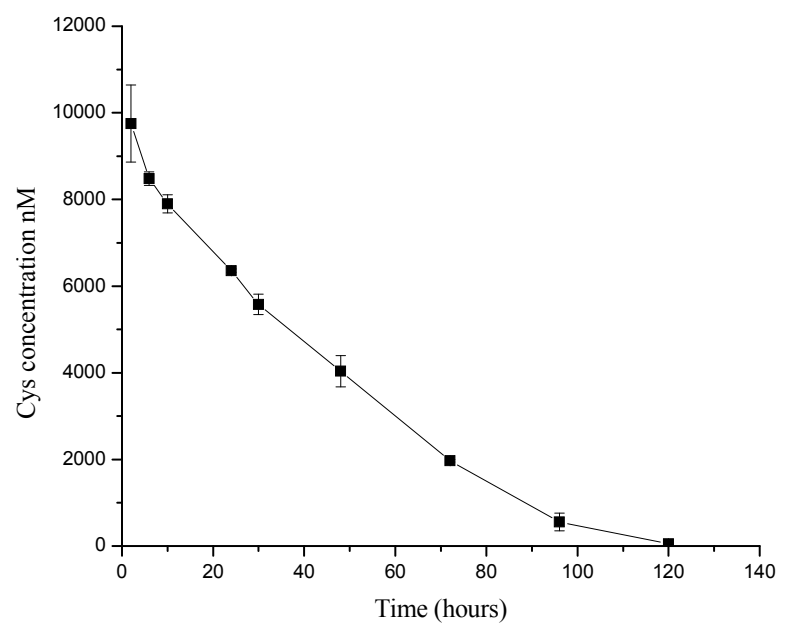

Figure 4.6 The kinetic data of $10 \mu \mathrm{M}$ Cys during the $\mathrm{HgS}(400 \mathrm{mg} / \mathrm{L})$ dissolution experiment. 


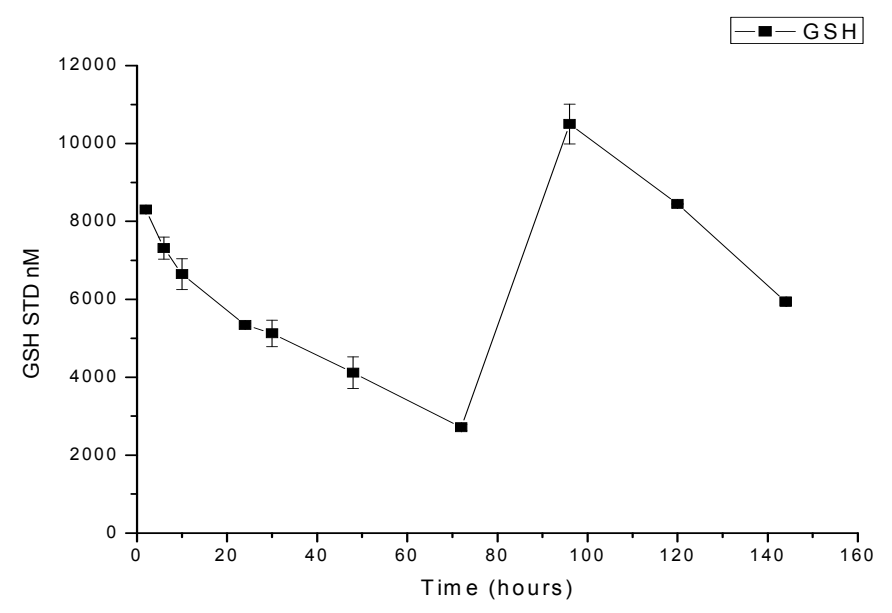

Figure 4.7 Kinetic data of GSH during the $\mathrm{HgS}(400 \mathrm{mg} / \mathrm{L})$ dissolution experiment. At initial, $10 \mu \mathrm{M}$ GSH was spiked into test tube. Another $10 \mu \mathrm{M}$ glutathione was added to test tube at 72 hours.

\subsubsection{Effects of ROS and DOM on HgS Dissolution (with Glass Beads)}

Enhancing Effect of ROS and DOM on HgS Dissolution. Experiments were first performed to investigate the effect of ROS (GSH and Cys, both initially added at $10 \mu \mathrm{M}$ and added again at 72 hours) and DOM (AHA, initially added at $22.5 \mathrm{mgC} / \mathrm{L}$ ) on $\mathrm{HgS}$ dissolution in the presence of glass beads. The kinetic data showed that $10 \mu \mathrm{M}$ Cys and GSH had significantly enhanced the dissolution of cinnabar (Fig 4.9 and 4.10). The dissolution of $\mathrm{HgS}$ was rapid at the initial 30 hours and reached nearly steady state afterwards. Rapid dissolution at initial stage is common for mineral dissolution experiment (Lasaga 1984; Barnett et al. 2001). When reaching equilibrium, the released mercury was similar for Cys and GSH (about 600 - 700 ppb).

For AHA, enhancing effect and rapid dissolution of $\mathrm{HgS}$ at initial period were also observed (Fig 4.11). Unlike small thiols, AHA enhanced the dissolution of $\mathrm{HgS}$ during 
the entire course of the experiment (up to 7 days), although $\mathrm{HgS}$ dissolution became slow after 30 hours. This result agrees with the work of Ravichandran et al. who reported that the dissolution rate of $\mathrm{HgS}$ in the presence of DOM reached nearly steady state after 7 days (Ravichandran et al. 1998). At the end of the experiment, AHA, through reacting with cinnabar, produced a significant amount of dissolved mercury (around $800 \mathrm{ppb}$ ) (Fig 4.11). This result was comparable to the dissolution of $\mathrm{HgS}$ in the presence of hydrophobic fractions of some aquatic DOM (22.5 $\mathrm{mgC} / \mathrm{L})$ in which the dissolved $\mathrm{Hg}$ was near 800 ppb after 7 days (Ravichandran et al. 1998).

HgS Dissolution at Low Concentrations of ROS. The concentration effect of ROS on $\mathrm{HgS}$ dissolution was studied by varying the concentrations of GSH or Cys. For GSH, 1 and $0.2 \mu \mathrm{M}$ of GSH were added initially at the beginning of experiment and it was found that at both levels, GSH could enhance the dissolution of $\mathrm{HgS}$. The dissolution effect appeared only before 24 hours, and after that time, the dissolved $\mathrm{Hg}$ decreased quickly to the $\mathrm{HgS}$ background level (HgS dissolution in DIW) (Fig 4.8). For Cys, the initial addition of $0.2 \mu \mathrm{M}$ of Cys did not increase the dissolution of $\mathrm{HgS}$ (4.12). Further experiments conducted by adding $0.2 \mu \mathrm{M}$ of Cys at regular time intervals $(0,2,4,6,10$, $24,26,28,30,46,48$ and 52 hours) indicate that continuous addition of Cys, even at low level $(0.2 \mu \mathrm{M})$, would enhance the dissolution of $\mathrm{HgS}$ (Fig 4.13). These results suggested that, probably due to the quick oxidation of thiols, an initial single addition of thiols at low concentrations, would have limited effect on $\mathrm{HgS}$ dissolution. 


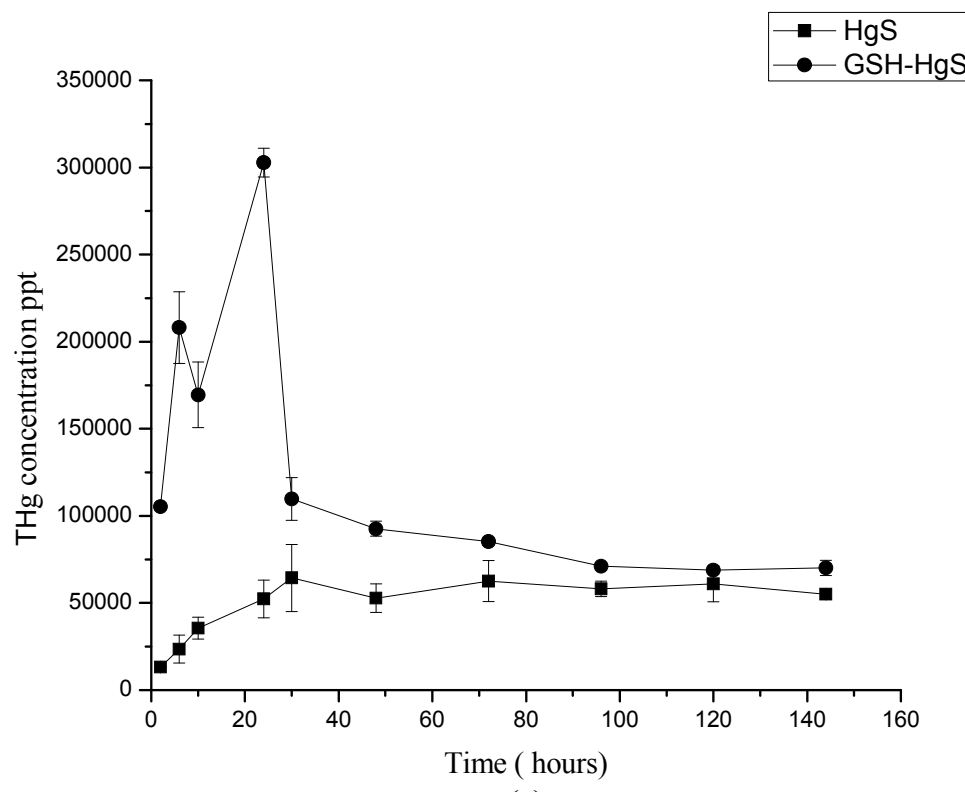

(a)

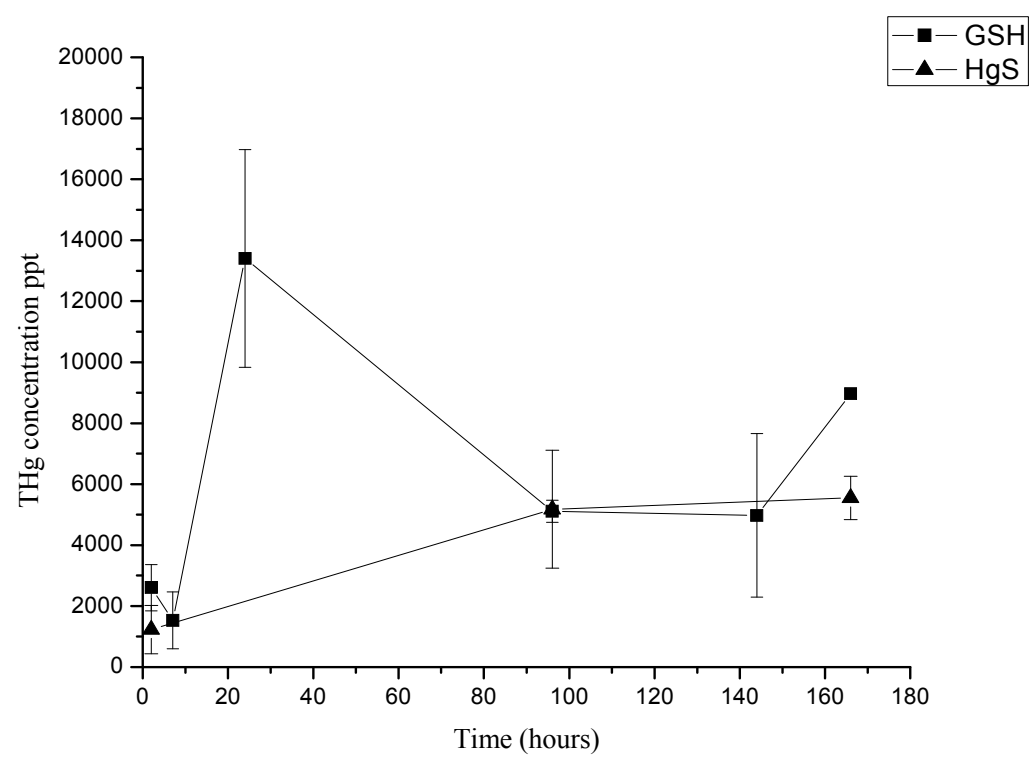

(b)

Figure 4.8 HgS dissolution (solid $\mathrm{HgS}$ concentration was $400 \mathrm{mg} / \mathrm{L}$ ) in presence of GSH at low concentrations: (a) $1 \mu \mathrm{M}$ and (b) $0.2 \mu \mathrm{M}$ 


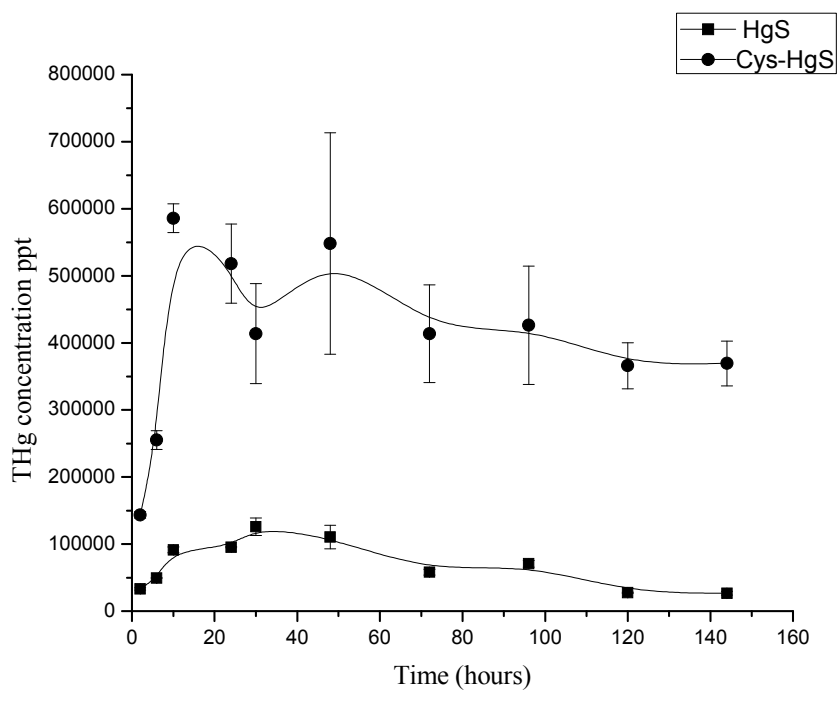

Figure 4.9 Kinetic data of dissolution of cinnabar $(400 \mathrm{mg} / \mathrm{L})$ in presence of $10 \mu \mathrm{M}$ Cys (add $8 \mu \mathrm{M}$ Cys at 72 hours)

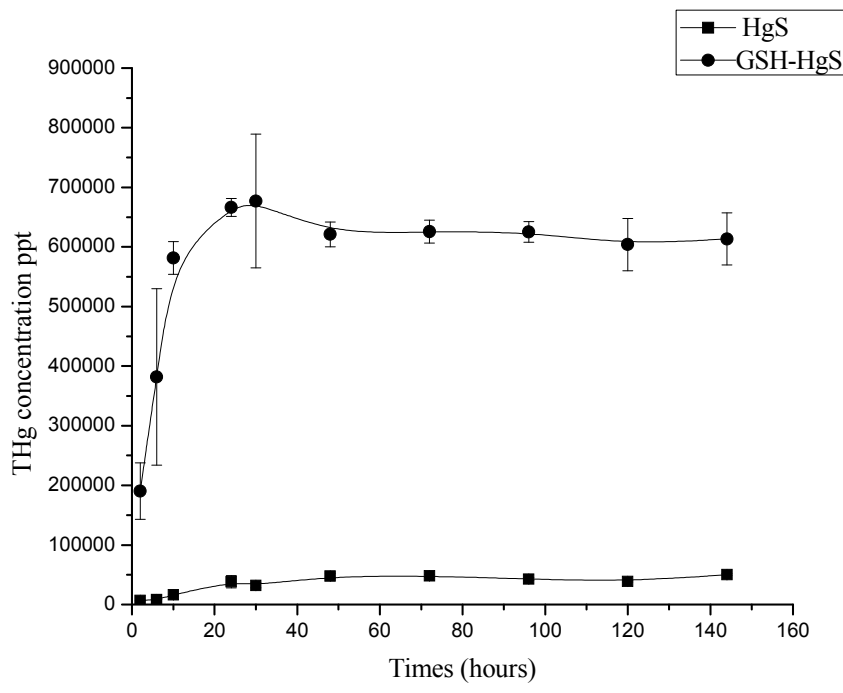

Figure 4.10 Kinetic data of dissolution of cinnabar $(400 \mathrm{mg} / \mathrm{L})$ in presence of $10 \mu \mathrm{M}$ GSH (add $8 \mu \mathrm{M}$ GSH at 72 hours). 


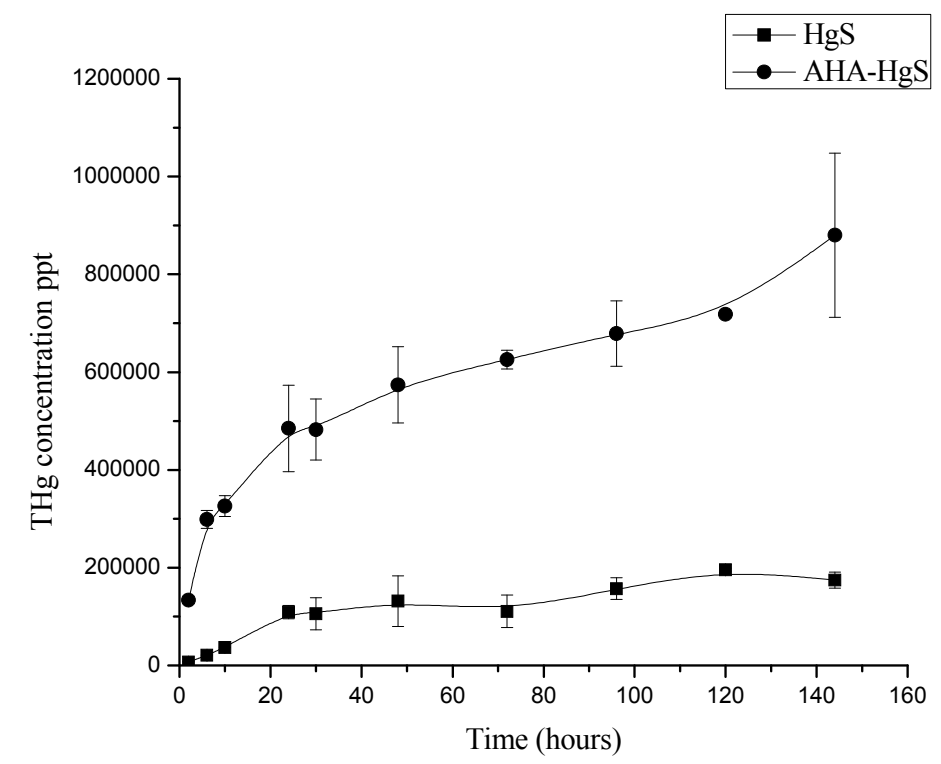

Figure 4.11 Kinetic data of dissolution of cinnabar $(400 \mathrm{mg} / \mathrm{L})$ in presence of AHA $(22.5$ $\mathrm{mgC} / \mathrm{L})$.

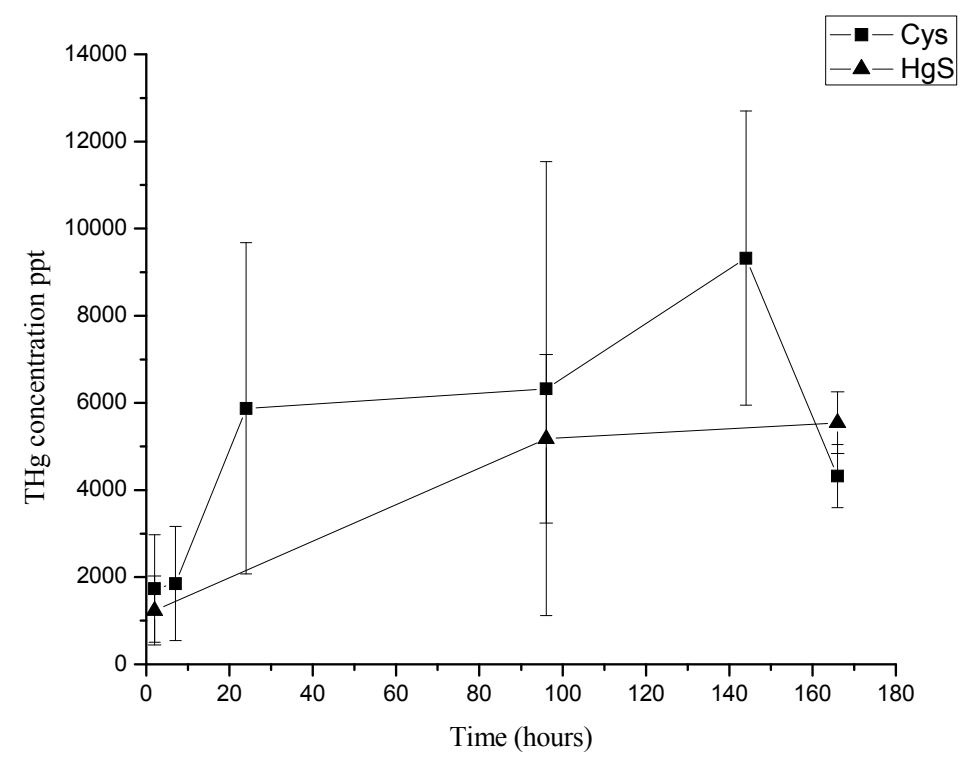

Figure 4.12 Effect of $200 \mathrm{nM}$ of Cys on cinnabar dissolution. The initial concentration of cinnabar was $400 \mathrm{mg} / \mathrm{L}$. Cys was initially added at the concentration of $200 \mathrm{nM}$ at the beginning of the experiment. 


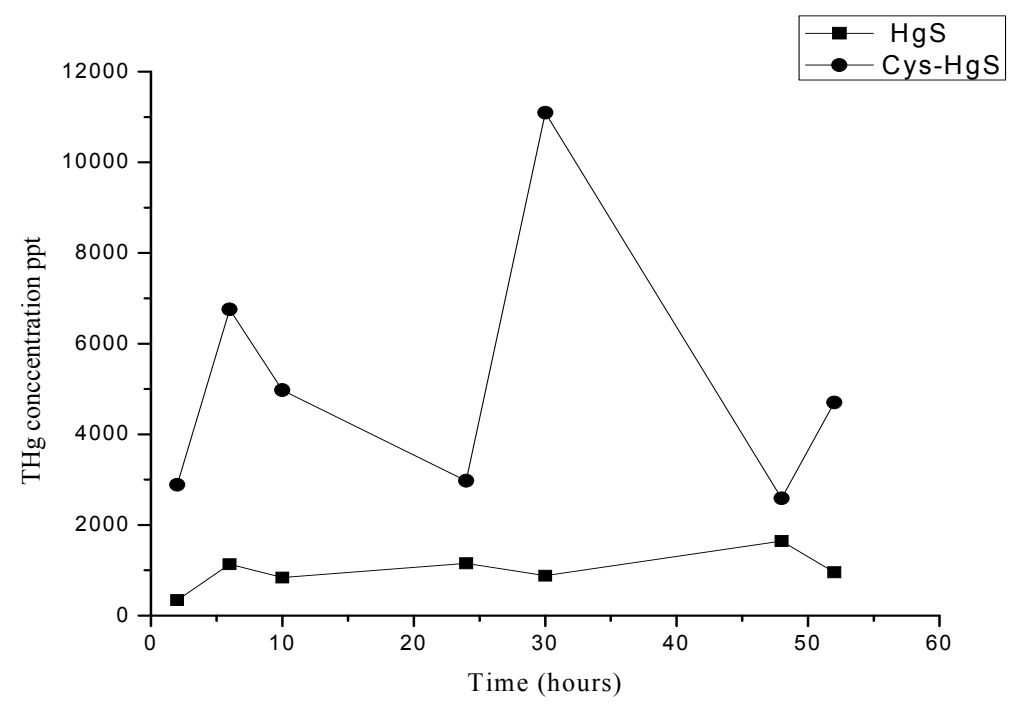

Figure 4.13 Effect of Cys (200 nM Cys was added at different time intervals, 0, 2, 4, 6, $10,24,26,28,30,46,48$ and 52 hours) on the dissolution of $\mathrm{HgS}$.

\subsubsection{Effect of ROS and DOM on HgS Dissolution (without Glass Beads)}

Concentration Effect of ROS and DOM on HgS Dissolution. The effect of different concentrations of ROS and DOM on $\mathrm{HgS}$ dissolution was studied by determining the dissolved $\mathrm{Hg}$ concentrations at 72 hours in the absence of glass beads. It was observed that the dissolution effect was related to the concentrations of Cys, GSH or DOM. With the increasing concentrations of ROS and DOM, more Hg was released from the $\mathrm{HgS}$ solids into the solutions. But for GSH, no significant differences were observed with respect to the enhanced $\mathrm{HgS}$ dissolution when $\mathrm{GSH}$ was 5 and $10 \mu \mathrm{M}$. It seemed that GSH showed the highest effect on dissolution, in comparison to Cys and AHA and the ability to enhance cinnabar dissolution was in the following order: GSH $>$ Cys $>$ AHA (Fig 4.14).

Effect of Different DOM on HgS Dissolution. Among the DOM tested, AHA was observed to be most effective in enhancing $\mathrm{HgS}$ dissolution, with WHA and WFA 
slightly enhancing $\mathrm{HgS}$ dissolution. In the presence of AHA (22.5 $\mathrm{mgC} / \mathrm{L})$, the concentration of dissolved mercury reached about $25 \mathrm{ppb}$ at 72 hours, whereas the concentration of the dissolved mercury was about $8-10$ ppb for WFA and WHA (also $22.5 \mathrm{mgC} / \mathrm{L})$. The control experiment suggested that the concentration of the dissolved mercury released from cinnabar in DIW was below 1 ppb (Fig 4.15), indicating that all DOM tested here can enhance $\mathrm{HgS}$ dissolution. The kinetic experiments suggested that the dissolution of $\mathrm{HgS}$ in the presence of the DOM tested showed a quick step during 0$16 \mathrm{hr}$ and a slow step after that time, with the dissolved $\mathrm{Hg}$ keeping increasing during the course of the experiment (up to 144 hours).
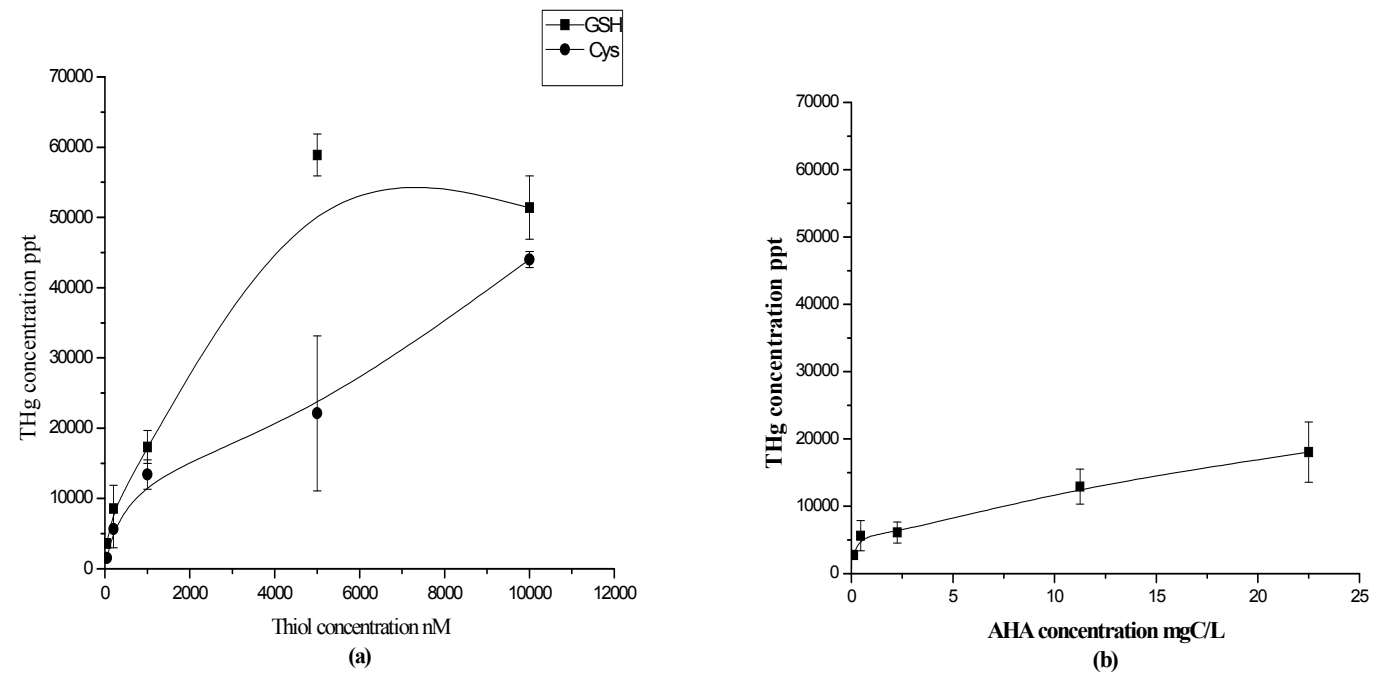

Figure 4.14 Total dissolved mercury concentrations from the dissolution of cinnabar (400 mg/L) in the presence of Cys and GSH (a), and AHA (b). 


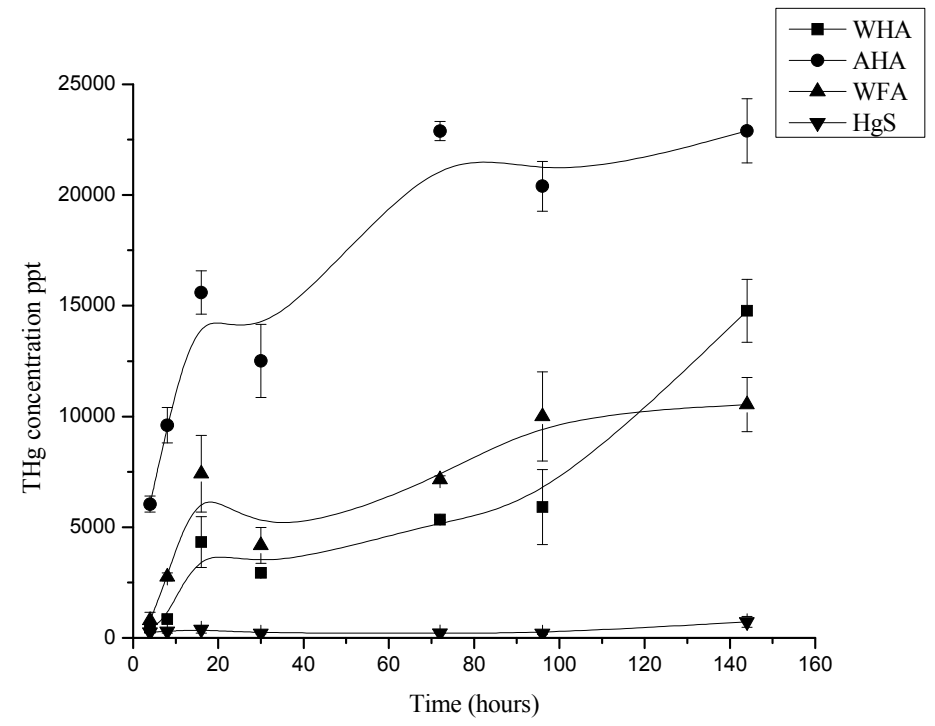

Figure 4.15 Kinetic data of cinnabar dissolution $(400 \mathrm{mg} / \mathrm{L})$ without glass beads was obtained in presence of AHA, WFA and WHA $(22.5 \mathrm{mgC} / \mathrm{L})$ in DIW

\subsubsection{Distribution of Hg Species during HgS Dissolution}

The speciation of the dissolved $\mathrm{Hg}$ (passing through $0.22 \mu \mathrm{m}$, including colloidal and truly dissolved $\mathrm{Hg}$ ) using centrifugal filtration devices (3 $\mathrm{kDa} \mathrm{MWCO}$ ) suggest that no truly dissolved mercury was detected when mercury sulfide was mixed with DIW, with most mercury being colloidal form $(>3 \mathrm{kDa}$ ) (Table 4.3). Similarly, in the presence of AHA, the truly dissolved mercury fraction was very small, amounting to only $2 \%$ of total dissolved mercury (Table 4.4). However, in the presence of small ROS (Cys and GSH, 10 $\mu \mathrm{M})$, the truly dissolved mercury $(<3 \mathrm{kDa})$ was a major fraction of the $\mathrm{Hg}$ released from $\mathrm{HgS}$ (about $40 \%$ of total dissolved mercury) (Tables 4.5 and 4.6 ).

These results suggested that, without ligand compounds, mercury sulfide might not be truly dissolved, which is in consistent with the extremely low solubility product of HgS. The dissolved mercury determined during the dissolution of cinnabar in DIW could be $\mathrm{HgS}$ colloids which are small enough to pass through $0.22 \mu \mathrm{m}$ but large than $3 \mathrm{kDa}$ 
(and thus retained by $3 \mathrm{kDa}$ filters). Deonarine and Hsu-Kim have showed that, upon mixing $\mathrm{Hg}^{2+}$ with sulfide, $\mathrm{HgS}$ nanoparticles could be formed and they were small enough to be mistaken as soluble complexes, if dissolved mercury is defined at $0.2 \mu \mathrm{m}$ cut off (Deonarine and Hsu-Kim 2009).

In the presence of large molecule AHA, the fraction of the truly dissolved Hg was very small. This could be due to the $\mathrm{Hg}$ dissoluted from $\mathrm{HgS}$ was in the colloidal $\mathrm{HgS}$ particles (since the presence of AHA could stabilize these colloids) and/or in the complexes with AHA. Since AHA is large molecule substances, as evidenced by the size exclusive chromatography work (Rajec et al. 1999) which showed that AHA included three main fraction: $>760 \mathrm{KDa}, 25-100 \mathrm{KDa}$ and $<5 \mathrm{KDa}$, even the complexes of $\mathrm{Hg}$ AHA could be retained by $3 \mathrm{kDa}$ filtration. Additional experiments using mercury standards to react with AHA confirmed that Hg-AHA complexes could not pass through 3 kDa MWCO membranes (Table 4.7). Colloidal mercury was around $94-98 \%$ of total mercury during the reaction between $22.5 \mathrm{mgC} / \mathrm{L}$ AHA and $100 \mathrm{ppb} \mathrm{Hg}$ standard. The reaction produced only 1 percent of total dissolved mercury in truly dissolved form (Table 4.7). At this stage, the question what $\mathrm{Hg}$ species ( $\mathrm{HgS}$ colloids or Hg-AHA complexes) are the main $\mathrm{Hg}$ species formed during the AHA-enhanced HgS dissolution remains unresolved. 
Table 4.3 Different mercury species presented during $\mathrm{HgS}$ dissolution control experiment. The initial concentration of $\mathrm{HgS}$ is $400 \mathrm{mg} / \mathrm{L}$. Separation of truly dissolved $(<3 \mathrm{kDa})$ and colloid $(>3 \mathrm{kDa}) \mathrm{Hg}$ species was conducted by microsep centrifugal devices with $3 \mathrm{k} \mathrm{MWCO}$ at $7000 \times \mathrm{g}$ for $20 \mathrm{~min}$.

\begin{tabular}{cccc}
\hline HgS & Fraction & $\begin{array}{c}\text { Mass } \\
(\mathrm{ng})\end{array}$ & $\begin{array}{c}\text { Recovery } \\
(\%)\end{array}$ \\
\hline Solution & $>3 \mathrm{k}$ & 26 & 82 \\
Tube one & $<3 \mathrm{k}$ & 21 & \\
& $>3 \mathrm{k}$ & No & \\
& & 21 & \\
\hline Tube two & & No & \\
\hline
\end{tabular}


Table 4.4 Different mercury species presented during $\mathrm{HgS}$ dissolution in the presence of AHA. The initial $\mathrm{HgS}$ concentration was $400 \mathrm{mg} / \mathrm{L}$ and concentration of AHA was 22.5 $\mathrm{mgC} / \mathrm{L}$. Separation of truly dissolved $(<3 \mathrm{kDa})$ and colloidal $(>3 \mathrm{kDa}) \mathrm{Hg}$ species was conducted by microsep centrifugal devices with $3 \mathrm{k} \mathrm{MWCO}$ at $7000 \times \mathrm{g}$ for $20 \mathrm{~min}$. Colloidal on the filter refers to $\mathrm{Hg}$ absorbed by the filter during separation and was determined by digesting filter followed by total $\mathrm{Hg}$ analysis.

\begin{tabular}{lcccc}
\hline AHA $+\mathrm{HgS}$ & Fraction & $\begin{array}{c}\text { Mass } \\
(\mathrm{ng})\end{array}$ & $\begin{array}{c}\text { Recovery } \\
(\%)\end{array}$ & $\begin{array}{c}\text { Total recovery } \\
(\%)\end{array}$ \\
\hline Solution & 49 & & 77 \\
Tube one & $>3 \mathrm{k}$ & 37 & 75 & \\
& $<3 \mathrm{k}$ & 1 & 2 & 69 \\
Tube two & $>3 \mathrm{k}$ & 33 & 67 & \\
\hline
\end{tabular}

Unlike AHA, the presence of small ROS (Cys and GSH) produced a considerable fraction of truly dissolved mercury during $\mathrm{HgS}$ dissolution. I suspect this fraction of truly dissolved $\mathrm{Hg}$ could be thiol-Hg complexes, formed through the interaction between thiol and $\mathrm{Hg}$. I further conducted a series of additional experiments to characterize the mercury species formed during thiol-enhanced $\mathrm{HgS}$ dissolution. 
Table 4.5 Different mercury species presented during $\mathrm{HgS}$ dissolution in the presence of Cys. The initial $\mathrm{HgS}$ concentration was $400 \mathrm{mg} / \mathrm{L}$ and the initial Cys was $10 \mu \mathrm{M}$. Separation of truly dissolved $(<3 \mathrm{kDa})$ and colloidal $(>3 \mathrm{kDa}) \mathrm{Hg}$ species was conducted by microsep centrifugal devices with $3 \mathrm{k} \mathrm{MWCO}$ at $7000 \times \mathrm{g}$ for $20 \mathrm{~min}$. Colloidal on the filter refers to $\mathrm{Hg}$ absorbed by the filter during separation and was determined by digesting filter followed by total $\mathrm{Hg}$ analysis.

\begin{tabular}{|c|c|c|c|c|}
\hline Cys + HgS & Fraction & $\begin{array}{c}\text { Mass } \\
\text { (ng) }\end{array}$ & $\begin{array}{c}\text { Recovery } \\
(\%)\end{array}$ & $\begin{array}{c}\text { Total recovery } \\
(\%)\end{array}$ \\
\hline \multirow[t]{2}{*}{ Solution } & & 218 & & \\
\hline & $>3 \mathrm{k}$ & 52 & 24 & 80 \\
\hline \multirow[t]{3}{*}{ Tube one } & $<3 \mathrm{k}$ & 92 & 42 & \\
\hline & $\begin{array}{l}\text { Colloid on the } \\
\text { filter }\end{array}$ & 30 & 14 & \\
\hline & $>3 \mathrm{k}$ & 96 & 44 & 102 \\
\hline \multirow[t]{2}{*}{ Tube two } & $<3 \mathrm{k}$ & 91 & 42 & \\
\hline & $\begin{array}{l}\text { Colloid on the } \\
\text { filter }\end{array}$ & 34 & 16 & \\
\hline
\end{tabular}


Table 4.6 Different mercury species presented during $\mathrm{HgS}$ dissolution in the presence of glutathione. The initial $\mathrm{HgS}$ concentration was $400 \mathrm{mg} / \mathrm{L}$ and GSH concentration was 10 $\mu \mathrm{M}$. Separation of truly dissolved $(<3 \mathrm{kDa})$ and colloidal $(>3 \mathrm{kDa}) \mathrm{Hg}$ species was conducted by microsep centrifugal devices with $3 \mathrm{kMWCO}$ at $7000 \times \mathrm{g}$ for $20 \mathrm{~min}$.

\begin{tabular}{|c|c|c|c|c|}
\hline $\mathrm{GSH}+\mathrm{HgS}$ & Fraction & $\begin{array}{c}\text { Mass } \\
\text { (ng) }\end{array}$ & $\begin{array}{c}\text { Recovery } \\
(\%)\end{array}$ & $\begin{array}{c}\text { Total recovery } \\
(\%)\end{array}$ \\
\hline \multirow[t]{2}{*}{ Solution } & & 241 & & \\
\hline & $>3 \mathrm{k}$ & 80 & 33 & 73 \\
\hline \multirow[t]{3}{*}{ Tube one } & $<3 \mathrm{k}$ & 87 & 36 & \\
\hline & $\begin{array}{l}\text { Colloid on the } \\
\text { filter }\end{array}$ & 11 & 4 & \\
\hline & $>3 \mathrm{k}$ & 65 & 27 & 72 \\
\hline \multirow[t]{2}{*}{ Tube two } & $<3 \mathrm{k}$ & 91 & 38 & \\
\hline & $\begin{array}{l}\text { Colloid on the } \\
\text { filter }\end{array}$ & 17 & 7 & \\
\hline
\end{tabular}

Hg Species during HgS dissolution in the Presence of Glass Beads. Although the total dissolved mercury obtained from GSH dissolution in the presence of glass beads was about ten times the amount obtained without glass beads, the amounts of truly dissolved mercury were similar in both cases (Table 4.8). It should be noted that, as a result of the differences in total dissolved $\mathrm{Hg}$ amounts, the fraction of the truly dissolved mercury was only $4 \%$ in the presence of glass beads, whereas around $40 \%$ in the absence of glass beads. This result showed that the use of glass beads in cinnabar dissolution 
increased the total amount of the dissolved mercury, probably through increasing the amount of colloidal $\mathrm{Hg}$ ( $\mathrm{HgS}$ colloids). Glass beads might increase the production of $\mathrm{HgS}$ colloids through the collision with the surfaces of $\mathrm{HgS}$ particles. The similar amounts of the truly dissolved $\mathrm{Hg}$ in the presence and absence of glass beads suggest that the truly dissolved Hg could be Hg-thiol complexes.

Table 4.7 Different mercury species presented during the reaction of AHA and Hg STD by microsep centrifugal devices with $3 \mathrm{k}$ MWCO under $7000 \times \mathrm{g}$ centrifuge force for 20 min. The initial Hg concentration was $100 \mathrm{ppb}$ and the initial AHA concentration was $22.5 \mathrm{mgC} / \mathrm{L}$.

\begin{tabular}{ccccc}
\hline $\begin{array}{c}\text { AHA + Hg } \\
\text { STD }\end{array}$ & Fraction & $\begin{array}{c}\text { Mass } \\
(\mathrm{ng})\end{array}$ & $\begin{array}{c}\text { Recovery } \\
(\%)\end{array}$ & $\begin{array}{c}\text { Total recovery } \\
(\%)\end{array}$ \\
\hline Solution & & 254 & & \\
Tube one & $>3 \mathrm{k}$ & 235 & 93 & 94 \\
& $<3 \mathrm{k}$ & 2 & 1 & \\
Tube two & $>3 \mathrm{k}$ & 247 & 97 & 98 \\
& $<3 \mathrm{k}$ & 3 & 1 & \\
\hline
\end{tabular}

Complexes Formed between GSH and Hg Standards. The centrifugal filtration devices were used to separate the $\mathrm{Hg}-\mathrm{GSH}$ complexes formed through reacting $\mathrm{Hg}$ standards with GSH. It was found that the majority of mercury-glutathione complex was in truly dissolved form (Table 4.9). The truly dissolved mercury was around $74 \%$ of total mercury during the reaction between $10 \mu \mathrm{M}$ GSH and $100 \mathrm{ppb}$ Hg STD. There was about $20 \%$ of mercury in colloidal form $(>3 \mathrm{kDa})$. The result gave the evidence that most GSH-Hg complexes could pass through $3 \mathrm{kDa}$ MWCO filters. Thus, if $\mathrm{Hg}-\mathrm{GSH}$ 
complexes were formed during the dissolution of $\mathrm{HgS}$ in the presence of $\mathrm{GSH}$, these complexes could be able to pass through the $3 \mathrm{kDa}$ filters and be identified as the truly dissolved Hg. The experiment provided further evidence that the truly dissolved mercury from thiol-enhanced $\mathrm{HgS}$ dissolution could be thiol-Hg complexes.

Separation of Hg Species under Different Centrifugal Forces. In addition to $7000 \times$ $\mathrm{g}, 9400 \times \mathrm{g}$ centrifugal force (for 20 minutes) was used for the separation of $\mathrm{Hg}$ species in the solutions from GSH-enhanced $\mathrm{HgS}$ dissolution (Table 4.10, and 4.11). It was observed that, under $9400 \times \mathrm{g}$ separation, there was only $5 \%$ of $\mathrm{Hg}$ being determined as the truly dissolved Hg. Comparing to $7000 \times$ g separation, the Hg colloids adsorbed on the filter membrane increased remarkably, reaching $40-70 \%$, under $9400 \times \mathrm{g}$ separation. Regardless of the absence or presence of glass beads, similar results were observed, which were incompatible with the truly dissolved mercury being $40 \%$ under $7000 \times \mathrm{g}$ centrifugal force in the absence of glass beads (Table 4.6). It could be possible that high centrifugal force precipitated colloidal $\mathrm{Hg}$ particles on the filter membrane, clogging the membrane and preventing the passing through of $\mathrm{Hg}$-GSH complexes. It would result in the observation of low truly dissolved Hg. These results suggested that the separation of $\mathrm{Hg}$ species using microsep centrifugal devices was related to the experimental conditions (including centrifugal force), which should be considered during the design of the experiments and the discussion of the results. 
Table 4.8 Different mercury species presented during $\mathrm{HgS}$ dissolution with and without glass beads in presence of GSH (shaking 72 hours at $200 \mathrm{rpm}$ ). The initial $\mathrm{HgS}$ concentration was $400 \mathrm{mg} / \mathrm{L}$ and the initial glutathione was $10 \mu \mathrm{M}$. Separation of truly dissolved $(<3 \mathrm{kDa})$ and colloid $(>3 \mathrm{kDa}) \mathrm{Hg}$ species was conducted by microsep centrifugal devices with $3 \mathrm{k} \mathrm{MWCO}$ at $7000 \times \mathrm{g}$ for 20 minutes.

\begin{tabular}{|c|c|c|c|c|c|c|c|}
\hline & \multicolumn{4}{|c|}{ With glass beads } & \multicolumn{3}{|c|}{ Without glass beads } \\
\hline & Fraction & $\begin{array}{l}\text { Mass } \\
\text { (ng) }\end{array}$ & $\begin{array}{c}\text { Recovery } \\
(\%)\end{array}$ & $\begin{array}{c}\text { Total } \\
\text { recovery } \\
(\%)\end{array}$ & $\begin{array}{l}\text { Mass } \\
\text { (ng) }\end{array}$ & $\begin{array}{c}\text { Recovery } \\
(\%)\end{array}$ & $\begin{array}{c}\text { Total } \\
\text { recovery } \\
(\%)\end{array}$ \\
\hline \multirow[t]{2}{*}{ Solution } & & 2397 & & & 241 & & \\
\hline & $>3 \mathrm{k}$ & 1339 & 56 & 71 & 80 & 33 & 73 \\
\hline \multirow{3}{*}{$\begin{array}{l}\text { Tube } \\
\text { one }\end{array}$} & $<3 \mathrm{k}$ & 100 & 4 & & 87 & 36 & \\
\hline & $\begin{array}{l}\text { Colloid } \\
\text { on the } \\
\text { filter }\end{array}$ & 251 & 10 & & 11 & 4 & \\
\hline & $>3 \mathrm{k}$ & 1419 & 59 & 74 & 65 & 27 & 72 \\
\hline \multirow{2}{*}{$\begin{array}{l}\text { Tube } \\
\text { two }\end{array}$} & $<3 \mathrm{k}$ & 101 & 4 & & 91 & 38 & \\
\hline & $\begin{array}{l}\text { Colloid } \\
\text { on the } \\
\text { filter }\end{array}$ & 249 & 10 & & 17 & 7 & \\
\hline
\end{tabular}


Table 4.9 Different mercury species presented during the reaction of GSH and Hg STD. The initial $\mathrm{Hg}$ concentration was $100 \mathrm{ppb}$ and GSH concentration was $10 \mu \mathrm{M}$. Separation of truly dissolved $(<3 \mathrm{kDa})$ and colloidal $(>3 \mathrm{kDa}) \mathrm{Hg}$ species was conducted by microsep centrifugal devices with $3 \mathrm{kDa}$ at $7000 \times \mathrm{g}$ for $20 \mathrm{~min}$.

\begin{tabular}{ccccc}
\hline $\begin{array}{c}\text { GSH }+\mathrm{Hg} \\
\text { STD }\end{array}$ & Fraction & $\begin{array}{c}\text { Mass } \\
(\mathrm{ng})\end{array}$ & $\begin{array}{c}\text { Recovery } \\
(\%)\end{array}$ & $\begin{array}{c}\text { Total recovery } \\
(\%)\end{array}$ \\
\hline Solution & & 296 & & \\
Tube one & $>3 \mathrm{k}$ & 68 & 23 & 97 \\
& $<3 \mathrm{k}$ & 219 & 74 & 96 \\
Tube two & $>3 \mathrm{k}$ & 66 & 22 & \\
\hline
\end{tabular}

Reactivity of Hg Species Formed through ROS-enhanced HgS Dissolution. In consideration that the truly dissolved $\mathrm{Hg}$ determined during ROS-enhanced $\mathrm{HgS}$ dissolution could be Hg-GSH or Hg-Cys complexes, further experiments were conducted to study the reactivity of the truly dissolved $\mathrm{Hg}$. It has been known that $\mathrm{Hg}-\mathrm{GSH}$ or $\mathrm{Hg}-\mathrm{Cys}$ complexes could be directly reduced by stannous chloride without a prior step of digestion (to break the Hg-S bond), which was confirmed by our experiments using Hg standards to react with Cys or GSH. After reacting mercury standard with GSH or Cys for 20 min on an orbital shaker, during which Hg-GSH or Hg-Cys complexes should be formed as this reaction is known to occur instantly, the mixture was directly analyzed using CVAFS without digestion and all $\mathrm{Hg}$ was found reducible by stannous chloride (Table 4.12). 
Table 4.10 Separation of mercury species in the solution from GSH-enhanced $\mathrm{HgS}$ dissolution in the absence of glass beads at $9400 \times \mathrm{g}$ centrifugal force. The initial $\mathrm{HgS}$ concentration was $400 \mathrm{mg} / \mathrm{L}$ and GSH concentration was $10 \mu \mathrm{M}$. Separation of truly dissolved $(<3 \mathrm{kDa})$ and colloid $(>3 \mathrm{kDa}) \mathrm{Hg}$ species was conducted by microsep centrifugal devices with $3 \mathrm{k} \mathrm{MWCO}$ at $9400 \times \mathrm{g}$ for $20 \mathrm{~min}$. Colloidal on the filter refers to $\mathrm{Hg}$ absorbed by the filter during separation and was determined by digesting filter followed by total $\mathrm{Hg}$ analysis.

\begin{tabular}{|c|c|c|c|c|}
\hline $\mathrm{GSH}+\mathrm{HgS}$ & Fraction & $\begin{array}{c}\text { Mass } \\
(n g)\end{array}$ & Recovery (\%) & $\begin{array}{c}\text { Total recovery } \\
(\%)\end{array}$ \\
\hline \multirow[t]{2}{*}{ Solution } & & 369 & & \\
\hline & $>3 \mathrm{k}$ & 184 & 50 & 123 \\
\hline \multirow[t]{3}{*}{ Tube one } & $<3 \mathrm{k}$ & 13 & 4 & \\
\hline & $\begin{array}{l}\text { Colloid on the } \\
\text { filter }\end{array}$ & 255 & 69 & \\
\hline & $>3 \mathrm{k}$ & 183 & 50 & 103 \\
\hline \multirow[t]{2}{*}{ Tube two } & $<3 \mathrm{k}$ & 13 & 4 & \\
\hline & $\begin{array}{l}\text { Colloid on the } \\
\text { filter }\end{array}$ & 181 & 49 & \\
\hline
\end{tabular}


Table 4.11 Separation of mercury species in the solution from GSH-enhanced $\mathrm{HgS}$ dissolution in the presence of glass beads at $9400 \times \mathrm{g}$ centrifugal force. The initial $\mathrm{HgS}$ concentration was $400 \mathrm{mg} / \mathrm{L}$ and GSH concentration was $10 \mu \mathrm{M}$. Separation of truly dissolved $(<3 \mathrm{kDa})$ and colloid $(>3 \mathrm{kDa}) \mathrm{Hg}$ species was conducted by microsep centrifugal devices with $3 \mathrm{k} \mathrm{MWCO}$ at $9400 \times \mathrm{g}$ for $20 \mathrm{~min}$. Colloidal on the filter refers to $\mathrm{Hg}$ absorbed by the filter during separation and was determined by digesting filter followed by total $\mathrm{Hg}$ analysis.

\begin{tabular}{|c|c|c|c|c|}
\hline $\mathrm{GSH}+\mathrm{HgS}$ & Fraction & $\begin{array}{l}\text { Mass } \\
(n g)\end{array}$ & $\begin{array}{c}\text { Recovery } \\
(\%)\end{array}$ & $\begin{array}{c}\text { Total recovery } \\
(\%)\end{array}$ \\
\hline \multirow[t]{2}{*}{ Solution } & & 3121 & & \\
\hline & $>3 \mathrm{k}$ & 1059 & 34 & 90 \\
\hline \multirow[t]{3}{*}{ Tube one } & $<3 \mathrm{k}$ & 146 & 5 & \\
\hline & $\begin{array}{l}\text { Colloid on the } \\
\text { filter }\end{array}$ & 1597 & 51 & \\
\hline & $>3 \mathrm{k}$ & 183 & 41 & 88 \\
\hline \multirow[t]{2}{*}{ Tube Two } & $<3 \mathrm{k}$ & 143 & 5 & \\
\hline & $\begin{array}{l}\text { Colloid on the } \\
\text { filter }\end{array}$ & 1306 & 42 & \\
\hline
\end{tabular}


Table 4.12 The thiol-Hg complex (Cys and GSH STD reacted with 200 ppb Hg STD) was analyzed by CVAFS without digestion.

\begin{tabular}{cccc}
\hline & $\begin{array}{c}\text { Thiol conc. } \\
(\mu \mathrm{M})\end{array}$ & $\begin{array}{c}\text { Recovery } \\
(\%)\end{array}$ & $\begin{array}{c}\text { Average recovery } \\
(\%)\end{array}$ \\
\hline Cys + Hg STD & 3 & $98 \pm 3$ & $97 \pm 2$ \\
GSH + Hg STD & 10 & $95 \pm 1$ & $96 \pm 2$ \\
\hline
\end{tabular}

The direct analysis of the solutions in the filtrate receivers of the centrifugal devices suggest that the truly dissolved $\mathrm{Hg}$ determined in GSH-enhanced dissolution $(10 \mu \mathrm{M}$ of GSH, without glass beads, and samples were taken at $72 \mathrm{hr}$ and separated using the microsep centrifugal filtration devices) could be completely reduced by stannous chloride (Table 4.13). It could be indicative of the presence of Hg-GSH complexes in the truly dissolved $\mathrm{Hg}$ fraction. However, the truly dissolved mercury fraction from the Cysenhanced $\mathrm{HgS}$ dissolution was observed to be partially (around 40\%) reducible by stannous chloride, suggesting the presence of other $\mathrm{Hg}$ species in addition to $\mathrm{Hg}$-Cys complexes (Table 4.14). Future studies are needed in order to further characterize the speciation of $\mathrm{Hg}$ species released due to $\mathrm{HgS}$ dissolution in the presence of ROS and DOM. 
Table 4.13 The truly dissolved mercury from cinnabar dissolution in presence of $10 \mu \mathrm{M}$ GSH was analyzed by CVAFS with and without digestion. Separation of truly dissolved $(<3 \mathrm{kDa})$ and colloid $(>3 \mathrm{kDa}) \mathrm{Hg}$ species was conducted by microsep centrifugal devices with $3 \mathrm{k} \mathrm{MWCO}$ at $7000 \times \mathrm{g}$ for $20 \mathrm{~min}$.

\begin{tabular}{ccccc}
\hline GSH + HgS & Analysis method & $\begin{array}{c}\text { Mass } \\
(\mathrm{ng})\end{array}$ & $\begin{array}{c}\text { Recovery } \\
(\%)\end{array}$ & $\begin{array}{c}\text { Average } \\
\text { recovery } \\
(\%)\end{array}$ \\
\hline Tube one & $\begin{array}{c}\text { Without } \\
\text { digestion }\end{array}$ & 36 & 95 & 97 \\
& With digestion & 39 & 98 & \\
Tube two & $\begin{array}{c}\text { Without } \\
\text { digestion }\end{array}$ & 39 & & \\
& With digestion & 40 & \\
\hline
\end{tabular}

Table 4.14 The truly dissolved mercury from cinnabar dissolution in presence of $10 \mu \mathrm{M}$ Cys was analyzed by CVAFS with and without digestion.

\begin{tabular}{ccccc}
\hline Cys + HgS & Analysis method & $\begin{array}{c}\text { Mass } \\
(\mathrm{ng})\end{array}$ & $\begin{array}{c}\text { Recovery } \\
(\%)\end{array}$ & $\begin{array}{c}\text { Average } \\
\text { recovery } \\
(\%)\end{array}$ \\
\hline Tube one & $\begin{array}{c}\text { Without } \\
\text { digestion }\end{array}$ & 15 & 43 & 43 \\
& With digestion & 35 & 43 & \\
Tube two & $\begin{array}{l}\text { Without } \\
\text { digestion }\end{array}$ & 15 & & \\
& With digestion & 35 & & \\
\end{tabular}




\subsection{Conclusions}

The presence of small ROS (e.g., Cys and GSH) and large DOM could significantly enhance the dissolution of $\mathrm{HgS}$, in particular when the concentrations of ROS and DOM were high. The dissolution of HgS in the presence of ROS and DOM was rapid at initial stage, and then reached nearly steady state for ROS, but kept increasing for dissolved organic matter.

The enhancing effect of ROS and DOM on $\mathrm{HgS}$ dissolution was related to the concentrations of ROS and DOM. With the increasing concentrations of ROS and DOM, more $\mathrm{Hg}$ was released from the $\mathrm{HgS}$ solids into the solutions. Among Cys, GSH, and AHA, it seemed that GSH showed the highest effect on $\mathrm{HgS}$ dissolution, followed by Cys and AHA in a decreasing order. Probably due to the quick oxidation, low concentrations of thiols, particularly with the single addition at the beginning of the experiments, would have limited effect on $\mathrm{HgS}$ dissolution.

Determination of $\mathrm{Hg}$ in a filtrate (e.g., $0.22 \mu \mathrm{m}$ used here) was often referred to as the dissolved Hg. The dissolved $\mathrm{Hg}$ so determined could include colloidal $\mathrm{Hg}$ (e.g., $\mathrm{HgS}$ colloids formed during ROS-enhanced $\mathrm{HgS}$ dissolution) and truly dissolved $\mathrm{Hg}$ (e.g., $\mathrm{Hg}$ ROS complexes formed through the complexation of the dissolute $\mathrm{Hg}$ and thiol groups). The speciation of the dissolved $\mathrm{Hg}$ (passing through $0.22 \mu \mathrm{m}$, including colloidal and truly dissolved $\mathrm{Hg}$ ) using centrifugal filtration devices (3 $\mathrm{kDa} \mathrm{MWCO}$ ) suggest that no truly dissolved mercury was detected when mercury sulfide was mixed with DIW, with most mercury being colloidal form $(>3 \mathrm{kDa})$. Similarly, in the presence of AHA, the truly dissolved mercury fraction is very small, amounting to only $2 \%$ of total dissolved mercury. However, in the presence of small ROS (Cys and GSH, $10 \mu \mathrm{M}$ ), the truly 
dissolved mercury $(<3 \mathrm{kDa}$ ) was a major fraction of the $\mathrm{Hg}$ released from $\mathrm{HgS}$ (about $40 \%$ of total dissolved mercury).

The truly dissolved mercury produced during $\mathrm{HgS}$ dissolution in the presence of small ROS (Cys and GSH) could be thiol-Hg complexes, formed through the interaction between thiol and Hg. A series of additional experiments suggested that, like the Hg-Cys or $\mathrm{Hg}$-GSH complexes formed by reacting $\mathrm{Hg}$ standards with Cys or GSH, the truly dissolved $\mathrm{Hg}$ formed during thiol-enhanced $\mathrm{HgS}$ dissolution could pass through $3 \mathrm{kDa}$ MWCO membranes and be directly reduced by stannous chloride. For GSH-enhanced dissolution, the truly dissolved $\mathrm{Hg}$ could be completely reduced by stannous chloride. For Cys-enhanced $\mathrm{HgS}$ dissolution, the truly dissolved mercury fraction could be partially (around $40 \%$ ) reduced by stannous chloride, suggesting the presence of other $\mathrm{Hg}$ species in addition to $\mathrm{Hg}$-Cys complexes.

Determination of the speciation and reactivity of $\mathrm{Hg}$ species released during $\mathrm{HgS}$ dissolution in the presence of ROS and DOM is important. This is because the Hg species released from $\mathrm{HgS}$ by ROS and DOM could be different, although both ROS and DOM could enhance the dissolution of $\mathrm{HgS}$. As revealed by the current study, unlike DOM which released $\mathrm{Hg}$ from $\mathrm{HgS}$ primarily in the colloidal form, ROS (Cys and GSH) could release a considerable fraction of truly dissolved $\mathrm{Hg}$ (possibly due the formation of $\mathrm{Hg}$ Cys or Hg-GSH complexes). The Hg released from ROS-enhanced $\mathrm{HgS}$ dissolution was chemically reactive (e.g., directly reducible by stannous chloride) and thus could be potentially bioavailable for $\mathrm{Hg}$ methylation. In fact, previous work has shown that the addition of cysteine to inorganic $\mathrm{Hg}$ solutions could promote mercury methylation, probably through the formation of Cys- $\mathrm{Hg}$ complexes which could be taken up and 
utilized by Hg methylators (Benoit et al. 1999; Schaefer and Morel 2009). Future studies are needed to further characterize the speciation, reactivity, and bioavailability of $\mathrm{Hg}$ species released as a result of $\mathrm{HgS}$ dissolution in the presence of ROS and dissolved organic matter. 


\section{Chapter V}

\section{SUMMARY AND FUTURE STUDIES}

\subsection{Summary}

\subsubsection{Covalent Affinity Chromatography Preconcentration for Thiol Analysis}

Covalent affinity chromatography-based methods were attempted for analysis of reduced organic sulfur (ROS) in environmental water samples. A method was developed for thiols preconcentration in water samples using affinity covalent chromatographic column or solid phase extraction and analysis using HPLC-UV or HPLC-FL. Thiopropyl sepharose 6B is very efficient for enrichment of Cys and GSH from water because of its unique affinity with thiols. The releasing of thiols from the thiopropyl sepharose gel could be done by using TCEP because it does not introduce interference for the separation and analysis of Cys and GSH. Under the optimized conditions, the detection limits of the method using HPLC-FL detection were 0.45 and $0.36 \mathrm{nM}$ for Cys and GSH, respectively. Our results suggest that covalent affinity methods (solid phase extraction or chromatographic preconcentration) are efficient for thiol enrichment and interference elimination. Applications of covalent affinity methods for preconcentration of thiols from environmental matrices are promising in developing a sensitive, reliable, and useful technique for thiol analysis in environmental water samples.

\subsubsection{Interaction of ROS with Mercury Sulfide}

The dissolution of mercury sulfide $(\mathrm{HgS})$ in the presence of ROS, including low molecular weight thiols (e.g., cysteine and glutathione) and dissolved organic matter (Odom et al. 1982), was investigated. The purpose of this study was to 1) quantify the 
effects of ROS on $\mathrm{HgS}$ dissolution, and 2) determine the speciation of the mercury released from ROS-induced $\mathrm{HgS}$ dissolution.

After passing the suspensions of $\mathrm{HgS}$ solids and ROS solutions through $0.22 \mu \mathrm{m}$ filters, the $\mathrm{Hg}$ in the filtrates (operationally defined here as dissolved $\mathrm{Hg}$, as it has been traditionally defined) was measured to quantify the effect of ROS on $\mathrm{HgS}$ dissolution. It was observed that the presence of small ROS (e.g., Cys and GSH) and large molecule DOM could significantly enhance the dissolution of mercury sulfide. The enhancing effect of ROS and DOM on $\mathrm{HgS}$ dissolution was related to the concentrations of ROS and DOM. With the increasing concentrations of ROS and dissolved organic matter, more $\mathrm{Hg}$ was released from the $\mathrm{HgS}$ solids into the solutions. Probably because of the quick oxidation, low concentrations of thiols, particularly with the single addition at the beginning of the experiments, would have limited effect on $\mathrm{HgS}$ dissolution. The presence of glass beads, which could collide with $\mathrm{HgS}$ solids and produce small (e.g., colloidal) $\mathrm{HgS}$ particles, would dramatically increase the concentrations of the measured dissolved $\mathrm{Hg}$ from ROS-enhanced $\mathrm{HgS}$ dissolution.

The $0.22 \mu \mathrm{m}$ cutoff-defined dissolved $\mathrm{Hg}$ could include colloidal $\mathrm{Hg}$ (e.g., $\mathrm{HgS}$ colloids) and truly dissolved $\mathrm{Hg}$ (e.g., $\mathrm{Hg}$-ROS complexes formed through $\mathrm{Hg}$-SH complexation). A centrifugal filtration method (with $3 \mathrm{kDa} \mathrm{MWCO}$ ) was employed to characterize the speciation and reactivity of the $\mathrm{Hg}$ released during ROS-enhanced $\mathrm{HgS}$ dissolution. Truly dissolved mercury (defined here as Hg passing through $3 \mathrm{kDa}$ MWCO membrane) could not be detected when mercury sulfide was mixed with only water. Similarly, in the presence of large molecule DOM, the truly dissolved mercury fraction is very small, amounting to only $2 \%$ of total dissolved mercury. However, in presence of 
small ROS (Cys and GSH, $10 \mu \mathrm{M}$ ), the truly dissolved mercury was a major fraction of the $\mathrm{Hg}$ released from $\mathrm{HgS}$ dissolution (about $40 \%$ of total dissolved mercury), probable due to the formation of Hg-Cys or Hg-GSH complexes. The truly dissolved $\mathrm{Hg}$ formed during GSH- or Cys-enhanced HgS dissolution was chemically reactive, as it could be directly reduced by stannous chloride (completely reducible for GSH and partially reducible for Cys), demonstrating its potential role in $\mathrm{Hg}$ transformation and bioaccumulation.

\subsection{Suggestions for Future Studies}

Reduced organic sulfur compounds are environmentally ubiquitous and play an important role in sulfur cycling as well as in biogeochemical cycles of toxic metals, in particular mercury. My work made some advances in 1) developing effective methods for analysis of ROS in environmental waters by applying covalent affinity chromatography for preconcentration, and 2) in understanding the role of ROS in Hg cycling by studying the effect of ROS on $\mathrm{HgS}$ dissolution. However, accurate analysis of environmental thiols is controlled by a number of processes, e.g., preconcentration of thiols from environmental matrices, elution of thiols from covalent columns, and derivatization of thiols for fluorescence detection. In addition to enhancing $\mathrm{HgS}$ dissolution, ROS could virtually influence every aspect of the biogeochemical cycling of Hg, e.g., complexation of ROS with dissolved $\mathrm{Hg}$ species. Based on the results of this research, future studies aiming at accurate analysis of environmental thiols and better understanding of the role of ROS in Hg cycling could be conducted by addressing the following issues. 
1. The enriched factor using covalent affinity solid phase extraction to preconcentrate thiols from environmental waters could be further improved, e.g., by optimizing the type and amount of the eluting reagents;

2. The in situ applications of covalent affinity column and solid phase extraction for preconcentration of environmental thiols could be investigated, since successful in situ application of these techniques could potentially simplify the work of environmental thiols analysis;

3. The mechanisms underlying the enhanced dissolution of $\mathrm{HgS}$ in the presence of ROS and DOM could be further investigated by theoretical (e.g., physicochemical) calculations and/or experimental methods (e.g., identification of the products of HgS dissolution);

4. In addition to the fractionation of $\mathrm{Hg}$ species that was studied in this work, the speciation of the $\mathrm{Hg}$ released during ROS-induced $\mathrm{HgS}$ dissolution could be investigated by other methods, e.g., identification of chemically specific $\mathrm{Hg}$ species using spectrometric techniques (e.g., LC-MS);

5. In addition to studying the reactivity of the $\mathrm{Hg}$ species released from ROSenhanced $\mathrm{HgS}$ dissolution (as demonstrated in this work), the bioavailability of these $\mathrm{Hg}$ species (e.g., Hg-ROS complexes) for $\mathrm{Hg}$ methylation and for biological uptake could be investigated. 


\section{REFERENCES}

Abukhalaf, I. K., N. A. Silvestrov, J. M. Menter, D. A. von Deutsch, M. A. Bayorh, R. R. Socci and A. A. Ganafa (2002). "High performance liquid chromatographic assay for the quantitation of total glutathione in plasma." Journal of Pharmaceutical and Biomedical Analysis 28(3-4): 637-643.

Al-Farawati, R. and C. M. G. Van Den Berg (2001). "Thiols in coastal waters of the western North Sea and English Channel." Environmental Science \& Technology 35(10): 1902-1911.

Amirbahman, A., A. L. Reid, T. A. Haines, J. S. Kahl and C. Arnold (2002). "Association of Methylmercury with Dissolved Humic Acids." Environmental Science \& Technology 36(4): 690-695.

Andrews, J. L., P. Ghosh, B. Ternai and M. W. Whitehouse (1982). "Ammonium 4chloro-7-sulfobenzofurazan: A new fluorigenic thiol-specific reagent." Archives of Biochemistry and Biophysics 214(1): 386-396.

Axen, R., H. Drevin and J. Carlsson (1975). "Preparation of modified agarose gels containing thiol groups." Acta Chemica Scandinavica, Series B: Organic Chemistry and Biochemistry B29(4): 471-474.

Baden, D. G. and T. J. Mende (1982). "Toxicity of 2 Toxins from the Florida Red Tide Marine Dinoflagellate, Ptychodiscus-Brevis." Toxicon 20(2): 457-461.

Bagiyan, G. A., I. K. Koroleva, N. V. Soroka and A. V. Ufimtsev (2003). "Oxidation of thiol compounds by molecular oxygen in aqueous solutions." Russian Chemical Bulletin 52(5): 1135-1141.

Barnett, M. O., L. A. Harris, R. R. Turner, T. J. Henson, R. E. Melton and R. J. Stevenson (1995). "Characterization of mercury species in contaminated floodplain soils." Water, Air, \& Soil Pollution 80(1): 1105-1108.

Barnett, M. O., L. A. Harris, R. R. Turner, R. J. Stevenson, T. J. Henson, R. C. Melton and D. P. Hoffman (1997). "Formation of mercuric sulfide in soil." Environ. Sci. Technol. 31: 3037.

Barnett, M. O., R. R. Turner and P. C. Singer (2001). "Oxidative dissolution of metacinnabar ([beta]-HgS) by dissolved oxygen." Applied Geochemistry 16(13): 1499-1512.

Belzile, N., C.-Y. Lang, Y.-W. Chen and M. Wang (2008). "The competitive role of organic carbon and dissolved sulfide in controlling the distribution of mercury in freshwater lake sediments." Science of The Total Environment 405(1-3): 226-238. 
Benoit, J. M., C. C. Gilmour and R. P. Mason (2001). "The influence of sulfide on solid phase mercury bioavailability for methylation by pure cultures of Desulfobulbus propionicus (1pr3)." Environmental Science \& Technology 35(1): 127-132.

Benoit, J. M., C. C. Gilmour and R. P. Mason (2001 (a)). "The Influence of Sulfide on Solid-Phase Mercury Bioavailability for Methylation by Pure Cultures of Desulfobulbus propionicus (1pr3)." Environ. Sci. Technol. 35(1): 127-132.

Benoit, J. M., C. C. Gilmour and R. P. Mason (2001 (b)). "Aspects of bioavailability of mercury for methylation in pure cultures of Desulfobulbus propionicus (1pr3)." Appl. Environ. Microbiol. 67: 51.

Benoit, J. M., C. C. Gilmour, R. P. Mason and A. Heyes (1999). "Sulfide Controls on Mercury Speciation and Bioavailability to Methylating Bacteria in Sediment Pore Waters." Environmental Science \& Technology 33(6): 951-957.

Berijani, S., Y. Assadi, M. Anbia, M.-R. Milani Hosseini and E. Aghaee (2006). "Dispersive liquid-liquid microextraction combined with gas chromatographyflame photometric detection: Very simple, rapid and sensitive method for the determination of organophosphorus pesticides in water." Journal of Chromatography A 1123(1): 1-9.

Biotech, A. P. (1998). "Thiopropyl sepharose 6B instruction".

Bloom, N. and W. F. Fitzgerald (1988). "Determination of volatile mercury species at the picogram level by low-temperature gas chromatography with cold-vapour atomic fluorescence detection." Analytica Chimica Acta 208: 151-161.

Bloom, N. S. and E. A. Crecelius (1983). "Determination of mercury in seawater at subnanogram per liter levels." Marine Chemistry 14(1): 49-59.

Boulegue, J., C. J. Lord and T. M. Church (1982). "Sufur speciation and associated tracemethals $(\mathrm{Fe}, \mathrm{Cu})$ in the pore waters of Great Marsh, Delaware." Geochimica Et Cosmochimica Acta 46(3): 453-464.

Brocklehurst, K., J. Carlsson, M. P. J. Kierstan and E. M. Crook (1974). Covalent chromatography by thiol-disulfide interchange. Methods in Enzymology. B. C. Raymond, Academic Press. Volume 34: 531-544.

Buffer, J. (1988). "'Complexation Reactions in Aquatic Systems" Ellis Horwood Ltd."

Burkstaller, J. E., P. L. McCarty and G. A. Parks (1975). "Oxidation of cinnabar by iron(III) in acid mine waters." Environmental Science \& Technology 9(7): 676678. 
Cai, Y., R. Jaffe and R. D. Jones (1999). "Interactions between dissolved organic carbon and mercury species in surface waters of the Florida Everglades." Applied Geochemistry 14(3): 395-407.

Capitan-Vallvey, L. F., A. Titos, R. Checa and N. Navas (2002). "High-performance liquid chromatography determination of $\mathrm{Zn}$-bacitracin in animal feed by postcolumn derivatization and fluorescence detection." Journal of Chromatography A 943(2): 227-234.

Cernichiari, E., G. J. Myers, N. Ballatori, G. Zareba, J. Vyas and T. Clarkson (2007). "The biological monitoring of prenatal exposure to methylmercury." NeuroToxicology 28(5): 1015-1022.

Cestari, A. R. and C. Airoldi (1997). "Chemisorption on thiol-silicas: divalent cations as a function of $\mathrm{pH}$ and primary amines on thiol-mercury adsorbed." Journal of Colloid and Interface Science 195(2): 338-342.

Chean, V., Gamble, D.S., (1974). "Metal-fulvic acid chelation equilibrium in aqueous NaNO3 solution." Soil Science Society of America Journal 34: 413-417.

Chou, S.-T., L.-E. Ko and C.-S. Yang (2001). "High performance liquid chromatography with fluorimetric detection for the determination of total homocysteine in human plasma: method and clinical applications." Analytica Chimica Acta 429(2): 331336.

Clarkson, T. W. (1993). "MERCURY - MAJOR ISSUES IN ENVIRONMENTALHEALTH." Environmental Health Perspectives 100: 31-38.

Cullen, W. R., B. C. McBride and J. Reglinski (1984). "The reduction of trimethylarsine oxide to trimethylarsine by thiols: a mechanistic model for the biological reduction of arsenicals." Journal of Inorganic Biochemistry 21(1): 45-60.

Daskalakis, I., M. D. Lucock, A. Anderson, J. Wild, C. J. Schorah and M. I. Levene (1996). "Determination of plasma total homocysteine and cysteine using HPLC with fluorescence detection and an ammonium 7-fluoro-2, 1, 3-benzoxadiazole-4sulphonate (SBD-F) derivatization protocol optimized for antioxidant concentration, derivatization reagent concentration, temperature and matrix $\mathrm{pH} . "$ Biomedical chromatography: BMC 10(5): 205-212.

Deonarine, A. and H. Hsu-Kim (2009). "Precipitation of Mercuric Sulfide Nanoparticles in NOM-Containing Water: Implications for the Natural Environment." Environmental Science \& Technology.

Drexel, R. T., M. Haitzer, J. N. Ryan, G. R. Aiken, K. L. Nagy and Mercury (2002). "sorption to two Florida Everglades peat: evidence for strong and weak binding 
and competition by dissolved organic matter released from the peat." Environ. Sci. Technol. 36: 4058.

Dyrssen, D. and M. Wedborg (1991). "The sulphur-mercury(II) system in natural waters." Water, Air, \& Soil Pollution 56(1): 507-519.

Frick, B., K. Schröcksnadel, G. Neurauter, B. Wirleitner, E. Artner-Dworzak and D. Fuchs (2003). "Rapid measurement of total plasma homocysteine by HPLC." Clinica Chimica Acta 331(1-2): 19-23.

Garcia, A. J. and R. Apitz-Castro (2002). "Plasma total homocysteine quantification: an improvement of the classical high-performance liquid chromatographic method with fluorescence detection of the thiol-SBD derivatives." Journal of Chromatography B 779(2): 359-363.

Gardner, W. S. and W. H. Miller (1980). "Reverse-phase liquid chromatographic analysis of amino acids after reaction with o-phthalaldehyde." Analytical Biochemistry 101(1): 61-65.

Giovanelli, J. (1987). "Sulfur amino acids of plants: an overview." Methods in Enzymology 143(Sulfur Sulfur Amino Acids): 419-426.

Glatz, Z., J. Psotova, O. Janiczek, K. Chroust and T. Jowet (1997). "Use of thiopropyl Sepharose for the synthesis of an adsorbent for the affinity chromatography of glutathione S-transferase." Journal of Chromatography, B: Biomedical Applications 688(2): 239-243.

Gong, K., X. Zhu, R. Zhao, S. Xiong, L. Mao and C. Chen (2005). "Rational Attachment of Synthetic Triptycene Orthoquinone onto Carbon Nanotubes for Electrocatalysis and Sensitive Detection of Thiols." Analytical Chemistry 77(24): 8158-8165.

Haitzer, M., G. R. Aiken and J. N. Ryan (2002). "Binding of Mercury(II) to Dissolved Organic Matter: The Role of the Mercury-to-DOM Concentration Ratio." Environmental Science and Technology 36(16): 3564-3570.

Han, F., S. Shiyab, J. Chen, Y. Su, D. Monts, C. Waggoner and F. Matta (2008). "Extractability and Bioavailability of Mercury from a Mercury Sulfide Contaminated Soil in Oak Ridge, Tennessee, USA." Water, Air, \& Soil Pollution 194(1): 67-75.

Han, F. X., Y. Su, D. L. Monts, C. A. Waggoner and M. J. Plodinec (2006). "Binding, distribution, and plant uptake of mercury in a soil from Oak Ridge, Tennessee, USA." Science of The Total Environment 368: 753-768. 
Harris, H. H., I. J. Pickering and G. N. George (2003). "The chemical form of mercury in fish." Science 301(5637): 1203-1203.

He, Z., S. J. Traina and L. K. Weavers (2006). "Sonochemical Dissolution of Cinnabar $(\alpha-\mathrm{HgS}) . "$ Environmental Science \& Technology 41(3): 773-778.

Hesterberg, D., J. W. Chou, K. J. Hutchison and D. E. Sayers (2001). "Bonding of Hg(II) to reduced organic sulfur in humic acid as affected by S/Hg ratio." Environ. Sci. Technol. 35: 2741.

Hill, P. G. and R. M. Smith (2000). "Determination of sulphur compounds in beer using headspace solid-phase microextraction and gas chromatographic analysis with pulsed flame photometric detection." Journal of Chromatography A 872(1-2): 203-213.

Hintelmann, H., P. M. Welbourn and R. D. Evans (1997). "Measurement of Complexation of Methylmercury(II) Compounds by Freshwater Humic Substances Using Equilibrium Dialysis." Environmental Science \& Technology 31(2): 489-495.

Hintelmann, H. and R.-D. Wilken (1995). "Levels of total mercury and methylmercury compounds in sediments of the polluted Elbe River: influence of seasonally and spatially varying environmental factors." Science of the Total Environment 166(1-3): 1-10.

Hiraku, Y., M. Murata and S. Kawanishi (2002). "Determination of intracellular glutathione and thiols by high performance liquid chromatography with a gold electrode at the femtomole level: comparison with a spectroscopic assay." Biochimica et Biophysica Acta (BBA) - General Subjects 1570(1): 47-52.

Holley, E. A., A. James McQuillan, D. Craw, J. P. Kim and S. G. Sander (2007). "Mercury mobilization by oxidative dissolution of cinnabar ([alpha]-HgS) and metacinnabar ([beta]-HgS)." Chemical Geology 240(3-4): 313-325.

Hsu, H. and D. L. Sedlak (2003). "Strong Hg(II) complexation in municipal wastewater effluent and surface waters." Environ. Sci. Technol. 37: 2743.

Hu, H., S. E. Mylon and G. Benoit (2006). "Distribution of the Thiols Glutathione and 3Mercaptopropionic Acid in Connecticut Lakes." Limnology and Oceanography 51(6): 2763-2774.

Huang, K.-J., C.-H. Han, J.-Y. Sun, D.-J. Niu, Z.-W. Wu, Y.-P. Xue, L.-J. Zhang and X.Q. Xiong (2010). "Sensitive Determination of Thiols Using SPE Coupled to LC with Fluorescence Detection." Chromatographia 72(11): 1049-1054. 
Huljev, S. a. (1971). "Investigations of mercury-pollutant interactions with humic acids by means of radiotracer." Nuclear Techniques in Environmental Pollution: 439446.

Hurley, J. P., J. M. Benoit, C. L. Babiarz, M. M. Shafer, A. W. Andren, J. R. Sullivan, R. Hammond and D. A. Webb (1995). "Influences of Watershed Characteristics on Mercury Levels in Wisconsin Rivers." Environmental Science \& Technology 29(7): 1867-1875.

Hurley, J. P., D. P. Krabbenhoft, C. L. Babiarz and A. W. Andren (1994). "Cycling of mercury across sediment-water interface in seepage lakes." American Chemical Society(Environmental Chemistry of Lakes and Reservoirs): 425-449.

Ichinose, S., M. Nakamura, M. Maeda, R. Ikeda, M. Wada, M. Nakazato, Y. Ohba, N. Takamura, T. Maeda, K. Aoyagi and K. Nakashima (2009). "A validated HPLCfluorescence method with a semi-micro column for routine determination of homocysteine, cysteine and cysteamine, and the relation between the thiol derivatives in normal human plasma." Biomedical Chromatography 23(9): 935939.

Imai, K., S. Uzu, S. Kanda and W. R. G. Baeyens (1994). "AVAILABILITY OF FLUOROGENIC REAGENTS HAVING A BENZOFURAZAN STRUCTURE IN THE BIOSCIENCES." Analytica Chimica Acta 290(1-2): 3-20.

Ivanov, A. R., I. V. Nazimov and L. Baratova (2000). "Determination of biologically active low-molecular-mass thiols in human blood: I. Fast qualitative and quantitative, gradient and isocratic reversed-phase high-performance liquid chromatography with photometric and fluorescence detection." Journal of Chromatography A 895(1-2): 157-166.

Ivanov, A. R., I. V. Nazimov, L. Baratova, A. P. Lobazov and G. B. Popovich (2001). "Determination of biologically active low-molecular-mass thiols in human blood III. Highly sensitive narrow-bore isocratic reversed-phase highperformance liquid chromatography with fluorescence detection." Journal of Chromatography A 913(1-2): 315-318.

Jackson, T. A., G. Kipphut, R. H. Hesslein and D. W. Schindler (1980). "Experimental study of trace metal chemistry in soft-water lakes at different pH levels." Canadian Journal of Fisheries and Aquatic Sciences 37(3): 387-402.

Jay, J. A., F. M. M. Morel and H. F. Hemond (2000). "Mercury Speciation in the Presence of Polysulfides." Environ. Sci. Technol. 34(11): 2196-2200. 
Jay, J. A., K. J. Murray, C. C. Gilmour, R. P. Mason, F. M. M. Morel, A. L. Roberts and H. F. Hemond (2002). "Mercury methylation by Desulfovibrio desulfuricans ND 132 in the presence of polysulfides." Appl. Environ. Microbiol. 68: 5741.

Joys, T. M. and H. Kim (1979). "o-Phthalaldehyde and the fluorogenic detection of peptides." Analytical Biochemistry 94(2): 371-377.

Kabzinski, A. K. (1998). "Application of covalent affinity chromatography with thioldisulphide interchange for determination of environmental exposition to heavy metals based on the quantitative determination of $\mathrm{Zn}$-thionein from physiological human fluids by indirect method based on analysis of metal contents." Biomed Chromatogr FIELD Full Journal Title:Biomedical chromatography : BMC 12(5): 281-290.

Kabzinski, A. K. M. (1997). "Application of solid-phase extraction to the preconcentration of metallothionein and metals from physiological fluids." Journal of Chromatography, A 766 $(1+2)$ : 121-131.

Karlsson, T. and U. Skyllberg (2003). "Bonding of ppb Levels of Methyl Mercury to Reduced Sulfur Groups in Soil Organic Matter." Environmental Science \& Technology 37(21): 4912-4918.

Kim, C. S., N. S. Bloom, J. J. Rytuba, G. E. Brown and Jr (2003). "Mercury speciation by $\mathrm{X}$-ray absorption fine structure spectroscopy and sequential chemical extractions: A comparison of speciation methods." Environ. Sci. Technol. 37: 5102.

Kim, C. S., G. E. Brown and Jr (2000). "Characterization and speciation of mercurybearing mine wastes using X-ray absorption spectroscopy (XAS)." $\underline{\text { Sci. Total }}$ Environ. 261: 157.

Kim, C. S., J. J. Rytuba, G. E. Brown and Jr (2004). "Geological and anthropogenic factors influencing mercury speciation in mine wastes: an EXAFS spectroscopy study." Appl. Geochem. 19: 379.

Kim, S., J. I. Kim, H. R. Park, M. K. Kim, Y. Chong and W. S. Yeo (2009). "Electrochemical Detection of Glutathione on SAMs on Gold Using an Electroactive Quininoid-Type Molecule." Bulletin of the Korean Chemical Society 30(11): 2574-2576.

Kok, R. J., J. Visser, F. Moolenaar, D. de Zeeuw and D. K. F. Meijer (1997). "Bioanalysis of captopril: two sensitive high-performance liquid chromatographic methods with pre- or postcolumn fluorescent labeling." Journal of Chromatography B: Biomedical Sciences and Applications 693(1): 181-189. 
Krezel, A. and W. Bal (1999). "Coordination chemistry of glutathione." Acta Biochimica Polonica 46(3): 567-580.

Lambertsson, L. and M. Nilsson (2006). "Organic material: the primary control on mercury methylation and ambient methyl mercury concentrations in estuarine sediments." Environ. Sci. Technol. 40: 1822.

Lamborg, C. H., C.-M. Tseng, W. F. Fitzgerald, P. H. Balcom and C. R. Hammerschmidt (2003). "Determination of the Mercury Complexation Characteristics of Dissolved Organic Matter in Natural Waters with "Reducible Hg" Titrations." Environmental Science \& Technology 37(15): 3316-3322.

Lasaga, A. C. (1984). "Chemical Kinetics of Water-Rock Interactions." J. Geophys. Res. 89(B6): 4009-4025.

Leal, M. F. C., M. Teresa, Vasconcelos S. D. and C. M. G. and Van Den Berg (1999). "Copper-induced release of complexing ligands similar to thiols by Emiliania huxleyi in seawater cultures." Limnol. Oceanogr 44(7): 1750-1762.

Lee, Y. H. and H. Hultberg (1990). "Methylmercury in some Swedish surface waters." Environmental Toxicology and Chemistry 9(7): 833-841.

Lin Ling, B., W. R. G. Baeyens, B. Del Castillo, K. Stragier, H. Marysael and P. De Moerloose (1989). "Use of enhancers in the HPTLC fluorescence analysis of thiols." Journal of Pharmaceutical and Biomedical Analysis 7(12): 1671-1678.

Lövgren, L., and Sjöberg, S., (1989). "Equilibrium approaches to natural water systems7. complexation reactions of copper (II), cadmium (II) and mercury (II) with dissolved organic matter in a concentrated bog-water."

Lowry, G. V., S. Shaw, C. S. Kim, J. J. Rytuba and G. E. Brown (2004). "Macroscopic and microscopic observations of particle-facilitated mercury transport from New Idria and Sulphur Bank mercury mine tailings." Environ. Sci. Technol. 38: 51015111.

$\mathrm{Lu}, \mathrm{X}$. and R. Jaffe (2001). "Interaction between $\mathrm{Hg}(\mathrm{II})$ and natural dissolved organic matter: a fluorescence spectroscopy based study." Water Res. 35: 1793.

Luo, J. L., F. Hammarqvist, I. A. Cotgreave, C. Lind, K. Andersson and J. Wernerman (1995). "DETERMINATION OF INTRACELLULAR GLUTATHIONE IN HUMAN SKELETAL-MUSCLE BY REVERSED-PHASE HIGHPERFORMANCE LIQUID-CHROMATOGRAPHY." Journal of Chromatography B-Biomedical Applications 670(1): 29-36. 
Mantoura, R. F. C. and J. P. Riley (1975). "The use of gel filtration in the study of metal binding by humic acids and related compounds." Analytica Chimica Acta 78(1): 193-200.

Martell, A. E., R. M. Smith and R. J. Motekaitis (1998). NIST critically selected stability constants of metal complexes data base, Department of Commerce, Gaithersburg.

Matrai, P. A., and R. D. Vetter (1988). "Particulate thiols in coastal water; The effect of light and nutrients on their planktonic production." Limnol. Oceanogr 33: 624631.

Merritt, K. A. and A. Amirbahman (2007). "Mercury dynamics in sulfide-rich sediments: Geochemical influence on contaminant mobilization within the Penobscot River estuary, Maine, USA." Geochimica et Cosmochimica Acta 71(4): 929-941.

Mestres, M., O. Busto and J. Guasch (2002). "Application of headspace solid-phase microextraction to the determination of sulphur compounds with low volatility in wines." Journal of Chromatography A 945(1-2): 211-219.

Mestres, M., M. P. Martí, O. Busto and J. Guasch (1999). "Simultaneous analysis of thiols, sulphides and disulphides in wine aroma by headspace solid-phase microextraction-gas chromatography." Journal of Chromatography A 849(1): 293-297.

Mestres, M., M. P. Martí, O. Busto and J. Guasch (2000). "Analysis of low-volatility organic sulphur compounds in wines by solid-phase microextraction and gas chromatography." Journal of Chromatography A 881(1-2): 583-590.

Mierle, G. and R. Ingram (1991). "The role of humic substances in the mobilization of mercury from watersheds." Water, Air, \&amp; Soil Pollution 56(1): 349-357.

Mikac, N., D. Foucher, S. Niessen and J.-C. Fischer (2002). "Extractability of HgS (cinnabar and metacinnabar) by hydrochloric acid." Analytical and Bioanalytical Chemistry 374(6): 1028-1033.

Mikac, N., D. Foucher, S. Niessen, S. Lojen and J. Fischer (2003). "Influence of chloride and sediment matrix on the extractability of $\mathrm{HgS}$ (cinnabar and metacinnabar) by nitric acid." Anal. Bioanal. Chem. 377: 1196.

Miller, C. L., R. P. Mason, C. C. Gilmour and A. Heyes (2007). "Influence of dissolved organic matter on the complexation of mercury under sulfidic conditions." Environ. Toxicol. Chem. 26: 624.

Miller, C. L., G. Southworth, S. Brooks, L. Liang and B. Gu (2009). "Kinetic Controls on the Complexation between Mercury and Dissolved Organic Matter in a 
Contaminated Environment." Environmental Science \& Technology 43(22): 8548-8553.

Molnar-Perl, I. (2001). "Derivatization and chromatographic behavior of the ophthaldialdehyde amino acid derivatives obtained with various SH-groupcontaining additives." Journal of Chromatography A 913(1-2): 283-302.

Mopper, K. and F. Taylor Barrie (1986). Biogeochemical Cycling of Sulfur. Organic Marine Geochemistry, American Chemical Society. 305: 324-339.

NCEDR (1996). Workshop on decision-making related to the clean-up of mercury contamination at lower East Fork Poplar Creek, Oak Ridge, TN.

Nolin, T., E. M. McMenamin and J. Himmelfarb (2007). "Simultaneous determination of total homocysteine, cysteine, cysteinylglycine, and glutathione in human plasma by high-performance liquid chromatography: Application to studies of oxidative stress." J. Chromatogr., B: Anal. Technol. Biomed. Life Sci. 852(1-2): 554-561.

Odom, J. V., T. M. Maida and W. W. Dawson (1982). "Pattern evoked retinal response (PERR) in human: effects of spatial frequency, temporal frequency, luminance and defocus." Current Eye Research 2(2): 99-108.

Oe, T., T. Ohyagi and A. Naganuma (1998). "Determination of gammaglutamylglutathione and other low-molecular-mass biological thiol compounds by isocratic high-performance liquid chromatography with fluorimetric detection." Journal of Chromatography B 708(1-2): 285-289.

Okabe, K., R. Wada, K.-i. Ohno, S. Uchiyama, T. Santa and K. Imai (2002). "Development of hydrophilic fluorogenic derivatization reagents for thiols: 4-(Nacetylaminosulfonyl)-7-fluoro-2,1,3-benzoxadiazole and 4-(Ntrichloroacetylaminosulfonyl)-7-fluoro-2,1,3-benzoxadiazole." Journal of Chromatography A 982(1): 111-118.

Osakada, K., A. Taniguchi, E. Kubota, S. Dev, K. Tanaka, K. Kubota and T. Yamamoto (1992). "New organosols of copper(II) sulfide, cadmium sulfide, zinc sulfide, mercury(II) sulfide, nickel(II) sulfide and mixed metal sulfides in N,Ndimethylformamide and dimethyl sulfoxide. Preparation, characterization, and physical properties." Chemistry of Materials 4(3): 562-570.

Owens, G. S. and W. R. LaCourse (1997). "Pulsed electrochemical detection of thiols and disulfides following capillary electrophoresis." Journal of Chromatography, B: Biomedical Sciences and Applications 695(1): 15-25. 
Panda, M., D. Jiang and H. W. Jarrett (2008). "Trapping of transcription factors with symmetrical DNA using thiol-disulfide exchange chemistry." Journal of Chromatography A 1202(1): 75-82.

Paquette, K. and G. Helz (1995). "Solubility of cinnabar (red HgS) and implications for mercury speciation in sulfidic waters." Water, Air, \& Soil Pollution 80(1): 10531056.

Paquette, K. E. and G. R. Helz (1997). "Inorganic Speciation of Mercury in Sulfidic Waters: The Importance of Zero-Valent Sulfur." Environmental Science \& Technology 31(7): 2148-2153.

Patai, S. (1974). The Chemistry of the Thiol Group, Pt. 2.

Patai, S. (1974). The Chemistry of the Thiol Group, Pt. 1.

Petrlova, J., R. Mikelova, K. Stejskal, A. Kleckerova, O. Zitka, J. Petrek, L. Havel, J. Zehnalek, V. Adam, L. Trnkova and R. Kizek (2006). "Simultaneous determination of eight biologically active thiol compounds using gradient elutionliquid chromatography with Coul-Array detection." Journal of Separation Science 29(8): 1166-1173.

Pfeiffer, C. M., D. L. Huff and E. W. Gunter (1999). "Rapid and accurate HPLC assay for plasma total homocysteine and cysteine in a clinical laboratory setting." $\underline{\text { Clinical }}$ Chemistry 45(2): 290-292.

Porcella, D. (1994). "Mercury in the environment: Biogeochemistry. Mercury Pollution: Integration and Synthesis." C. J. Watras and J. W. Huckabee. Boca Raton, FL, CRC Press: 3-19.

Poulton, S. W., M. D. Krom and R. Raiswell (2004). "A revised scheme for the reactivity of iron (oxyhydr)oxide minerals towards dissolved sulfide." Geochimica et Cosmochimica Acta 68(18): 3703-3715.

Pyzik, A. J. and S. E. Sommer (1981). "Sedimentary iron monosulfides: Kinetics and mechanism of formation." Geochimica et Cosmochimica Acta 45(5): 687-698.

Rabenstein DL, Isab AA and R. RS (1982). "A proton nuclear magnetic resonance study of the binding of methylmercury in human erythrocytes." Biochim Biophys Acta 696: 53-64.

Rajec, P., P. Gerhart, F. Macášek, I. Shaban and P. Bartoš (1999). "Size exclusion (radio) chromatography of aqueous humic acid solutions with cesium and strontium." Journal of Radioanalytical and Nuclear Chemistry 241(1): 37-43. 
Raoof, J. B., R. Ojani and M. Baghayeri (2009). "Simultaneous electrochemical determination of glutathione and tryptophan on a nano-TiO2/ferrocene carboxylic acid modified carbon paste electrode." Sens. Actuators, B B143(1): 261-269.

Ravichandran, M. (2004). "Interactions between mercury and dissolved organic matter--a review." Chemosphere 55(3): 319-331.

Ravichandran, M., G. R. Aiken, M. M. Reddy and J. N. Ryan (1998). "Enhanced Dissolution of Cinnabar (Mercuric Sulfide) by Dissolved Organic Matter Isolated from the Florida Everglades." Environmental Science \& Technology 32(21): 3305-3311.

Ravichandran, M., G. R. Aiken, J. N. Ryan and M. M. Reddy (1999). "Inhibition of Precipitation and Aggregation of Metacinnabar (Mercuric Sulfide) by Dissolved Organic Matter Isolated from the Florida Everglades." Environmental Science \& Technology 33(9): 1418-1423.

Reddy, M. M. and G. R. Aiken (2001). "Fulvic Acid-Sulfide Ion Competition for Mercury Ion Binding in the Florida Everglades." Water, Air, \& Soil Pollution 132(1 - 2): 89-104.

Rizzo, V., L. Montalbetti, M. Valli, T. Bosoni, E. Scoglio and R. Moratti (1998). "Study of factors affecting the determination of total plasma 7-fluorobenzo-2-oxa-1,3diazole-4-sulfonate (SBD)-thiol derivatives by liquid chromatography." Journal of Chromatography B 706(2): 209-215.

Rydén, L. a. H. N. (1981). "'Covalent chromatography as a means of isolating thiol peptides from large proteins: Application to human ceruloplasmin"." Journal of chromatography A 215: 314-350.

Santa, T., C. Aoyama, T. Fukushima, K. Imai and T. Funatsu (2006). "Suppression of thiol exchange reaction in the determination of reduced-form thiols by highperformance liquid chromatography with fluorescence detection after derivatization with fluorogenic benzofurazan reagent, 7-fluoro-2,1,3benzoxadiazole-4-sulfonate and 4-aminosulfonyl-7-fluoro-2,1,3-benzoxadiazole." Biomedical Chromatography 20(6-7): 656-661.

Schaefer, J. K. and F. M. M. Morel (2009). "High methylation rates of mercury bound to cysteine by Geobacter sulfurreducens." Nature Geosci 2(2): 123-126.

Schuster, E. (1991). "The behavior of mercury in the soil with special emphasis on complexation and adsorption processes - a review of the literature." Water, Air, and Soil Pollution 56: 667-680. 
Skyllberg, U. (2008). "Competition among thiols and inorganic sulfides and polysulfides for $\mathrm{Hg}$ and $\mathrm{MeHg}$ in wetland soils and sediments under suboxic conditions: Illumination of controversies and implications for $\mathrm{MeHg}$ net production." JOURNAL OF GEOPHYSICAL RESEARCH 113: G00C03, doi:10.1029/2008JG000745.

Skyllberg, U., Bloom, P.r., Nater, E.A., Xia, K., Bleam, W.F., (1997). "Complexation of $\mathrm{Hg}(\mathrm{II})$ to reduced sulfur in soil organic matter." Humus-Nordic Humus Newsletter 4: 11-12.

Skyllberg, U., K. Xia, Bloom, P.R., E. A. Nater and W. F. Bleam (2000). "Binding of mercury (II) to reduced sulfur in soil organic matter along upland-peat soil transects." J. Environ. 29: 855-865.

Slowey, A. J., S. B. Johnson, J. J. Rytuba and G. E. Brown (2005). "Role of Organic Acids in Promoting Colloidal Transport of Mercury from Mine Tailings." Environmental Science \& Technology 39(20): 7869-7874.

Slowey, A. J., J. J. Rytuba and G. E. Brown (2005). "Speciation of Mercury and Mode of Transport from Placer Gold Mine Tailings." Environmental Science \& Technology 39(6): 1547-1554.

Takeda, M., Y. Miyanoiri, T. Nogami, K. Oda, T. Saito, K. Kato, J.-i. Koizumi and M. Katahira (2007). "Structural Analysis of the Fundamental Polymer of the Sheath Constructed by Sphaerotilus natans." Bioscience, Biotechnology, and Biochemistry 71(12): 2992-2998.

Tang, D., C.-C. Hung, K. W. Warnken and P. H. Santschi (2000). "The distribution of biogenic thiols in surface waters of Galveston Bay." Limnology and Oceanography 45(6): 1289-1297.

Tang, D., M. M. Shafer, K. Vang, D. A. Karner and D. E. Armstrong (2003). "Determination of dissolved thiols using solid-phase extraction and liquid chromatographic determination of fluorescently derivatized thiolic compounds." Journal of Chromatography, A 998(1-2): 31-40.

Tang, D., L.-S. Wen and P. H. Santschi (2000). "Analysis of biogenic thiols in natural water samples by high-performance liquid chromatographic separation and fluorescence detection with ammonium 7-fluorobenzo-2-oxa-1,3-diazole-4sulfonate (SBD-F)." Analytica Chimica Acta 408(1-2): 299-307.

Thing, M., J. Zhang, J. Laurence and E. M. Topp (2010). "Thiol-disulfide interchange in the tocinoic acid/glutathione system during freezing and drying." Journal of Pharmaceutical Sciences 99(12): 4849-4856. 
Tossell, J. A. (1999). "Theoretical studies on the formation of mercury complexes in solution and the dissolution and reactions of cinnabar." Am. Mineral. 84: 877883.

Tossell, J. A. (2001). "Calculation of the Structures, Stabilities, and Properties of Mercury Sulfide Species in Aqueous Solution." J. Phys. Chem. A 105(5): 935-

Toyo'oka, T., S. Uchiyama, Y. Saito and K. Imai (1988). "Simultaneous determination of thiols and disulfides by high-performance liquid chromatography with fluorescence detection." Analytica Chimica Acta 205: 29-41.

Turkmen, M., S. K. Dentel, P. C. Chiu and S. Hepner (2004). Analysis of sulfur and nitrogen odorants using solid-phase microextraction and GC-MS.

Uchiyama, S., T. Santa, N. Okiyama, T. Fukushima and K. Imai (2001). "Fluorogenic and fluorescent labeling reagents with a benzofurazan skeleton." Biomedical Chromatography 15(5): 295-318.

USEPA (1991). "Reregistration Eligibility Document Facts: Sulfur. US EPA, Pesticides and Toxic Substances."

USEPA (2001). "Characterization and Eh/pH-Based Leaching Tests of MercuryContaining Mining Wastes from the Sulfur Bank Mercury Mine, Lake County, California ".

Vairavamurthy, A. and K. Mopper (1990). "Field method for determination of traces of thiols in natural waters." Analytica Chimica Acta 236(2): 363-370.

Vairavamurthy, M. A., D. Maletic, S. Wang, B. Manowitz, T. Eglinton and T. Lyons (1997). "Characterization of Sulfur-Containing Functional Groups in Sedimentary Humic Substances by X-ray Absorption Near-Edge Structure Spectroscopy." Energy \& Fuels 11(3): 546-553.

Wang, F., A. Tessier and J. Buffle (1998). "Voltammetric determination of elemental sulfur in pore waters." Limnology and Oceanography 43(6): 1353-1361.

Wang, Q., J. M. Chong and J. Pawliszyn (2006). "Determination of thiol compounds by automated headspace solid-phase microextraction with in-fiber derivatization." Flavour and Fragrance Journal 21(3): 385-394.

Waples, J. S., K. L. Nagy, G. R. Aiken and J. N. Ryan (2005). "Dissolution of cinnabar $(\mathrm{HgS})$ in the presence of natural organic matter." Geochim. Cosmochim. Acta 69: 1575 . 
Whittle, M. C., J. F. Stobaugh and O. S. Wong (2000). "High-performance liquid chromatographic method for the determination of homocysteine in human plasma using a water-soluble phosphine reducing agent and fluorogenic derivatization." Chromatographia 52(Suppl.): S78-S82.

Wu, F., Y. Cai, D. Evans and P. Dillon (2004). "Complexation between $\mathrm{Hg}(\mathrm{II})$ and dissolved organic matter in stream waters: an application of fluorescence spectroscopy." Biogeochemistry 71(3): 339-351.

Xia, K., U. L. Skyllberg, W. F. Bleam, P. R. Bloom, E. A. Nater and P. A. Helmke (1999). "X-ray absorption spectroscopic evidence for the complexation of $\mathrm{Hg}$ (II) by reduced sulfur in soil humic substances." Environmental Science \& Technology 33(2): 257-261.

Xia, K., F. Weesner, W. F. Bleam, P. A. Helmke, P. R. Bloom and U. L. Skyllberg (1998). "XANES Studies of Oxidation States of Sulfur in Aquatic and Soil Humic Substances." Soil Sci Soc Am J 62(5): 1240-1246.

Yin, Y. J., H. E. Allen, C. P. Huang, D. L. Sparks and P. F. Sanders (1997). "Kinetics of mercury(II) adsorption and desorption on soil." Environ. Sci. Technol. 31: 496.

Yoshida, Y., Y. Ohiwa, M. Shimamura, T. Izumi, S. Yoshida, K. Takahashi, S. Miyairi, M. Makimura and A. Naganuma (2003). "Optimum conditions for derivatization of glutathione, cysteine and cysteinylglycine in human plasma with ammonium 7fluorobenzo-2-oxa-1,3-diazole-4-sulfonate for accurate quantitation by highperformance liquid chromatography." Journal of Health Science 49(6): 527-530.

Zhang, J., F. Wang, J. D. House and B. Page (2004). "Thiols in wetland interstitial waters and their role in mercury and methylmercury speciation." Limnology and Oceanography 49(6): 2276-2286.

Zhang, W. and Y. Cai (2003). "Purification and Characterization of Thiols in an Arsenic Hyperaccumulator under Arsenic Exposure." Analytical Chemistry 75(24): 70307035. 
VITA

\section{SEN CHEN}

1984-1988

B.S., Environmental Chemistry

NanKai University

Tianjing, China

1988-1993

Assistant Professor

China Medical University

Shenyang, China

1993-2006

Tenure track Lecturer

China Medical University

Shenyang, China

2006-2011

PhD Student

Graduate Assistant

Everglade Foundation Fellowship

Florida International University

Miami, Florida

1999-2002

Water purification Consultant

Wanfang Industry and Commerce joint-stock Limited Company

Shenyang, China

\section{PUBLICATIONS AND PRESENTATIONS}

Lu Shengman, Chen Sen. Chapter 7: Oxidation Reduction and Electrode Potential. In: Xu Chuanxiang, Lu Shengman and Yu Chengzhong(Ed). Medical Elemental Chemistry (the third edition) Advanced Medical College Textbook Harbin Press 2000.

Lu Shengman, Chen Sen. Chapter 7: Oxidation Reduction and Electrode Potential. In: $\mathrm{Xu}$ Chuanxiang, Lu Shengman and Yu Chengzhong (Ed). Exercises and Answers in Medical Elemental Chemistry (the third edition). Advanced Medical College Textbook Harbin Press 2000.

Xu Chuanxiang, Liu Guihua, Wang Baozhen, Chen Sen. Medical Elemental Chemical Experiment (the third edition). Advanced Medical College Textbook Harbin Press 2000.

Mao Song, Chen Sen, He Anguang. Effect of Porphyromonas gingivalis on the mRNA expression of IL-8 and MCP-1 in human umbilical vein endothelial cells. Chinese Journal of Conservative Dentistry, 12(2):72-75, 2002. 
Mao Song, Chen Sen, He Anguang. Effect of Porphyromonas gingivalis on human umbilical vein endothelial cell proliferation. Journal of China Medical University, 31(2): 125-131, 2002.

Liu Guihua, Chen Sen. The Study on nitrogen phosphorus complex fertilizer. J of Norman Bethune University of Medical science, 19(5):73-74, 1993. 